\title{
Phospholipid flip-flop in activated platelets
}

Citation for published version (APA):

Comfurius, P. (1989). Phospholipid flip-flop in activated platelets. [Doctoral Thesis, Maastricht University]. Rijksuniversiteit Limburg. https://doi.org/10.26481/dis.19890922pc

Document status and date:

Published: 01/01/1989

DOI:

10.26481/dis.19890922pc

Document Version:

Publisher's PDF, also known as Version of record

\section{Please check the document version of this publication:}

- A submitted manuscript is the version of the article upon submission and before peer-review. There can be important differences between the submitted version and the official published version of record.

People interested in the research are advised to contact the author for the final version of the publication, or visit the DOI to the publisher's website.

- The final author version and the galley proof are versions of the publication after peer review.

- The final published version features the final layout of the paper including the volume, issue and page numbers.

Link to publication

\footnotetext{
General rights rights.

- You may freely distribute the URL identifying the publication in the public portal. please follow below link for the End User Agreement:

www.umlib.nl/taverne-license

Take down policy

If you believe that this document breaches copyright please contact us at:

repository@maastrichtuniversity.nl

providing details and we will investigate your claim.
}

Copyright and moral rights for the publications made accessible in the public portal are retained by the authors and/or other copyright owners and it is a condition of accessing publications that users recognise and abide by the legal requirements associated with these

- Users may download and print one copy of any publication from the public portal for the purpose of private study or research.

- You may not further distribute the material or use it for any profit-making activity or commercial gain

If the publication is distributed under the terms of Article $25 \mathrm{fa}$ of the Dutch Copyright Act, indicated by the "Taverne" license above, 


\section{PHOSPHOLIPID FLIP-FLOP IN ACTIVATED PLATELETS}





\section{PHOSPHOLIPID FLIP-FLOP IN ACTIVATED PLATELETS}

\section{PROEFSCHRIFT}

ter verkrijging van de graad van doctor aan de Rijksuniversiteit Limburg te Maastricht, op gezag van de Rector Magnificus, Prof. Dr. F.I.M. Bonke, volgens het besluit van het College van Dekanen, in het openbaar te verdedigen op vrijdag, 22 september 1989 , om 16.00 uur

DOOR

PAUL COMfURIUS

geboren te Utrecht in 1947. 
Promotor: Prof. Dr. R.F.A. Zwaal

Co-promotor: Dr. E.M. Bevers

Beoordel ingscommissie:

Prof. Dr. G.J. van der Vusse (Maestricht), voorzitter. Prof. Dr. H. Chap (Toulouse)

Dr. B. Roelofsen (Utrecht)

Prof. Dr. C.P.A. van Boven (Maastricht)

Prof. Dr. P.J.C. van Breda Vriesman (Maastricht)

Dit werk is gedeeltelijk financieel ondersteund door een programmasubsidie ( $\mathrm{nr}$. 900-526-093) van MEDIGON.

Het verschijnen van dit proefschrift werd mede mogeli.jk dankzij gewaardeerde $f$ inanciele steun van:

- De Nederlandse Hartstichting

- De Stichting Dr. Ir. J.H.J. van de Laar voor wetenschappelijk biochemisch onderzoek.

- De Jan Dekkersstichting \& Dr. Ludgardine Bouwmanstichting

- De Stichting het Scholten-Cordes fonds. 
page

\section{Preface}

Chapter 1: The enzymatic synthesis of phospha-

tidylserine and purification by CM-cellulose column chromatography.

Cowfurius, P., Zaal, R.F.A. (1977)

Biochin. Biophys. Acta $488,36-42$.

Appendix: Enzymatic synthesis of phosphatidy 1 serine on small scale by use of a one-phase system. Colfurius, P., Bewers, E.H, Zmal, R.F.A.

Subitited.

Chapter 2: On the relation between membrane asymmetry and blood coagulation.

Zwal, R.F.A., Confurius, P., van Deenen, L.L.M. (1977) Nature $268,358-360$.

Chapter 3: The nature of the binding site for

prothrombinase at the platelet surface as revealed by lipolytic enzymes.

Bevers, E.M., Confurius, P., Zwall, R.F.A. (1982) Eur. J. Eiochew. 122, 81-85.

Chapter 4: Changes in membrane phospholipid distribution during platelet activation.

Bevers, E.M., Comfurius, P., Zwaal, R.F.A. (1983) Biochim. Biophys. Acta 736, 57-66.

Chapter 5: Platelet prothrombin converting activity in heriditary disorders of platelet function.

Bevers, E.H., Comfurius, P., Nieumenhuis, H.K., Levy-Toledano, S., Enouf, J., Belluci, S.. Caen, J.P., Zwal, R.F.A.

(1986) Br.J. Haemato1.63, 335-345.

Chapter 6: Stimulation of prothrombimase activity

of platelets and erythrocytes by sub-lytic

treatment with phospholipase $C$.

Confurius, P., Bevers, E.M., Zwaal, R.F.A.

(1983) Bioché. Biophys. Res. Comm. 117, B03-808.

Chapter 7: The involvement of eytoskeleton in the regulation of transbilayer movement; of phospholipids in human blood platelets. Cowfurius, P., Bevers, E.H., Zwad, R.F.A. (1985) Biochis. Biophys. Acta 815, 143-148. 
Chapter 8: Interaction between phosphatidylserine and isolated cytoskeleton of human bllood platelets.

Colfurlus, P., Bevers, E.H., Zwal, R.F.A. (1989) Biochid. Biophys. Acta, in press.

General discussion.

Summary

Samenwatting 123

Dankwoord 125

Curriculum vitae 127

List of publications 129 


\section{PREFACE}

The articles comprising the contents of this thesis have been published in a time span of ten years. I want to emphasize that discussions as they appear in the different. chapters are written in the context of the then existing knowledge. In the general discussion of this thesis an attempt is made to integrate these views into a model describing the present views on regulation of phospholipid asymmetry in platelet plasma membranes.

The first part of the following introduction is meant to provide some relevant background information on platelets, coagulam tion and the involvement of platelet membranes in coagulation. In the second part an outline is presented of the questions leading to the experiments described in each of the different chapters. 


\section{IMTFODLICT IOW}

Platelet function and marpholosy.

Platelets are the smallest cells present in the circulation. They are disk-shaped with a diameter of about 2 microns. In the unstimulated form, platelets are non-adherent to each other or the vessel wall, but capable of sticking to both if properly activated. Platelets play a role in a variety of processes, such as inflammation, wound-healing and immunological reactions. Their main function, however, lies in their pivotal role in the haemostatic process.

Platelets are formed in the bone-marrow as fragments of megakaryooytes. They have no nucleus, thus being virtually unable to synthesize proteins, and have an average lifetime of about 8 days. Their ultrastructure was studied extensively by means of electron microscopy (for a comprehensive review see Ref. 1). A schematic view of the main morphological features of the platelet is presented in Fig. 1. The cell is surrounded by a plasma membrane, showing several deep invaginations (open canalicular system), which increase the surface area and Eive the platelet a characteristic spongelike appearance.

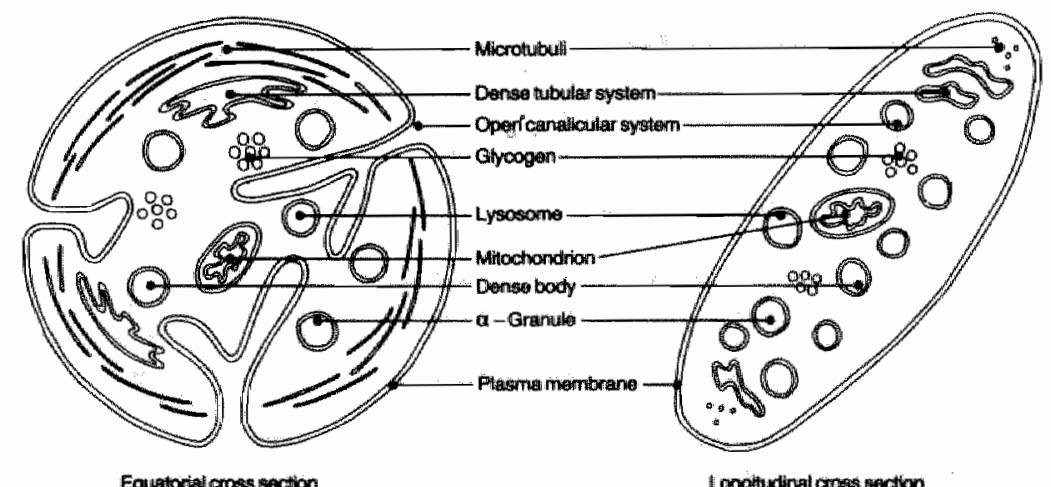

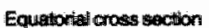

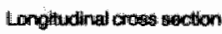

Fig.1: Horphology of the ustivulated discoid platelet.

In the cytosol several kind of storage compartments can be detected. Some of these have a secretory function (dense bodies, $\alpha$-granules and lysosomes), while others (mitochondria) provide the platelet with the necessary metabolic energy, the source of which is formed by numerous glycogen Eranules. In the equatorial cross section a ring of microtubuli is visible, which upon activation of the platelets migrates to the cernter of the cell 1 by means of depolymerization-polymerization eycles 
penultimate stage of the cascade. These phenomena, which are strictly surface-related, are stimulatory in nature.However, also involvenent in negative feedback of coagulation is possible. For instance, inactivation of factor $X a$ by the plasma protein antithrombin III is prevented by binding of factor Xe to the pllatelet surface [26]. On the other hand, the inactivation of factor Va by activated protein $C$ is mhanced by binding to the platelet surface [27]. Apart from these properties of platelets which are directly related to their surface, a wide variety of compounds involved in coagulation is released from the storage granules upon stimulation [19]. In this thesis, however, attention is focussed on the role of platelets in the catalysis of factor $X a$ and thrombin

formation.

\section{Role of lipid in Xa and thrombin formation.}

Both factor $X_{a}$ and thrombin are formed through limited proteolysis of their zymogens by a complex of an enzyme, a protein cofactor and the substrate assembling at a suitable membrane phospholipid surface. Factor IX, factor $X$ and prothrombin are wembers of the family of proteins that undergo a posttranslational, vitamin $K$ dependent carboxylation in the liver. Several glutamic acid residues near the $\mathbb{N}$-terminus of these proteins are carboxylated to gamma-carboxyglutamic acid [28]. Binding of these proteins to a lipid surface occurs by formation of calcium bridges between the negatively charged gammacarboxyglutamic acid residues of the proteins and negative charges present in the lipid surface. In the case of factor Xa ceneration, the enzyme factor IXa associates with the cofactor VIIIa at a phospholipid surface, forming so-called tenase complex. This complex efficientiy brings about the limited proteolysis needed to form the active enzyme Xa from its aymogen factor $X$. A similar complex existis for formation of thrombin from its precursor, prothrombin. In this case factor Xe is the enzyme and Va the cofactor, together forming the prothrombinase complex after binding to a lipid surface has taken place. Although the effect of platelets and lipids on the reaction of the prothombinase complox is mainly considered in this thesis, it should be kept in mind that the tenase complex is affected in a similar fashion.

The function of lipids in coagulation can in a first approximation be described as surface-catalysis, involving an increase in the local concentration of proteins by binding to a phospholipid surface and, hence, stepping up the reaction. Another reason for the increase in reaction velocity is the juxtaposing of the molecules, induced by their binding to a surface, which leads to a higher ratio of productive collisions between enzyme and substrate $[29,30]$.

In vitro, this surface can be composed of any mixture 
of phospholipids containing net negatively chared polar head groups, although the catalytic efficiency is certainly dependent on the kind of lipid molecule bearing such charge. Comparing the activities of lipids containing different polar headgroups, it was shown [31] that optimal catalytic efficiency can be achieved by the use of phosphatidylserine (PS). Although any lipid surface carrying negative charge is capable of stimulating thrombin formation, binding affinity to PS-containing surfaces is favoured presumably because a six-coordinated complex ith calcium can be formed, involving the phos phate, amino and carboxyl groups of PS on the one hand and the two carboxyl groups of gamma-carboxyglutamic acid plus another electron-donating group of the protein on the other. The resulting strong binding of clottine factors to a PS-containing phospholipid surface explains the potent catalytic effect of phosphatidylserine in blood coagulation, relative to other anionic phospholipids. It should be mentioned that neutral phospholipids can play a modulating role in the procoagulant efficiency of a 1ipid surface once $P S$ is present [32].

\section{Lipid orsanization of the platelet plasma membrane.}

Platelets, like other cells, are protedted from their environment by a plasma membrane in which asiymetry prevails with respect to both proteins and phospholipids. For erythrocytes as well as for platelets it was shown [33-37] that the outer monolayer of the plasma membrane consists primarily of the neutral choline containing lipids phosphatidylcholine" (PC) and sphingomyelin (Sph) and part of the phosphatidylethanolamine (PE) which is present on both sides of the membrane. The negatively charged 1ipids phosphatidylserine (PS) and phosphatidylinositol (PI) are almost exclusively located in the inner leaflet of the membrane. This asymmetry means that the outer surface of the cell is almost completely devoid of negatively charged phospholipids; thus hardly being able to stimulate the enzymatic conversion of factor $X$ and prothrombin.

We have shown that activation of platelets by the combined action of collagen and thrombin, as likely occurs at the site of vascular injury, gives rise to progressive randomization of phospholipids in the membrane bilayer [38]. Thus, the original asymmetrio distribution of lipids is lost upon activation, leading to exposure of PS at the platelet outer surface. The activated platielet thus acquires the capability to increase the rate of factor $\mathrm{Xa}$ and thrombin formation, thereby also restricting the clotting process to the site of injury, where platelet activation accurs. The question arises which molecular mechanisms in platelets are responsible for the transfor mation of an inert cell into a body capable of accelerating coagulation by several orders of magnitude. 


\section{Referenoges.}

1 White, J.G. (1987)

in "Haemostas ig and phrombosis" (Bloom, A. L., Thonas, D.P.; eds.) pp. 20-46. Churohi11 Livingstone, New York.

2 Steiner, M. I I adal, $Y,(1979)$

d. C1in. Invest. $63,443-448$.

3 Kenney, D.M., Chao, F.C. (1980)

J. Cel1 Physiol. 103, 389-398.

4 White, J.G., Rao, G.H.R. (1983)

Am. J. Pathol. 112, 207-217.

5. Skear, R.J. (1981)

in Res. Monographs Cel1 T'issue Physiol, 5. "Platelets

in Biology and Pathology, vol 2 "Gordon, W.L. "ed.)

pp. 321-348. Elsevier/North Holland Biomedical Press.

6 White, J.G. (1984)

in "The dell biology of the secretory process" (Cantin, M. ed.) pp. 541-564. Karger, New York.

7 Crawford, $\mathbb{N}$. (1985)

Adv. Exp. Med. Biol. 192, 1-13.

G Kaser-Glanzmann, R., Jakabova, M., George, J.M.,

Luscher, E. F (1978)

Biochim. Biophys. Act 512, 1-12.

9. Menashi, S., Davis, C., Crawford, M. (1982)

FHBS Letters 140, 298-302.

10 Baumgartner, H.R. (1977)

Thromb. Haemost. $37,1-16$.

11 Hawiger, $J,(1987)$

Ann. N. Y. Acad. Soi. 509, 131-141.

12 Chiang, T.M., Kang, A.H. (1982)

J. Biol. Chem. 257,7581-7586.

13 Sakariassen, K. S., Bolhuig, P.A., Sixma, J.J. (1979) Nature $279,636-638$.

14 Nieuwenhuis, H.K., Sakariassen, K.S., Houdijk, W.P., Nievelstein, P.F., Sixma, J.J. (1986)

Blood 68, 692-695.

1.5.Fox, J.E.B., Phillips, D.R. (1983)

Semin. Haematol. 20, 243-260.

16 Zucker, M. B., Nachmias, V.T. (1985)

Arterioselerosis $5,2-18$.

17 Maofarlane, R.G. (1964)

Nature 202, $498-499$.

18 Davie, E.W., Ratnofe, O.D. (1964)

Soience 145, 1310-1312.

19 Bewers, E.M., Rosing, J., Zwaal, R.F.A. (1987)

in "Platelet: in Biology and Pathology III" (Macintyre, Gordon, eds ") pp. 127-160 Elsevier Science Publishers (Biomedical division).

20 Walsh, P.N., Griffin, J.H. (1981)

Blood $57,106-118$.

21 Kodame. K., Kato, H., Iwanaga, S. (1985)

J. Bilochem. 97,139 .

22 Osterud, B., Harper, E., Rapaport, S. I., Lavine, K. K. (1979) Scand. J. Haematol. 22, 205. 
23 Miletich, J.P., Jackson, C.M., Majerus, P.W. (1977) Proo. Nat. Acad. Sci. USA 74, 4033.

24 Kane, W.H., Lindhout, M.J., Jackson, C.M., Majerus, P.W. (1980) J. Biol. Chem. 255, 1170.

25 Rosing, J., van Rijn, J.L.M.L., Bevers, E.M., van Dieijen, G., Comfurius, P., Zwael, R.F.A. (1985) Blood 65, 319

26 ElIis, V., Scully, M. F, Kakkar, V.V. (1984) Biochemistry 23,5882 .

27 Harris, K.W., Esmon, C.T. (1985) J. Biol. Chem. 260, 2007.

28 Suttie, J.W., Jackson, C.M. (1977) Prysiol. Rev. 57, 1-70.

29 Rosine, J., Tans, G., Govers-Riemslag, J.W.P., Zwael, R.F.A." Hemker, H.C. (1980) J. Biol. Chem. 255,274-283.

30 van Dieijen, G., Tans, G., Rosine, J., Hemker, H.C. (1981) J, Biol. Chem. 256, 3433-3442.

31 Rosing, J., Speijer, H., Zwaal, R.F.A. (1988) Biochemistry $27,8-11$.

32 Zwael, R.F.A., Bevers, E.M., Comfurius, P. (1986) in "New Comprehensive Biochemistry vol 13: Blood Coagulation" (Zwagl, R.F.A., Hemker, H.C., eds..) pp. 141-169. Elsevier, Amsterdam.

33 Zwaal, R.F.A., Roelofien, B., Comfurius, P., van Deenen, L. L.M. (1975) Biochim. Biophys. Acta 406, 83-96.

34 Chap, H.J., Zwaal, R.F.A., van Deenen, L.I.M. (1977) Biochim. Biophys. Acta $467,146-164$.

35 Perret, B., Chap, H., Douste-Blazy, L. (1979) Biochim. Biophys. Acta 556, 434-436.

36 Zwaal, R. F.A. (1978) Biochim. Biophys. Acta 515,"163-205.

37 Schick, P.K. (1979) Semin. Haematol. 16, 221-233.

38 Bevers, E.M., Comfurius, P., van Rijn, J.L.M.L., Hemker, H.C., Zwaal, R.F.A. (1982) Eur. J. Biochen. 122, $429-436$.

39 Tans, G., van Zutphen, H., Comfurius, P., Henker, H.C., Zwal, R.F.A. (1979) Eur, f. Biochem. 95, 449-457.

40 Cullis, P.R., de Kruijfe, B. (1979) Biochim. Biophys. Acta 559, 399-420.

41 de Kruijff, B., Verkleij, A.J. van Echteld, C.J.A., Gerritsen, W.J., Mombers, C., Noordam, P.C., de Gier, I. (1979) Biochim. Biophys. Acta 555, 200-209.

42 Mauco, G., Chap, H. Simon, M. F., Douste-Blary, L. (1978) Biochimie 60, 653-661.

43 Allan, D., Low, M.G., Finear, J.B., MicheI I, R. H. (1975) Biochim. Biophys. Acta 413, 309-316.

44 Chap, H. , Douste-Blazy, L. (1974) Eur. J. Biochem. 48, 351-356.

45 Mombers, C., de Gier, J., Denel, F. A., van Deenen, L. L.M. (1980) Biochim. Biophys. Acta 603, 52-62.

46 Sato, S.B., Ohrishi, S. (1983)

Eur. J, Biochem. 130, 19-25.

47 Maksymiw, R., Sui, S. F., Gaub, H., Sarkmann, E, (1986) Biochemistry 26, 2983-2990. 
48 Rybloki, A.C., Heath, B., Lubin, B., Schwartz, R.S. (1988) J. Clin. Invest. 81, 255-260.

49 Hagst, C.W.M., Plasa, G., Kamp, D., Deuticke, B. (1978) Eiochin. Biophys. Acta 509, 21-32.

50 Lubin, B., Chiu, D., Bastacky", B., Roelofisen, B., van Deenen, L.L.M. (1981) J. Clin. Invest. $67,1643-1649$.

51 Heest, C.W.M. (1982)

Biochim. Biophys. Acta 694, 331-352.

52 Phillips, D. P., Jakabova, M. (1977) J. Biol. Chem. 252, 5602-5605.

53 White, G.C. (1980)

Biochim. Biopkys. Acta 631, 130-138.

54 Mogowan, E.B., Yeo, K. T., Detwiler, T.C. (1983) Arch. Biochem. Biophys. 227, 287-301.

55 Fox, J.E.B., Phil11ps, D.R. (1983)

Semin. Haematol. 20, 243-260.

56 Seigneuret, M., Devaux, P.F. (1984) Proo. Nat1. Acad. Sol. USA 81, 3751-3755.

57 Daleke, D.L., Huestis, W.H. (1985) Biochemistry $24,5406-5416$.

58 Tilley, L., Cribier, S., Roelofsen, B., Op den Kamp, J.A.F., van Deenen, L.L.M. (1986) FEBS Letters $194,21-27$.

59 Martin, O.C., Pagano, R.E. (1987) J. Biol. Chem. 262, 5890-5898.

60 Willianson, P. Antia, R., Schlegel, R.A. (1987) FEBS Letters $194,21-27$.

61 Connor, J., Schroit, A.J. (1988) Biochemistry 27, 848-851.

62 Bevers, E.M., Tilly, R., Senden, J., Comfurius, P., Zwaal, R.F.A. (1989) Biochemistry 28, 2382-2387. 
THE ENZYMATIC SYNTHESIS OF PHOSPHAT IDYLSERINE AND PURIFICATION BY CM-CELLULOSE COLUNAN CHROMATOGRAPHY.

Summary.

Phosphatidylserine has been prepared from phosphatidylcholine by a one-step transphos. phatidylation reaction catalyzed by phospholipase $D$ in the presence of $\mathrm{L}$-serine. The resulting mixture of phosphatidylserine and phosphatidic acid is easily and rapidly separated by CM-cellulose column chromatography using stepwise elution with solvents containing an increasing percentage of methanol in chloroform. The overall yield of the procedure is $40-50 \%$ dependent on the scale of the preparation. CM-cellulose collumn chromatography proved to be extremely useful in separating phospholipid mixtures obtained by phosphatidyltransferase reactions of phospholipase $D$ and is also suitable for fractionation of other lipid extracts. 
Introduction.

As discussed in the introduction of this thesis, phospthatidylserine plays a crucial role in blood coagulatiom. Sinoe the total chemical synthesis of this phospholipid is a complicated and time consuming task [1-5], its role in a variety of membrane processes has mainly been sudied using preparations obtained by tissue extraction. This results in a wixture of phosphatidylserine wpecies with respect to the fatty acid composition. In order to be able to prepare phosphatidylserine wth defined fatty acids quikly and easily, we reevaluated its enzymatic synthesis using the base-exchange reaction catalyzed by phospholipase D.

Phospholipase D (phosphatidylcholine phosphatidohydrolase, EC 3.1.4.4) hydrolyses the terminal phosphate diester bond of glycerophospholipids with production of phosphatidio acid. It has also been shown to catalyze the transfer of the phosphatidyleroup from phosphatidylcholine to various primary alcokols [6-10]. Until now, however, no aignificant transferase activity has been observed using L-merine as the acceptor molecule. Upon reinvestigation of the transferase activity of phospholipase $D$ we found that conwersion of phosphatidyloboline into phosphatidylserine can occur at elevated temperature using saturated solutions of serine. The resulting mixture of phosphatidy serine and phosphatidic acid is easily and rapidly separated by CM-cellulose column chromatography. This colum is eluted step-wise with solvents containing increasing percentages of methanol in chloroform.

The overall yield of the procedure is 40-50\%, depending on the scale of the preparation. CM-cellulose chromatography proved to be extremely useful in separating phospholipid mixtures obtained by phosphatidyltransferase reactions of phospholipase $D$ and is also suitable for the fractionation of other lipid extracts.

\section{Materials and methods.}

He phosphatidyloholine was prepared from egs yolk as described by Singleton et al. [11]. Two synthetic phosphatidylcholines were prepared as described before [12]: 1,2dimyristoy 1-sn-glyoero-3-phosphocholine $\quad 14: 0 / 14: 0-$ phosphatidylchol ine) and $1,2-$ dielaidoy $1-5 n-$ gycero-3-phosphochol ine ( $18: 1 t-/ 18: 1 t-$-phosphatidy lcholine).

Phospholipase $D$ was partially purified from the inner, yellowish-white leaves of savoy cabbage by heat treatment and acetone precipitation according to the method of Davidson and Long [13]. After acetone treatment the precipitate was suspended in water (approximately $20 \mathrm{ml}$ per $400 \mathrm{~g}$ of cabbage leaves) and immediately lyophilized. The white powder obtained was stored at $-20^{\circ} \mathrm{C}$.

For routine assays of enzymatio activity, hydrolysis of egE yolk lipoprotein was measured by continuous 
titration of the acid produced, using a Radiometer automated titrator with curve recording. The egs yolk Iipoprotein substrate was prepared by homogenizing the yolk of one egg in $100 \mathrm{ml}$ destilled water. After centrifugation t $27.000 \times \mathrm{g}$ for 30 minutes the supernatant was collected and sodium dodecylsulphate wes added to a final concentration of $6.66 \mathrm{wg} / \mathrm{ml}$. The assay was performed using $15 \mathrm{ml}$ of the lipoprotein solution (containing approximately $1 \mathrm{mg} / \mathrm{ml}$ lipid phosphorus to which $1 \mathrm{ml}$ of $1 \mathrm{M} \mathrm{CaCl} z$ was added prion to the addition of enayme. This results in a marked increase in turbidity. The enzymatio reaction was carried out at $37 \mathrm{C}$ for 5 minutes at $\mathrm{pH}$ 5.6. The consumption of $0.02 \mathrm{~N} \mathrm{NaOH}$ was usually linear for at least 10 minutes. One unit of phospholipase $D$ is defined as the amount of enzyme which 1 iberates 1 mol of titratable $\mathbb{H}^{+}$per minute at $37^{\circ}$ C. In spite of the turbidity of the reaction mixture, the number of units appeared to be comparable with the number of international units (I.U.) found in the substratedecrease assay as described previously [14]. The phospholipase D preparttion from savoy cabbage usually showed an activity of approximately $1 \mathrm{I}$.U./mg dry weight. The activity decreased by some $20 \%$ per month upon storage at $-20^{\circ} \mathrm{C}$.

The transphosphatidylation reaction catalyzed by phospholipase $D$ was carried out in the presence of L-serine either with ege phosphatidylcholine or with the synthetic lecithins 1,2 -dimyristoy $1-5 n-g 1$ yeerom-3-phosphocholine or 1,2-dielaidoy 1-sn-klycero-3-phosphocholine. "The phosphatidylcholines were dissolved in diethylether (distilled from $P=O$ to remove traces of aloohol) at a concentration of $20 \mathrm{mg} / \mathrm{ml}$. L-serine (Merck) was first lyophilized from a $10 \%(\omega / v)^{\prime}$ aqueous solution to remove traces of methanol and subsequently dissolved at $45^{\circ} \mathrm{C}$ in different concentrations up to saturation ( $46 \% \mathrm{w} / \mathrm{v})$ in 100 mM acetate buffer (pH 5.6) containing $100 \mathrm{mM}$ CaClz. Phospholipase $D$ was added to the serine solution at $45^{\circ} \mathrm{C}$ to final concentration of 1 I. $0 . / m 1$. An equal volume of tho phosphatidylcholine solution in ether was addod and the incubation flask was immediately closed, to minimize ether evaporation. Incubation was carrried out at $4 y^{\mathrm{g}} \mathrm{C}$ with stirring to ensure complete mixing of both phases. Usual1y, additional portions of phospholipese $D$ equal to the starting amount were added after 30 and 60 minutes.

Incubation was stopped after 90 minutes by addition of two volumes (with respect to the volume of the acetatebuffex) $100 \mathrm{mM}$ EDTA. Ether was evaporated at room temperature under a stream of nitrogen and the aqueous layer was mixed with 4.3 volumes of chloroform/methanol $(5: 8, v / v)$ ard stirred for 30 minutes [15]. This single phase mixture was filtered through a glass filter G-2 to remove precipitated serine. The filtrate was stirred for 10 minutes after addition of 1 volume of water and 3.7 volumes of chloroform. In this extraction procedure "volumes" refer to the volume of acetate buffer plus EDTA solution. After centrifugation (10 min., $1000 \mathrm{x}$ ) the lower chloroform 
layer was collected and evaporated to dryness under reduced pressure. Apter remowing traces of water by repeatedly adding absolute ethanol and evaporating, the residue as dissolved in chloroform. Similar incubations wexe carried out at $37^{\circ}$ C in which serine was replaced by other primary alcohols. Ethanoldine, dycerol, methanol, or ethanol were used to establish optimal conditions leading to the highest yields of the respective phosphoelycerides.

Preswollen CM-cellulase (CM-52, sodium form, Whatman) was suspended in methanol and decanted several times to remove small fibers and effectively replace water by ormanic solvent. Columns were packed as desoribed by Rouser et $a 1,[16]$ for DEAE-cellulose. On top of the bed a L llas wool plug and some glass beads were placed in order to prevent disturbance of the adsorbent during solvent changes. Prior to applying the lipids, methanol was renoved by eluting the colum with at least 10 bedvolumes of chloroform. A rapid separation of phosphatidylserine from phosphatidic acid, phosphatidylmethanol, unconverted phosphatidylcholine and traces of free serine was carried out as follown.

The lipid solution in chloroform was applied to the colum in concentration up to $50 \mathrm{mg} / \mathrm{ml}$ with a maximum load of 5 me total lipid per ml bedvolume. After elution with 3 bedwolumes of chloroform, phosphatidic acid (together: with traces phosphatidylmethanol and residual phosphatidylcholine) was eluted with 20 bedvolumes of $20 \%$ methanol in chloroform $(v / v)$. Phosphatidylserine was subsequently eluted with 6 bedvolumes of chloroform/methanol $(1: 1, v / v)$ and any free serine was removed by elution with 10 bedvolumes pure methanol, resulting in regeneration of the column. The column can be used repeatedly with reproducible performance. Since the cellulase can easily be operated at flowrates of $250 \mathrm{ml} / \mathrm{hour}$ without affecting the separation, the procedure is extremely rapid and oan usully be performed within 2 days. Stopping elution overnight during the separation procedure has no influence on the final resolution. No differences in separation were observed when the procedure was scaled up to separate 1 ram of the phospholipid mixture.

For analytical purposes, the phospholipids were separated by two-dimensional thin-layer chromatography using the procedure of Broekhuyse [17], and quantitated as phosphorus by a modification of the procedure of Fiske and Subbarow [18]. Differential scanning calorimetry was carried out as described by van Dijck et al. [19].

Results and discussion.

In agreement with previous investigations [8,9], 90-95\% of phosphatidylcholine can be converted into phosphatidy lmethanol, phosphatidylethanol, phosphatidy lethanolamine and phosphatidylglycerol at optimal concen- 
trations of the acceptor molecule. The remaining $5-10 \%$ is converted into phosphatidic acid (Fig. 1 ).

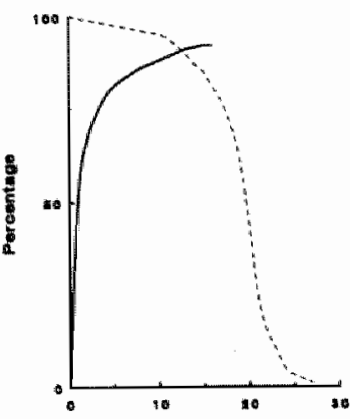

* Methenal $(v / v)$

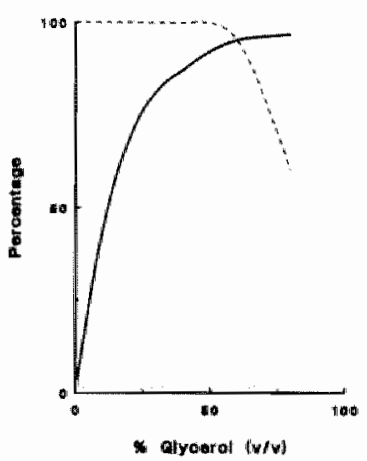

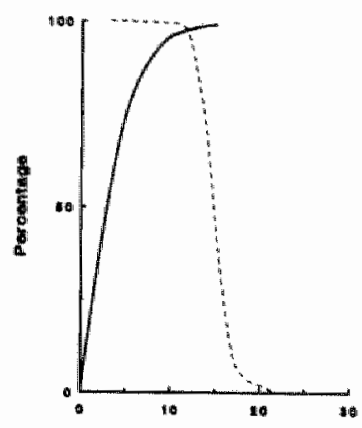

* Extheno: (wiv)

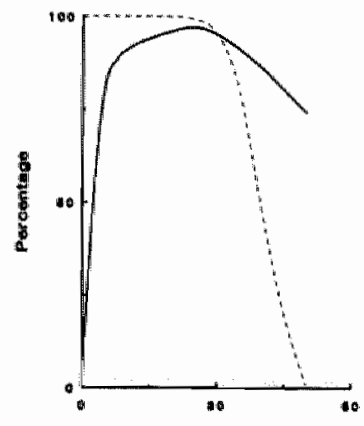

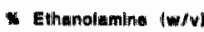

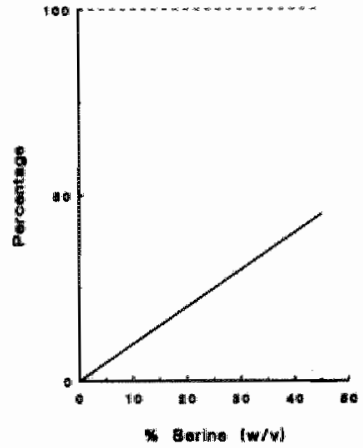

Fig.1: Influence of the acceptor cancentration or the conversion of phosphatidylcholine into the respective phosphoglycerides. , pepcentage of transphosphatidylation.

, percentage conversion of lecithin under the conditions éployed. Optiol canditions are reached whereboth lities are axial. The reaction in the presence of serite $4 a$ car caled out at $450 \mathrm{C}$, whereas the reactions usitig other accutors were carried out at 3700 . 
Himher concentrations of the acceptor lead to (partial) inectivation of phospholipase $D$ and result in an incomplete corversion of phosphatidylcholine under the conditions employed. On the other hand, the percentage conversion of phosphatidy lcholine into phosphatidy lserine shows a inear increase th the serine concentration up to the gaturetion point ( $46 \%$, w/v at $45^{\circ} \mathrm{C}$ ), where some $45 \%$ of the phosphatidylcholine is converted into phosphatidylserine, the remainder being hydrolysed to phosphatidic acid. Raising the $p H$ to $\mathrm{B} .5$ increases the solubility of serine to $55 \%(w / v)$. Incubating at this pH with a 10 times higher concentration of phospholipase $D$ results in a conversion of about 55\% of phosphatidylcholine into phosphatidylserine. However, due to the large amount of phowpholipase D required to produce complete conversion of phosphatidylcholine at $\mathrm{pH} 8.5$, this $\mathrm{pH}$ is of no practical walue in relatively lare scale preparations of phosphatidylserine. No significant change in percentage conversion into phosphatidylserine was found with the three phosphatidyloholine preparations used. Moreover, no differences in fatty acid composition were observed between the phosphatidylcholines and the phosphatidy serines produced after transphosphatidylation. Also the ratio of phosphatidylserine to phosphatidic acid was not found to be dependent on the incubation time.

Separation of phosphatidylserine from the resulting mixture after transphosphatidylation could easily and rapidly be achieved by CMmellulose column chromatography, using chloroform/methamol mixtures as eluent. Other adsorbents, such as silica Gel [20] or DEAE-cellulose [16] were found to be unsatisfactory in this respect. The recovery of phosphatidylserine from the column appeared to be 95-100\% and the lipid was pure as judged by two-dimensional thin-layer chromatography. Differential scanning calorimetry of the two phosphatidylserines prepared from dimyristoyl-lecithin and dielaidoyl-1ecithin, was carried out on samples hydrated in buffer of pH 7.5 , containing $40 \mathrm{mH}$ "Tris/acetate and $100 \mathrm{mM}$ NaCl. The heating scans revealed sharp phase transitions at $3^{\circ} \mathrm{C}$ for dimyristoy $1-$ phosphatidylserine ard at $22.5^{\circ}$ C for dielaidoylphosphatidylserine, confirming the notion that the phosphatidy serines are essentilally pure. It should be mentioned that other investigators [21] have shown that both temperature and enthalpy of the phase transition of synthetic phosphatidylserines are dependent on pll and ionic strength, making a comparison with other phospholipids premature at the present state of knowledge.

By using a stepwise elution with solvents containing increasing percentages of methanol in chloroform, separation of other phospholipid mixtures can be succesfully achieved. The percentage of methanol at which certain lipids start to lute from the column is given in

Table I. Small differences in the methanol concentration at which elution starts, still permits substantial separation. 
METHANOL CONCENTRATION IN CHLOROFORM REQUIRED TO RILUTE: PHOSPHOLIPID FROM CM-CELLULOSE (SODTUM-FORM)

\begin{tabular}{|c|c|}
\hline Vold methanol & I. Dids eluted \\
\hline 0 & $\begin{array}{l}\text { Free fatty acid, cholesterol, di- and } \\
\text { tri-acylibycerol }\end{array}$ \\
\hline 3 & Diphosphatidy le lyoerol \\
\hline 4 & Phosphat idy lcholine \\
\hline 5 & 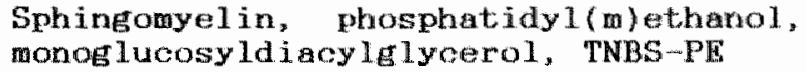 \\
\hline 9 & Phosphatidy lethanol am ine \\
\hline 12.5 & Phosphatidic acid \\
\hline 15 & DiElucosyldiacy le lycerol \\
\hline 20 & Phosphatidylg lycerol \\
\hline 23 & Lysophosphat idyl chol ine \\
\hline $30-35$ & Phosphatidylserine \\
\hline $35-50$ & Phosphatidy inositol \\
\hline 100 followed by 0 & Regeneration \\
\hline
\end{tabular}

For example, mixtures of equal amounts of phosphatidyl-choline and sphingomyelin can be separated to such an extent that approximately $80 \%$ of each phospholipid is obtained in pure form. Some sphingonyelin starts to leave the column after prolonged elution with $4 \%$ of methanol, where the tail of the phosphatidylcholine lraction elutes. As soon as this occurs, elution is continued with $5 \%$ of methanol, first resulting in a mixture of sphingomyelin and the remaining phosphatidylcholine, followed by the appearance of pure sphingomyelin. Although this: separation is quantitatively inferior to separation on silicic acid, the procedure is considerably more rupid. Complete separation between two phospholipid olasses can easily be obtained when the interval of methanol concentration exceeds 2 volw, making the method extremely useful for phosphalipid mixtures obtained from phospholi ase $D$ catalyzed base-exchange reations. In treneral, a smaller lution volume is required when lipids are eluted at a higher methanol concentration than strictily necass ary.

The basis for lipid separation on CM-cellulowe is not. completely understood. Separations by ion-exchange chromatography gemerally proceed through ion-exchatuge reactions and hydrogen bond equilibria. It is likely that in chloroform, wich has a very low dielectric constant, repulsion between negative charges is minimal since little or no dissociation of ion-pajes occurs. This would allow unspecific adsorption, possibly also hydrogen bonding of phospholipids to CM-cellulose. Increasing the dielectric constant by addition of methanol will also increase the 
repulstion of gradually dissociating negative charges, resulting in elution of the lipids wer repulsion exceeds counteract ing adsorption.

Finally, it is concluded that conversion of phosphatidylcholine into phosphatidylserine by phospholipase $D$ catalyzed transphosphatidylation followed by rapid purification on CM-cellulose columns allows the preparation of a ide variety of phosphatidylserines from synthetic phosphatidylcholine andogs. This enables a eystematical investigation on the role of phosphatidylserine in biomembranes and lipoproteins.

\section{References.}

1 Baer, $\mathbb{E}^{*}$, Maurukas, J. (1955)

J. Biol. Chem. 212,25-38.

2 de Has, G.H., van Zutphen, H., Bonsen, P.P.M., van Devner, L. L.M. (1964)

Rec. Prav. Chim. Pays-Bas 83, 99-116.

3 Aneja, R., Chadha, J.S., Davies, A.P. (1970)

Biochim. Biophys. Aata 218, 102-111.

4 Slotboom, A.J., Bonsen, P.P.M. (1970)

Chem. Phys. Ifipids 5, 301-397.

5 Rosenthal, A.F. (1975) Methods Enzymol. 35 B, 429-529.

6 Bensor, A.A., Freer, S., Yang, S.F". (1965)

9th Intern. Cone. Biochem. Lipids, Noordwijk an Zee, The Nether lands.

7 Bartels, C. T. "var Deenen, L. L.M. (1966)

Biochim. Biophys. Acta 125, 395-397.

8 Yang, S.F., Freer, S., Bonsen, P.P.M. (1967)

J. Biol. Chem, 242, 477-484.

9 Dawson, R.M.C. (1967) Biockem. J. 102, 205-210.

10 Lennarz, W.J., Bonsen, P.P.M., van Deenen, L.L.M. (1967) Biochemistry 6, 2307-2312.

11 Sineleton, W. S., Gray, M.S., Brown, M.L., White, J.L. (1065) J. Am. Oil. Chem. Soc. 42, 53-56.

12 van Deenen, L. L.M., de Haas, G.H. (1964)

Adv. Lipid. Res. 2, 168-229.

13 Davidson, M., Long, C. (1958)

Biochem. J. $69,458-466$.

1.4 2wal, R.F.A., Roelofsen, B. "Comfurius, P., van Deenen, L. L. M. (1975) Biochim. Biophys. Aota 406, 83-96.

15 Renkonen, O., Kosunen, T. U., Renkonen, O.V. (1963) Anr. Med. Exp. Biol. Fenniae (Helsinki) 41, 375-381.

16 Rouser, G. "Kritchevsky, G. Yamamoto, A., Simon, G., Ga 11 . C., Bauman. A.J. (1969)

Methods Enzymol. 14, 272-317.

17 Broekhuyse, R.M. (1969) Clin. Chim. Acta 23, 457-461.

18 Buttoher, C.J.F., van Gent, C.M., Pries, C. (1961) Anal. Chim. Acta 24, 203-204. 
19 van Dijck, P.W.M., de Kruijff, B., van Deenen, L. L.M., de Gier, J., Demel, R.A. (1976)

Biachim. Biophys. Acta 455, 576-587.

20 Sweeley, C.C. (1969)

Methods Encymol. 14, 254-267.

21 MacDonald, R.C., Simon, S.A., Baer, E. (1976)

Biochemistry $15,885-891$. 


\section{ENZYMATIC SYNTHESIS OF PHOSPHIATIDYLSERINE BY USE OF A ONE-PHASE SYSTEM.}

Summary.

A modification of the phospholipase $D$ catalyzed synthesis of phosphatidylserine is described, which allows the handiing of small quantities of lipid without the need for an ether-water system.

By using octylglucoside to disperse the lipid during the enzymatic conversion it was possible to reduce the volume of the reaction mixture to $50-100 \quad \mu 1$. The amount of lipid that can be handled in such small volumes is in the order of micrograms. This facilitates the syathesis of phosphatidylserine frow rare or expensive phosphatidylcholine species. 
In 1977 described [1] the enzywatic conversion of phosphatidylchol ine (PC) into phosphatidylserine (PS). The reaction, basse-exchange catalyzed by phospholipase D (phosphatidylchol ine phosphatidohydrolase, E.C. 3.1.4.4), is carried out at $45^{\circ} \mathrm{C}$ in a two phase system composed of a solution of PC in diethylether and a saturated solution of serine in acetatebuffer. The purpose of developing this procedure wass to prepare PS species with a defined fatty acid composition, starting from commercially available PC species and avoiding the laborious total chemical synthesis of PS.

Since then, increasing interest has arisen in PS molecules containing groups whose fate can be easily assessed by various physical and chemical methods. For instance, in research aimed at elucidating mechanisms underlying transbilayer movement and the maintenance of phospholipid asymmetry in biological membranes, various labeled PS species are used. Some recent examples are the inoorporation of radiolabeled PS in erythrocytes, followed by enzymatic degradation to determine the fraction which remains in the outer monolayer upon prolonged incubation [2]. A similar technique employs a fluorescent analog of PS, where the fraction of label still present in the outer monoleyer is assessed by exchange with phospholipid vesicles [3]. Phosphatidylserine containing a spin-label was used in several cells to evaluate their capacity to transport exogenously added aminophospholipids to the inner monolayer of the cells by an energy-dependent translocating system [4-6]. Radio-iodinated, photoactivatable lipid was used in an attempt to identify erythrocyte membrane proteins involved in such a phospholipid transport over the plasma membrane $[7,8]$.

These labeled lipids are in general available only in small amounts and are rather expensive. To prepare PS from the respective phosphatidylcholines by the use of a two-phase system consisting of water and ether layers, incubated at temperature well above the boiling point of ether, limits the minimal volume that can be handled conveniently. When small amounts of PC are used, the overall yield of the procedure will be lower, mainly because of adsorption problems.

We found that ether could be replaced by detergent as a solute for the lipids, which makes it possible to perform the synthesis in a one-phase system at microscale (volumes less than $1 \mathrm{ml}$ ). In such a system the lipids are presented to the phospholipase in the form of a mixed micel of 1 ipid and detergent. Using a proper detergent this micellar structure is such that the phospholipase D can modify the PC molecules at a rate comparable to that found in an etherwater system. 
Phosphatidy lobol ine (from ege yolk), sodiumdodecylsul-.. fate (SDS), sodiumdeoxycholate (DOC), Triton X-100 and actylelucopyranaside were obtained from Sigma. Phospholipase $D$ was partially purified from the inner leaves of Savoy cabbage as described [1]. A11 other reagents were of the highest grade available.

Incubations were carried out by first drying PC in a Elass tube by a stream of nitrogen. The $\mathrm{PC}$ was three times solubilized in pure chloroform and dried again, to remove traces of methanol or ethanol which could give rise to unwanted side-products like methyl-or ethyl-phosphatidic acid [1]. To the dry $P C$ a solution is added, containing calcium, acetate, detergent and serine. This solution is prepared at $55^{\circ} \mathrm{C}$ by mixing $1 \mathrm{M} \mathrm{CaCl}=$. $1 \mathrm{M}$ Na-actate, deter gent, L-serine and water. Final concentrations are $0.1 \mathrm{M}$ $\mathrm{Ca}^{2-}, 0.1 \mathrm{M}$ acetate, $50 \% \mathrm{w} / \mathrm{w}$ serine and $2 \% \mathrm{w} / \mathrm{v}$ detergent. The resulting $p H$ is between 5.4 and 5.8 . The reaction is started by adding phospholipase $D$ to the mixture in a ratio of 1 International Unit (I.U.) per 10 mg of lipid (the I.D. is defined as the amount of enzyme which converts 1 mol of substrate per minute at $370 \mathrm{C}) . \mathbb{E} \times$ traction, purification and anglysis by two-dimensional. thin-1ayer chromatography of the resulting lipid mixtures were performed as described before [1]. When PS species are synthesized which are relatively water-soluble, it is preferable to use an one-phase extraction procedure described by Reed et al. [9] to avoid loss of matterial by partitioning of lipid over two phases. Briefly, after complexing calcium by EDTA, to the resulting solution five volumes of methanol are added, followed by five volumes of chloroform. After stirring for ten minutes the mixture is centrifuged to remove insoluble material. The supernatant is evaporated and dried by repeated evaporation from absolute ethanol. Finally, the lipid is extracted from the dried material with pure ohloroform and puritied by CM-cellullose chromatography. 
Results and Discussion.

We compared the detergents sodiundodecylsulfate, sodiumdeoxycholate, Triton $X-100$ and octylglucoside in their capacity to replace diethylether as a solute for PC in the enzymatic synthes is of PS.

\section{TABLE I}

Conversion of PC to PS in the presence of detergents.

\begin{tabular}{lccc} 
Detergent & $\begin{array}{c}\text { Inc. time } \\
\text { (hours) }\end{array}$ & $\begin{array}{c}\text { PC degradation } \\
(\%)\end{array}$ & $\begin{array}{c}\text { PS formation } \\
(\%)\end{array}$ \\
TX-100 & 3 & - & - \\
SDS & 3 & 50 & 25 \\
& & & \\
DoC & 1 & 45 & 15 \\
& 2 & 87 & 29 \\
& 3 & 94 & 21 \\
& 4 & 96 & 25 \\
Octylglucoside & 1 & & \\
& 2 & 67 & 25 \\
& 3 & 93 & 41 \\
& 4 & 95 & 46 \\
\hline
\end{tabular}

In all cases a detergent concentration of $2 \%($ m/y) is used. Incubations were carried out for the tiale indicated in the table. Degradation is expressed as the fraction of lecithin converted. The alount of PS formed is expressed as fiaction of the amount of lecithin present at zepo tide.

of these detergents, octylglucoside proved to be the most effective, both with respect to the percentage of $\mathrm{PC}$ transformed into $P S$ in the reaction and to the reaction velocity (Table I). We found that when $10 \mathrm{mg} / \mathrm{m} 1$ of $P C$ is used, at least $1 \% \mathrm{w} / \mathrm{v}$ of octylglucoside is needed to allow complete conversion of PC under the conditions employed (Table II). This is in line with the very high oritical micellar concentration of octylglucoside, which implies a monomeric concentration of several $\mathrm{mg} / \mathrm{ml}$, leaving very little detergent to allow formation of mixed micels of detergent and 1 ipid when less than $10 \mathrm{mg} / \mathrm{ml}$ octylglucoside is present. Based on the sudden increase in light scattering which is observed when increasing amounts of PC are dispersed in a solution of octylglucoside, up to $25 \mathrm{mg} / \mathrm{ml}$ of $\mathrm{PC}$ can be solubilized in the form of mixed micels when $2 \% \mathrm{w} / \mathrm{v}$ octylglucoside is used (data not 
shown), before bilayer structures are formed in which PC cannot efficiently be converted by phospholipase $\mathbb{D}$.

\section{TABLE II}

Effect of octylglucoside concentration on the efficiency of $\mathrm{PC}$ conversion.

Octylglucoside (\% $w / v)$

0.5

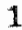

2

5
$\mathrm{PC}$ degradation

(\%)

56

95

95

95
PS formation

(\%)

17

41

38

39

Incubations were carried aut for three hours. petylalucoside colcentrations are expessed as weight per yalue. Degradation and pa for ation are expressed in the sale way a stated in the legend to Table $I$.

In conclusion, a method is described for the enaymatic synthesis of PS in a one-phase system, using octylg lucoside to diperse the lipids. One advantage of this system is that small quantities of expensive and rare species of $\mathrm{PC}$ can be handled in small volumes, thereby reducints losses from adsorption during the procedure. Also it is likely that more polar PC species with a lower solubility in ether, like short chain lecithins or species containing bulky polar groups, will be more efficiently converted to PS using this method compared to the twomphase system.

\section{References.}

1. Confurius, P., Zwaal, R.F.A. (1977)

Biochim. Biophys. Acta 488, 36-42.

2. Tilley, L., Cribier, S., Roelofsen, B., Op den Kamp, J.A.F., van Deenen, L. L.M. (1986)

FEBS Letters 194, 21-27.

3. Connor, J., Schroit, A.J. (1987)

Biochenistry 26, 5099-5105.

4. Zachowski, A., Favre, E., Cribier, S., Herve, P., Devaux, P.F. (1986) Biochenistry 25, 2585-2590.

5. Sune, A., Bette-Bobillo, P., Bienvenue, A., Fellmann, P., Devaux, P.F. (1987) Biochenistry 26, 2972-2978.

6. Zachowski, A., Herrmann, A., Paraf, A., Devaux, P. F. (1987) Biochim. Biophyss. Acta 897, 197-200. 
7. Bchroit, A.J., Marsen, J., Ruoho, A.E. (1987) Biocherigtry 26, 1812-1819.

8. Zarbowki, A., Fellmann, P., Herve, P., Devaux, P. F. (1987) FEBS Letters 223, 315-320.

9. Reed, C.F., Swisher, S.M., Marinetti, G.V., Eden, E.G. (1960) I. Lab. Clin. Med. 56, 281-285. 
ON THE RELATION BETWEEN MENBRANE ASYMMETRY AND BLOOD COAGULATION.

Sumpary

Various mixtures of phospholipids were tested on their ability to shorten the clotting time of plasma in a Stypven assay. Also, different types of sealed or non-sealed erythrocyte membraness were used. It is shown that only lipid mixtures containing $P S$, and membrane preparations: in which the cytoplasmic side is exposed (i.e. lysed cells or insideout sealed vesicles) are able to shorten the elotting time. A physiologioal relation between membrane phospholipid asymmetry and the regulation of haemostasis is proposed. 
Introduction.

Although there is compelling evidence that membrane components are non-randomly distributed between the two gurfaces, the physiological significance of membrane asymetry has so far remained obscure. Since the exterior aurface of blood aeli membranes is presumably devoid of negatively charged phospholipids which have a regulatory role in blood olotting, $A$ possible function of Iipid asymmetry in the coagulation process can be anticipated. We describe here experiments devised to show that the asymetric distribution of membrane phospholipids in blood cellas may serwe a biological purpose, by contributing to maintain the delicate balance between regulating hemosta보 and avoid ing thrombosi.

The main function of phospholipids in blood coagulation is to provide a catalytic surface on which various coagulation factors interact, thus increasing their local concentrations. For example, the final lipid-activated step in the coagulation process is the conversion of prothrombin in thrombin by the prothrombinase complex, which requires at least four components in addition to prothrombin, the proteins factor $X_{a}$ and $V_{a}$, calcium-ions and phospholipids [1]. Of these components, only factor $X a$ is able to convert prothrombin into thrombin by limited proteolysis $[1-5]$, but its individual action is considerably slower than with the complete prothrombinase complex [6].

In situ, the platelet plasma membrane presumably provides the phospholipid-water interface (platelet factor 3), which is required to accelerate the coagulation process [7]. It has been shown [8-10] that the clot-promoting activity of phospholipids in vitro is not attributable to a certain phospholipid class, but to a specific nesative charge of the phospholipid surface. In particular, negatively charged phospholipids such as phosphatidyligerine and phosphatidylelycerol (when properly diluted with neutral phospholipids 1 ike lecithin or phosphatidy thanolamine) exhibit maximal activation of the coagulation process $[11,12]$.

It is generaliy accepted that membranes are highly asymmetric structures both with respect to their proteins and their lipids [13-16]. It was shown that the non-random distribution of phospholipids between the interior and exterior half of the platelet plasma membrane is similar to that of the erythrocyte membrane [17]. In both membranes. phosphatidylserine is apparently nearly exclusively located in the cytoplasmic surface, whereas the outer monolayer of both membranes consists of neutral phospholipids, particularly sphingomyelin. The other two major phospholipid classes, phosphatidylcholine and phosphatidylethanolamine are present on both membrane sides though not to the same extent. He report here on the possible implications of blood cell nembrane asymmetry for the coagulation process. Since methods are readily available 
to prepare different types of sealed and non sealed erythrocyte ghosts, this type of membrane has been used in the present study rather than the platelet surface membrane wich is more difficult to manipulate.

\section{Methods:}

Blood from healthy volunteers was collected in 0.13 mol/1iter sodium citrate ( 9 vol blood + 1 vol citrate). Red cells, non-sealed ghosts and resealed right.side out ghosts were prepared as described before [18]. Inside-out sealed ghost vesicles were prepared acoording to Steck [19]. Platelet poor plasma was obtained by centrifugation of the blood for 10 minutes at $5000 \mathrm{~g}$. Phosphatidyloholine: (PC) and phosphatidylethanolamine (PE) were prepared from egg yolk [20]. Sphingonyelin was isolated from bovine brain [21]. Phosphatidylserine was isolated from pig brain [22]. Liposomes were prepared by mixing together the proper amounts of lipids as solutions in chloroforw. After evaporation of the oreanio solvent by a stream of nitrom gen, a solution of $\mathrm{NaCl}(0.9 \% \mathrm{w} / \mathrm{v})$ was added. By vortexing for 5 minutes in the presence of two glass beads, Iipo. somes were formed with a final lipid concentration of 4 molliter. The coagulant activity of these preparations was determined by their ability to shorten the alotiting time on recalcification of 'normal' human platelet poor plasma in the presence of Russell's viper venom.

Coagulation assays were performed as follows: $0.1 \mathrm{ml}$ of platelet poor plasma was incubated at $37^{\circ} 6$ for 30 seconds with $12 \mathrm{ng}$ of Russel1"s viper venom (RVV). Upon recalcification this amount gave a blank coagulation time of 100 seconds. After incubation with RVV $0.1 \mathrm{ml}$ of various dilutions of the different 1 ipid or cell prepara tions were added, followed by $0.1 \mathrm{mI} \mathrm{CaCl}=125$ moll $/ \mathrm{i}$ ter). A stopwatich was started simultaneously with the addition of $\mathrm{CaCl}$. The time required for the formation of a firm fibrin clot was determined by the arrest of a rotating metal wire ( 2 mo lexgth, cut from thegular puper clip), driven by a magnetic stirrer. This method dave the sane clotting times as observed using traditional Kolle hook, but the standard deviations are smaller and usually below 1\%. For the presentation of coagulant antivity of membranes and lipids we report direotly the olotting times, rather than attempt to convert these to somo arbitrary units of activity. It is realized that such clotting times are a complex function of lipid activity, but no real advantage is gained by using conventiona] log-log calibration curves obtained by serial dilution of plasma. In view of the wide range of final phospholipid concentrations used, the values on the abscissa are plotted logarithmically. 
Results and discussion.

When only the outside of the erythrocyte membrane is oxposed (either intact cells or resealed right-side out ghosts) no significant reduction of the blank clotting time is observed over alde range of lipid concentrations (fig.1). On the other hand, when either the membrane interior (inside-out wesicles) or both membrane sides (non-sealed ghosts) are exposed, a two- to threefold reduction of the coagulation time is observed at optimal concentrations.
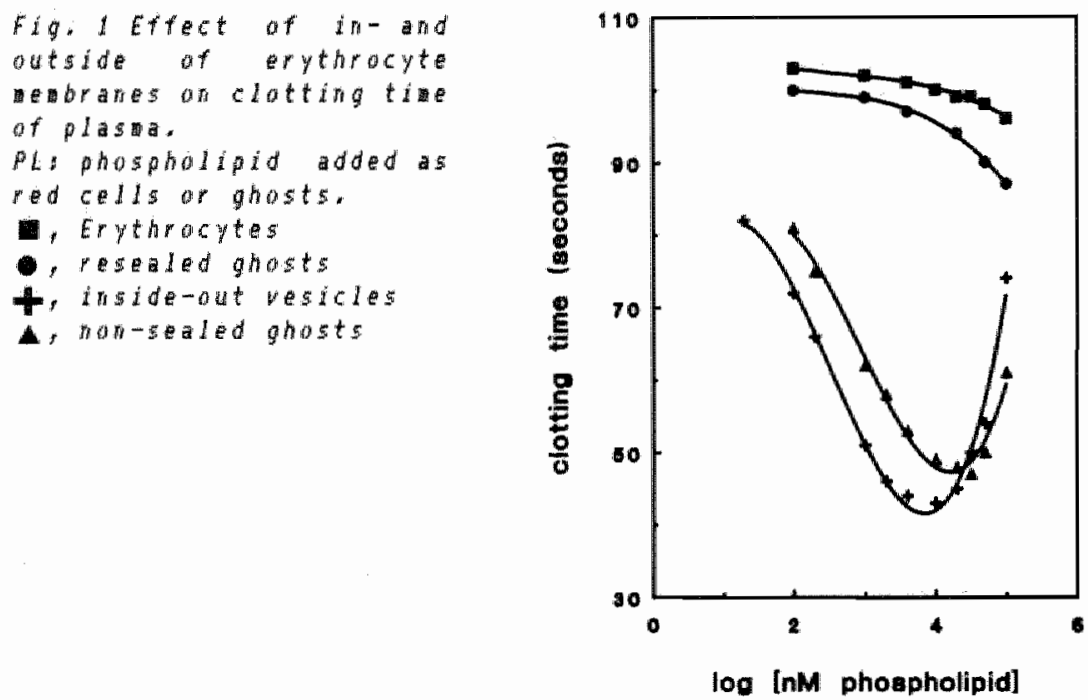

At higher lipid concentrations clotting time increases. This is consistent with the view that excess of 1 ipid will result in a dilution of coagulation factors at the 1 ipid surface [23]. The results suggest that only the phospholipids at the membrane interior have procoggulant activity, also since inside-out ghost vesicles are slightly more active than non-sealed thosts.

This hypothesis was further investigated by testing liposomes with the same phospholipid composition as present in the outer balf and inner half of human red cell membranes and pig platelet plasma membranes (Table 1, data calculated from refs 17 and 24). Handshaken 1 iposomes were uswd rather than sonicated vesicles, to avoid artificially induoed phospholipid asymmetry which is known to occur in mixed vesicles as a result of charge differences and packing properties [25]. It should be noted, however, that using multilamellar liposomes only 10-15\% of the lipids 
TABLE I

Mole ratios of phospholipids in liposomes simulating outer and inner half of erythrooyte and platelet plasma membrane

\section{Red cell membrane} Outer half Inner half
Platelet plasmamembrane Outer half Inaer half

$\begin{array}{lrrrr}\text { PC } & 44 & 15 & 26 & 34 \\ \text { Sph } & 44 & 10 & 52 & 4 \\ \text { PE } & 12 & 47 & 20 & 28 \\ \text { PS } & 0 & 28 & 2 & 34\end{array}$

are available at the outer surface [26]. As shown in fig. 2, liposomes having the same composition as present in the outer membrane half of either red cell nenbranes or platelet plasma membranes do not reduce whatever the blank clotting time.
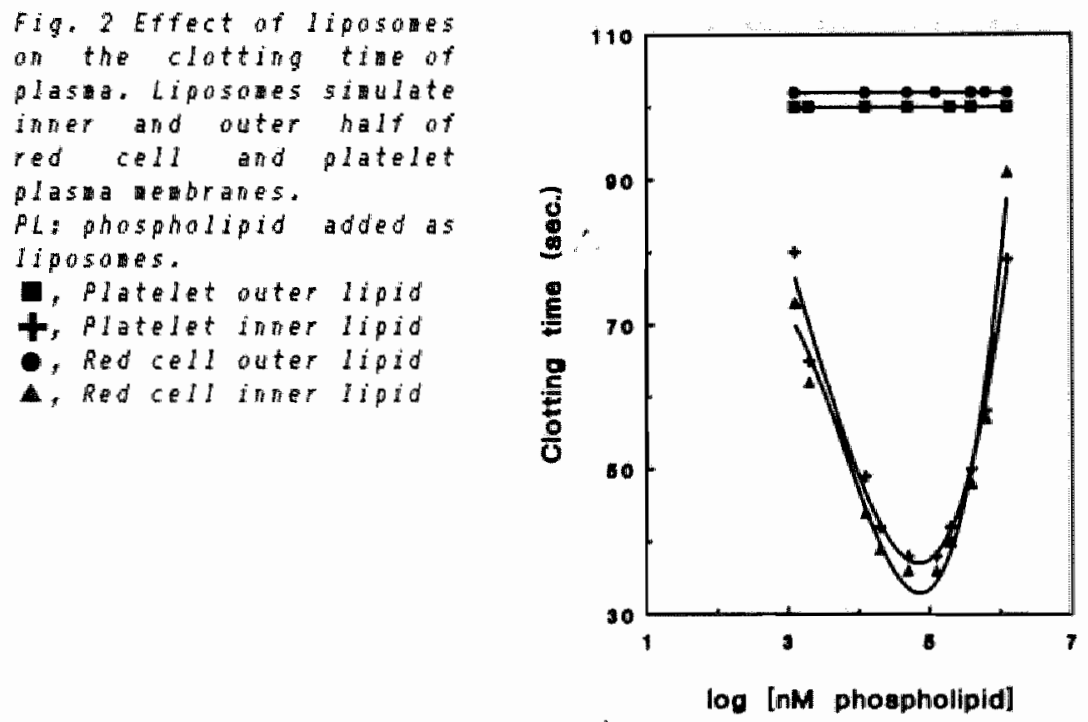

On the other hand, liposomes with the same phospholipid composition as the inner half of red cell or platelet plasma membranes produce a threefold reduction of tho coagulation time at optimal concentrations. The amount of? lipid required is higher than with ghosts, since only a fraction of the total lipid is available at the surface of 
hindishaken liposomes.

It is realized that the measurement of procoagulant activity of the lipids is not performed at one particular transitory stage of the blood clotting process, in spite of the presence of Russel1's wipier venom which is known to activate both factor $X$ and factor $V$ [27]. Nevertheless, the results strongly suggest that the outer surface of blowd cells is devoid of phospholipids which are active in blood coagulation, mainly due to the absence of any vignificant amount of phosphatidylserine. This phospholipid comprises about $30 \%$ of the phospholipids at the membrane interior, representing a concentration which has been shown to be optimal in activating prothrombin by the prothrombinase complex [11].

The presence of procoagulant phospholipids only at cytoplasmic surfaces of blood cells is not only consistent with phospholipid asymetry in membranes, but might also represent an important mechanism both in avoiding thrombosis end in regulating hemostasis. It could be judged as potentially dangerous to have procoagulant phospholipids at: the outer surface of blood cells, which may bring about a 'permanent' condition of hypercoagulability. This fact itself could provide a physiolofical reason for an asymetric phospholipid distribution in blood cell membranes. On the other hand, after disruption of the vessel wall the sequence of platelet adhesion, release reaction and $A D P-i n d u c e d$ platelet aggregation, presumably accounts for the primary arrest of bleeding. Provided that platelet factor 3 artivity becomes available during this process, its exposure should come after the release reaction, since no phosphatidylserine can be labelled from the outside during the release reaction [28]. Moreover, it has been demonstrated that only small fraction of lipid procoagulant activity becomess available during release reaction compared with the activity obtained upon lysis $[29,30]$.

This raises the question whether during or after Cormation of the primary hemostatic platelet plug, either (partial) lysis or an as yet unknown mechanism which translocates phosphatidylserine through the plasma membrane is necessary to provide a catalytic surface for interacting coagulation factors. 
1 Seegers, W.H., Sakuragawa, N., MoCoy, L. E., Sedensky, J. A., Dombrose, F. A. (1972)

Thrombosis Research $1,293-310$.

2 Papahad jopoulos, D., Hanahan, D.J. (1964)

Biochim. Biophys. Acta 90, 436-439.

3 Milstone, J.H. (1964) Fedr. Proo, 23, 742-748.

4 Barton, P.G., Jackson, C.M., Hanahan, D.J. (1967) Nature $214,923-924$.

5 Hemker, H.C., Esnouf, M.P., Hemker, P.W., Swart, A.C.W., Macfarlane, R.G. (1967) Nature 215, 248-251.

6. Jobin, F., Esnouf, M.P. (1967) Bioohem. J. 102, 666-674.

7 Marcus, A.J. (1966) Adw. Lîp. Reg. 4, 1-37.

8 Bangham, A.D. (1961) Nature 192, 1197-1198.

9 Papahed jopoulos, D., Hougie, C., Hanahan, D.J. (1962) Proc. Soo. Exp. Biol. Med. 111, 412-416.

10 Daemen, F.J.M., van Arkel, C., Hart, H.Ch., van der Drift, C., van Deenen, L. L.M. (1965)

Thromb. Diath. Haemorrk. 13, 194-217.

11 Bul1, R.K., Jevons, S., Bartor, F.G. (1972) J. Biol. Chem. 247, 2747-2754.

12 Gite1, S.N., Owen, W.G., Esmon, C.T., Jaokson, C.M. (1973) Proo. Nat1. Acad. Soi. USA 70, 1344m1348.

13 Bretsoher, M.S. (1973) Soience 181, 622-629.

14 Zwal, R. F.A., Roelofsen, B., Colley, C.M. (1973) Biochim. Biophys. Acta 300, $159-182$

15 Bretscher, M.S., Raff, M.C. (1975)

Nature $258,43-49$.

16 Marchesi, V.T., Furthmayr, H., Tomita, M. (1976)

Ann. Rew. Biochem. 45, 667-698.

17 Chap, H., Zwaal, R.F.A., van Deener, L. I. M. (1977) Biochim. Biophys. Acta 467, 146-164.

18 Zwaal, R.F.A., Roelofsen, B., Comiurius, P., van Deerien, L. L.M. (1975)

Biochim. Bioptiys. Aote 406, 83-96.

19 Steck, T.L. (1974) Meth. Merbr. Biol. 2, $245-281$

20 Sireleton, W.S., Gray, M.S., Brown, M.L., White, J.L. (1965)

J. An. Oil. Chen. Soo, 42, 53-56.

21 Ansel1, G. B., Spanner, S. (1961)

Biochem. I. $79,176-184$.

22 Sanders, H. (1967) Biochim. Biophys. Acta 144, 485-487.

23 Hemker H.C. (1975)

Handbook of Hamopbilia $31-48$ (eds. Brimktous. K. M. Hemker, H.C.) Exerpta Mediog Arnsterdam.

24 Verkleij, A.J., Zwaal, R.F.A., Poelotem, B. " Comfurius, P., Kastelijn, D., van Deenen, L. L. M. (1973) Biochim. Biophys. Acta 323, 178-193.

25 Berden, J.A., Barker, R.W., Fadda, G.K. (1975) Biochim. Biophys. Acta 375, 186-208.

26 Bangham, A.D., de Gier, J., Greville, G.D. (1967) Chem. Phys. Lipjds 1, 225-246. 
27 Sokiffman, S., Therdor, I., Rapaport, S.J. (1969) Biochemistry 8, $1397-1405$.

29 Sohick, P.K., Kurioa, K.B., Chacko, G.K. (1976) J. Clin. Jnvest. $57,1221-1226$.

29 Sixma, J.J., NiJessen, J.G. (1970) Thxomb. Diath. Haenorrh..24, 206-213.

30 Joigt, J.H., Dolezel, G., Lloyd, J.V., Kinlough-Rathbone, R.L. Mustard, J.F. (1974)

I. Lab. Clin. Med. 84, 474-482. 
THE NATURE OF THE BINDING SITE FOR PROTHRONBINASE AT THE PLATELET SURFACE

AS REVEALED BY LIPOLYTIC ENZYMES.

\section{Summary.}

The nature of the receptor for the prothrombinase complex at the surface of non-activated platelets was investigated by measuring the platelet prothrombin converting activity with a chromogenio substrate assay, after treatment of the platelets with various phospholipases or three different. proteolytic enzymes. Platelet prothrombin converting activity decreased only after treatment with those phospholipases which are able to hydrolyse phospholipids in the intact platelet and also have the capability to degrade negatively charged phospholipids, phosphatidylserine and phosphatidylinositol. Those phospholipases which do hydrolyse phospholipids in the intact platelet but have no activity towards phosphatidylserine (and phosphatidylinositoly produce an increase in the platelet prothrombin converting activity.

Proteolytic treatment of platelets with trypsin, chymotrypsin or papain did not result in a decrease of prothrombin converting activity. It is concluded that negative ly charged phosphatidylserine and possibly phosphatidy inositol are involved in the prothrombin converting activity of non-acti vated platelets. Any involvement of platelet membrane proteins in a receptor for the components of the prothrombinase complax could not be demonstrated. 
The conversion of prothrombin into thrombin by factor $\mathrm{Xa}$ in the presence of factor $\mathrm{Va}$ and $\mathrm{Ca}^{2-}$ is known to occur efficiently on negatively charged phosphoi.jpid surfaces [1]. Mixtures of phosphatidylserine and phosphatidylcholine have been shown to produce a drop in the apparent Kin for prothrombin from far above to far below the physiological concentration of 2 MM [2]. In platelets, the negatively charged phospholipids, i.e.

phosphatidylserine and phosphatidylinositol, are predominantly contined to the inner leaflet of the plasma membrane and to intracellular membranes [3-5]. These lipids under certain conditions become available on the exterior surface after platelet activation, which can explain: the higher procoagulant activity of activated ael 1 s $[6-8]$.

It was sugented by Miletich et al. [9-11] and Dahlbsok and Stenflo [12] that factor $V_{a}$ serves as the receptor for factor Xa at the platelet surface. Approximately $200-300$ binding sites for factor $X a$ were found at the axirface of thrombin-activated platelete that have undergone the release reaction. Moreover, it was demonstrated that the binding sites for the factor Va/factor Xa complex are already present at the outer surface of unstimulated platelets [13]. Activation of platelets by thrombin appears to be required only to release factor Va from the platelets wich then serves as the receptor for factor Xa. The nature of the factor Va/factor $X a$ binding site is at present unknown, but the finding of a patient deficient in these sites has led to the suggestion that some protein component is probably required [14].

In view of the fact that it cannot be excluded that minor amounts of phosphatidylserine are present at the membrane exterior [4-6] and participate in prothrombin conversion, the influence of different phospholipases on the prothrombinactivation sites is of interest. PhosphoIfipases A have been shown by Verheijet al. [15] to exhibit anticoagulant properties in clotting assays that are sensitive to negatively charged phospholipids. This is due to hydrolysis of phospholipids which can only occur wh those phospholipases having an appreciable penetration power in highly packed monomolecular lipid films.

Moreover, only phospholipases with high penetration power have been shown to be able to attack phospholipids in intaot red cel1s $[16,17]$ and platelets [4].

In this study, we have compared the effect of a number of highly purified phospholipases on the platellet prothrombin converting activity (in the presence of factor Va), using chromogenic substrate assay avoiding platelet activation by the thrombin formed. Furthermore, the influence of proteolytic treatment of platelets on their prothrombin-converting activity has been tested. The data have implications for the involvement of simall amounts of phosphatidylserine in the prothrombin-activation sites at 
the outer surface of nonstimulated platelets.

\section{MATERIALS AND METHODS.}

Phosphol ipase preparations.

The following phospholipases were purified acoording to Zwaal et al. [16]. Phospholipase As rrum Naja naja venom (Koch Light), phospholipase As from bee venoth (Apis mellifica) (Koch Light), phospholipase As from Crotalus adamanteus (Koch Light), phospholipase $C$ from Bacillus cereus, phospholipase C from Clostridium welohi i and sphingomyelinase C from Staphylococous aureus. All phospholipases were diluted to a final concentration of $0.5 \mathrm{I} . \mathrm{U} . / \mathrm{ml}$ in $50 \%(\mathrm{v} / \mathrm{v})$ Elycerol. The international unit (I.U.) is defined as the as amount of enzyme which degrades 1 mol of substrate per minute $37^{\circ} \mathrm{C}$.

Phospholipids.

Brain phosphatidylserine and egs phosphatidyloholine were purchased from Sigma. Phosphatidylethanolamine was synthesized from phosphatidylcholine as described before [18]. Sphingomyelin was from Kooh Light. All lipids used were chromatographically pure.

Protein preparations.

Bovine prothrombin was prepared acoording to the method of Owen et al. [19]. Prothrombin concentrations were calculated from the absorbance at 280 nm usine an extinction coefficient of 15.5 for a $10 \mathrm{mg} / \mathrm{ml}$ solution in a $1 \mathrm{~cm}$ cuvet, and $72 \mathrm{kD}$ for the molecular weidht of prothrombin [19]. Bovine factor $x$ was prepared from factor $X$ by $R V V-X$ as described by Fujikawat al. [20]. Factor $X a$ concentrations were calculated after titration of active sites according to smith [21]. Factor $v$ was isolated as described by Esmon [22] and modified by Lindhout [23]. Factor $V(0.3$ mg/mi) was activated with RVV-V ( $1 \mu_{\mathrm{g} / 100} \mathrm{\mu g}_{\mathrm{g}}$ factor V) and the secific activity of

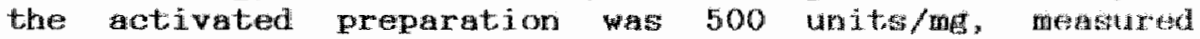
according to Kappeler [24]. One unit is defined ws the amount of factor $V$ present in $1 \mathrm{ml}$ normal bovine platina. The concentration of factor Va was calculated assuning a molecular weight of $330 \mathrm{kD}$ for factor $\mathrm{V}[25]$.

Isolation of platelets.

Fresh blood was draw from healthy male voluriterers, who had not taken any medication for at least a wek. As anticoagulant acid-citrate-dextrose $(0.18 \mathrm{M}$ flucose, 0.00 $M$ trisodium eitrate, $0.052 M$ citric acid) was used in a ratio of one volume for every five volumes of blood. Ila telet rich plasma was obtained after centrifugation at $120 \mathrm{~g}$ for 10 minutes. Platelets were isolated by orturifugation ( $1400 \mathrm{~g}, 15 \mathrm{~min}$ ) and the pellet was gently resuspended in a calciumfree Hepes buffer pH 6.\% containing 137 $\mathrm{mM} \mathrm{NaCl}, 2.68 \mathrm{mM} \mathrm{KCl}, 10 \mathrm{mM}$ Hepes, $1.7 \mathrm{mM} \mathrm{MgCl}, 25 \mathrm{mM}$ glucose and $0.05 \%$ fatty-acid free human serum allowin. Cells were washed twice and finally resuspernded in the same buffer at pH 7.4. Platelet concentration was deter 
mined with a Coulter Counter and adjusted to a count of $5 \times 10^{\circ}$. w $1^{-1}$. All platelet handling was carried out at room temperature.

Megurement of thromin formation after phospholipase treatrent of platelets and lipid vesicles.

Platelet suspensions of $2 \mathrm{ml}$ were incubated in plastic cuvettes at 370 C under stirring in a spectrophotometer.

Prior to the addition of $40 \mathrm{kl}$ phopholipase (final

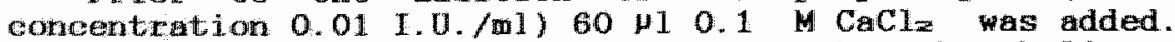
At different time intervals during the phospholipase treatment, $35 \mu 1$ of a mixture containing 30 aM factor $X a$ and 60 nM factor $\mathrm{Va}$ were added to the cuvette. 2 minuties after the addition of the factors $X_{a}$ and $V a, 100 \mu 1$ chromogenic substrate $(\$-2238,5 \mathrm{mM})$ was added. Thrombin formation was started by adding $40 \mu l$. $44 \mathrm{H} /$ prothrombin to the cuvette. The absorbance change was registered as a function of time. Because all phospholipases were dissolved in $50 \%(\mathrm{w} / \mathrm{w})$ glycerol, measurements of thrombin formation using control platelets, were performed after addition of 40 H. $50 \%$ glycerol in stead of the phosphoipase solution.

Prothrombin converting activity of pure phospholipid vesioles and the effect of various phospholipase treatments on this activity was deterwined under the same conditions as used for platelets. Phospholipid vesicles (1 $\mathrm{HM}$ phospholipid) were prepared by sonication [26]. They were composed of $26 \%$ phosphatidylcholine, $20 \%$ phosphatidylethanolamine, $2 x$ phosphatidylserine and $52 \%$ sphingomyelin. This composition is comparable to the phospholipid composition of the outer leaflet of the platelet plasme membrane [6].

\section{Results.}

Addition of factor $X a$, factor $V a$ and prothrombin to intact platelets in the presence of $\mathrm{Ca}^{2+}$-ions results in the formation of thrombin which in turn can activate platelets to ageregate and release their granule contents. It will be clear that platelet activation by thrombin thus formed, should be avoided. Addition of the ohromogenic substrate (specific for thrombin) $\$-2238$ will cause competition between this substrate and platelets for thrombin. Indeed we found that addition of $5-2238$ to washed thuman platelets effectively inhibits aggregation and release induced by thrombin (data not shown). The inhibitory affect of $\$-2238$ towards factor $X_{a}$ is of little importance here, since in all experiments the starting ratio of factor $X a$ to $S-2238$ is the same. Moreover, less then $10 \%$ of the chromogenio substrate is converted during measurements of prothrombin-converting activity.

The advantage of this competitive inhibitor is that the amount of thrombin formed by the prothrombinase complex can still be measured. In the incubation system described here, the complete prothrombinase complex is 
present, together with the substrate used to determine the amount of thrombin formed. In this system the change in absorbance at 405 no is a linear function of the square of time, because both the formation of thrombin by the prothrombinase complex and the conversion of $\mathrm{S}-2238$ are linear with time. The rate of thrombin formation in these experiments was therefore calculated from a plot of absorbance versus the square of time, and a calibration curve with known amounts of active site titrated thrombin.

The effect of prolonged inoubation of six different phospholipases on the prothrombin converting activity of washed human platelets is shown in Fig. 1.
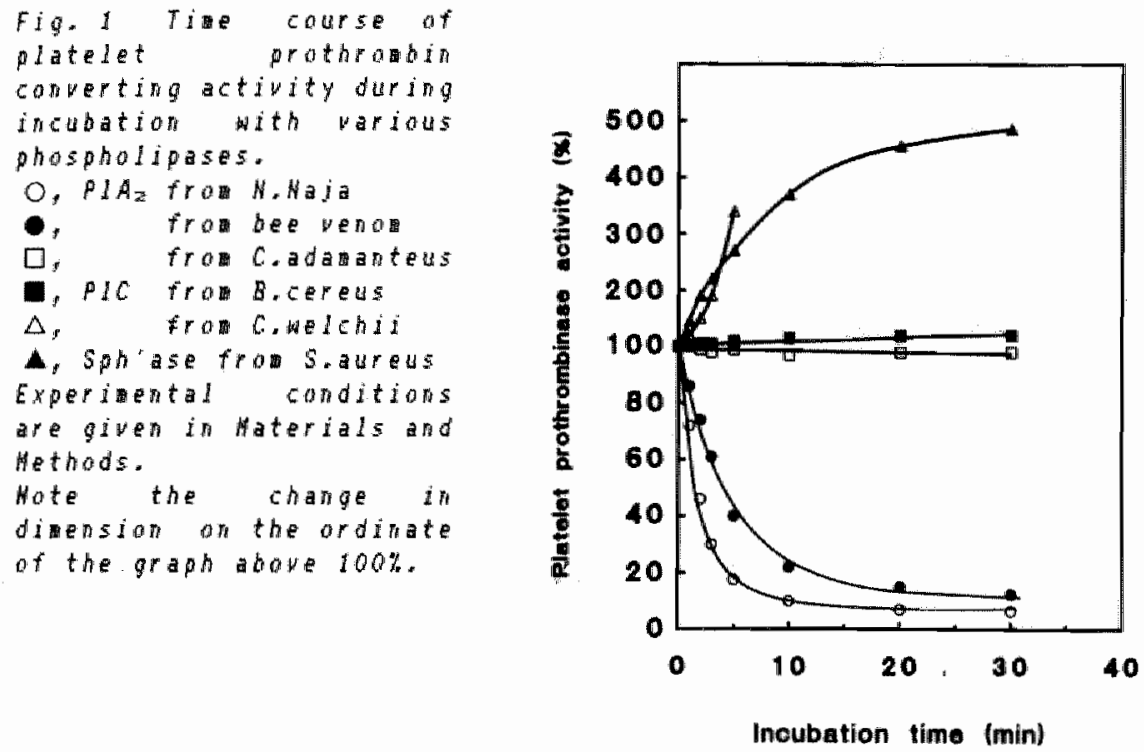

Based on the effect they exert on the prothrombin conver tine activity of non-stimulated platelets, these phospholipases can be divided into three groups. There are those phospholipases that lower the platelet procoagulant activity (phospholipase $A=$ frow bee vernom and the sam enzyme from Naja naja snake venom). There are phospholip. ases which do not affect the platelet prothrubirin converting activity (phospholipase $C$ from Bacillus oereus and phospholipase As from Crotalus adamanteus . Finally there is the group of phospholipases able to increase the prothrombinmconverting activity (sphingomyelinase from Staphylococcus aureus and phospholipase $\mathrm{C}$ from clostridium welchii. Extensive lysis of the platelets ocours upon 
treatment wh phospholipase $C$ from $C$. welchii, which is the reason why in this case an incubation period of less then 5 ninutes: was taken.

In order to obtain further indications concerning the senificance of phospholipids in the prothrombin conver ting activity of non-stimulated platelets, the effect of the above mentioned phospholipases on the prothrombin converting activity of vesicles composed of phospholipids present in the outer monolayer of the platelet plasma mombrane was studied. These vesicles which mimick the latelet outer surface as far as phospholipids are concerned, were treated wth phospholipases for 30 minutes and the resulting prothrombin converting activity is compared ith the activity of platelets after 30 minutes incubation ith these phospholipases. The data are Hiven in Table 1. With the exception of phospholipase Aa from $C$. adamanteus and phospholipase $C$ from $B$. cereus, the changess in prothrombin-convertiru activity of the vesicles produced by the action of the different phospholipases are very similar to the effects observed on intact platelets.

\section{TABLE I}

The effect of different phospholipaseson the prothrombin converting activity of platelets and phosipholipid vesicles which mimic the outer surface of the platelet membrame.

Results are given for prothrombin converting activity after 30 in phospholipase treatment.

Phospholipase Source

Prothrombin converting
activity in
platelets vesicles

\begin{tabular}{|c|c|c|c|}
\hline & & $\boldsymbol{x}$ & $\mathbf{x}$ \\
\hline None & - & 100 & 100 \\
\hline Phospholipase As: & $\begin{array}{l}\text { C. adamanteus } \\
\text { N. na.ja } \\
\text { bee venom }\end{array}$ & $\begin{array}{r}96 \\
8 \\
13\end{array}$ & $\begin{array}{l}5 \\
3 \\
2\end{array}$ \\
\hline Phospholipase C & $\begin{array}{l}\text { B. cereus } \\
\text { C. welchil }\end{array}$ & $\begin{array}{l}103 \\
300^{-}\end{array}$ & $\begin{array}{r}8 \\
250\end{array}$ \\
\hline Sphingomuelinase & S. aureus & 380 & 1000 \\
\hline
\end{tabular}

- Prothrombin converting activity after 5 min phospho1 ipase treatment.

It should be emphasized here that the phospholipid composition of the vesicles may differ from that of the outer monolayer of the platelet, because it is not feasible to determine the amount of phosphatidylserine in the outer leaflet within a range of acouracy of only a few percent $[4,5]$. Therefore the absolute activities of both preparations cannot be compared. For this reason the 
data in Table 1 are expressed as percentages.

To see whether platelet-membrane proteins are also involved in the formation of the prothrombinase complex at the platelet surface, we also compared the prothrombin converting activity of platelets treated ith Sepharosem coupled trypsin, chymotrypsin and papain. None of theste proteolytic enzymes gave a reduction of the prothrombin converting activity. Although this does not exclude that a membrane protein receptor plays a role in the formation of the prothrombinase complex at the platelet surface, the involvement of such a protein seems to be unlikely unless it is stable to, or protected against, proteolytio attack by these enzymes.

\section{Discussion.}

Four out of six phospholipases which were used in this study are able to hydrolyse phospholipids in intact platelets, namely both phospholipases Az from Naja rita and bes venom " phospholipase $C$ from Clostridium welchil and sphingomyelinase. The other two phosphollpases uged, phospholipase As from Crotalus adamanteus ard phospholipase C from Bacillus cereus cannot attack phospholipids in intact platelets. Why certain phospholipases are able to hydrolyse phospholipids in the intact cells whereas others are not, was explained by Chap et al. [4] in ana]ogy tho the work on the erythrocyte $[16,17]$. Only those phospho. lipases which are able to attack monolayers of choline containing phospholipids with surface pressure above 310 $\mu N / \mathrm{cm}$ are able to excert their action towards intact platelets. The inability of phospholipase Aa from C. ada manteus and phospholipase $C$ from B. cereus to hydrolyse platelet phospholipids is reflected in the failure of these enzymes to affect the platelet prothrombin conver ting activity. On the other hand, of the four phospholip ases which can act on the intlact platelet, two enzymes produce a decrease in platelet prothrombin oorvertine activity (phospholipases Az from N. naja ard bee venon). while the other two phospholipases (C.welchil phospho lipase $C$ and sphingomyelinase) bring blout an increast in the platelet prothrombin converting actility.

The different effects of these phospholipases on the platelet prothrombin converting activity are explained by the difference in substrate specificity of these en towards phospholipids. The Elycerophospholipids (phosphatidylcholine, phosphatidylethamomine, phosuhat idy l serinf and phosphatidylinositol) are all proper substrates for the two phospholipase Az enzymes. Only these two enzymer cause a decrease in platelet prothromin wonvertine activity. In contrast, sphingomyelinase ard phosphol ipsses $C$ from $C$. welchi have somewhat different substrate specificities. However, these enzymes have in common that they do not hydrolyse negatively charged phosphatidylser-. ine. Sphingomyel inase can anly attack sphingomyelin. The 
C. welchii mayme degrades all phospholipids (including sphingomyelin except phosphatidylserine and very poorly hydrolyses phosphatidylinositol. It is concluded that a decreves in platelet prothrombin converting activity only accurs after treatment wth those phospholipases that are able to hydrolyse negatively charged phospholipids in the intect platelet nembrane.

The increase in prothrombin converting activity observed after trestment with two of the phospholipases might have seweral explanations. Significant lysis of the platelets during incubation with the enzyme of $C$. welchi is partially responsible for the lare increase in prothrombin-converting activity. This is due to the exposure of the membrane inner surface in which the majity of negatively charged phospholipids is present $[4,5]$. Arother phenomenon, trans]ocation of phosphatidy 1serine, leading to enhancement of prothrombin conversion, independent of cell lysis, is described in chapter 6 .

However, the increased prothrombin-converting activity found as a result of treatment by sphingomyelinase cannot be explained by lysis, since the cytoplasmic enzyme lactate dehydrogenase is not detectable in the supernatant after inoubation. From the experiments demonstrating the asymmetric distribution of phospholipids over the platelet plasma membrane $[4,5]$ we conclude that incubation of platelets with sphingomyelinase does not lead to exposure of phosphatidylserine at the outer surface of the cells, as will occur upon incubation with the $C$. welchii phospho1ipase C [chapter 6]. Two other possibilities may explain the increased rate of thrombin formation during sphingomyel inase treatment. First, the action of sphingomyelinase leads to the formation of ceramide droplets in the membrane as a result of phase separation between the glycerophospholipids and the product of sphingomyelin degradation as was demonstrated by Verkleij et al. [27]. This leads to an increase in the phosphatidylserine concentration in the segregated phospholipid regions of the platelet outer monolayer which will affect the binding constants of the different components of the prothrombinase complex. A second explanation is that the formation of ceramide results in a decreased packing density of the lipids in the platelet membrane. This may affect the binding properties of especially factor Va with the membrane. It was suggested by Bloom et al. [28], that the interaction of factor $V_{a}$ ith a phospholipid is considered to be hydrophobic which requires penetration of factor $\mathrm{Va}$ into the phospholipid bilayer. Further investigations have shown that the decrease in sphingonyelin per sé might be the major cause for the increase in platelet prothrombin converting activity after sphingomyelinase treatment. Using sphingomyelin vesicles containing $10 \%$ PS (mol/mol), prothrombinase activity was shown to increase 5-8 fold upon replacing Sph by PC [29].

The effects on the prothrombin-converting activity of artificial membranes which mimic the outer surface of the 
platelet plasma membrare are essentially the same as those observed for platelets. Only under those conditions where negatively charged phospholipids are hydrolysed, a decrease in prothrombin-converting activity ocours. In contrast to the results seen ith platelets, phospholipase As from $C$. adamanteus as well as the phospholipase $c$ from B. cereus decrease the prothrombin converting activity of these phospholipid vesicles. However, in this case both enzymes are able to degrade phospholipids (inoluding phosphatidylserine) presumably due to the different. packing density of the phospholipids caused by the bith curvature of the surface of small phospholipid vesjeles. The increase in prothrombia converting activity of the phospholipid vesicles caused by incubation with sphingo myelinase or phospholipase $C$ from $C$. welchil way be explained by a local increase of phosphatidylserine concentration in the segregated phospholipid regions and/or a decrease in packing of the residuall phospholipids as a result of the formation of ceramides and diacylelycerol, respectively.

Combining the results obtained with platelets ard phospholipid vesicles, we conclude that the motatively charged phospholipid phosphatidylserint (and possibly also phosphatidylinositoll play an essential role in the activation of prothrombin by factors $X_{n}$ and $V a$ or tho surface of non-stimulated platelets. It should be emphas. ized that the products of hydrolysis of phosphatidylsentine by phospholipase As are lysophosphatidylserine and fathy acids. Both these compounds were shown by Verheij at: a]. [15] to have no procoagulant activity.

It should be mentioned that the loss of platelet. prothrombin-converting activity is not the result of a shielding effect caused by the birding of phospholipase $A$. to the surface of the platelet or phospholipid veside.

Inactivation of phospholipase As (either from $N$. naj or from bee venom) with p-bromophenacylbromide [30], does not ohange the prothrombin converting atelivity of platelets, nor that of phospholipid vesioles (data not shown). p-Bromophenacy 1 bromide destroys the active contre but not the phospholipid binding-site of phospholipase A\% [31] indicating that the hydrolytio activity rather than the binding of the enzyme to a phospholipid surface is: responsible for the loss in problumbin convertinf? activity. He conclude that negatively kharged phentac lipids, presumably small amounts of phosphatidylserine localized at the cell outer surface, are regponsilile fror the observed prothromin converting activity of non stimu lated platelets. Whether the binding of frotor $x_{\text {a }}$ innd factor $\mathrm{Va}$ is exclusively dependent on the presence of these negatively charged phospholipidrs canout. bes comoluded from the present data because rates of thromin formation have been measured which also requires the bindirut of prothrombin. However, the involvement of platelet membrane proteins in the formation of the prothronbinast: complex at the platelet surface could not be demonstinted. 


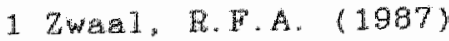

Birotim. Biophys. Acta $515,163-205$.

2 Rosing, J." Tans, G., Govers-Rienslag, J.h.P., Zwaal, R. F. A., Herker, A.C. (1980)

J. Biol. Cher. $255,274-283$

3 Sohick, P.K.; Kurica, K. B. Chacko, G.K. (1976) J. Cin. Invest. 57, 1221-1226.

4 Chap, H.j., Zwael, R.F.A., $\operatorname{ran}$ Deenen, L. L.M. (1977) Biochim. Biophyg. Acta 467, 146-164.

5 Perret, B., Chap, H.J., Douste-Blazy, L. (1979) Biochin. Biophyg. Acta 556, 434-446.

6 Zwaal, F.F.A., Comfurius, P., van Deenen, L.L.M. (1977) Nature (Lond.) 268, 358-360.

7 Bevers, E.M., Comfurius, P., Zwas1, R.F.A. (1979) Thromb. Haenostasis 42, 211 .

8 Zwat, R.F.A., Rosing, J., Tans, G., Bevers, E.M., Hemker, H.C. (1980)

in The ReEulation of Coagulation Taylor, F. B. and Mann, K. eds.) pq. 95-115. North-Holland, Amsterdam.

9 Miletiob, J.P. "Jacken, C.M. Ma.jerus, P.W. (1977)

Proc. Nat1. Acad. Soi. USA 74, 4033-4036.

10 Miletich, J.P.; Jackson, C.M. "Majerus, P. W. (1978) I. Biol. Chem. 253,6908-6916.

11 Miletich, J.P., Majerus, D.W., Majerus, P.W. (1978) J. C1in. Irvest. 62, 824-831.

12 Dahlback, B., Stetiflo, J. (1978) Biochemistry $17,4938-4945$.

13 Kane, W.H. "Lindhout, M.J., Jeckson, C.M. "Majerus, P.W. (1980) J. Biol. Cherr 255, 1170-1174.

14 Miletioh, J.P., Kane, W.H., Hofmann, S.L., Stanford, N. , Majerus, P.W. (1979) Blood 45, 1015-1022.

15 Verheij, H.M., Boffa, M. C., Rotheri, C., Brykaert, M.C., Vereer, R., de Haas, G.H. (1980)

Eux. J. Biochem. 112, 25-32.

16 Zwal, R. A., Roelofigen, B., Comfurius, P', van Deener, L.I.W. (1975) Biochim. Biophys. Acte 406,83-96.

17 Deme1, R.A., Geurts var Kesse1, W. S.M., Zwad, R.F.A. Roglafsen, B., van Deenen, L.L.M. (1975)

Biockim. Biophys. Acta 406, 97-107.

18 Comfurius, P., Zwal, R. F.A. (1977)

Bioobim, Biophys. Acta 448, 36-42.

(Thus thesis, chapter 1).

18 Owen, W.G., Esmon, C.T., Jackson, C.M. (1974) J. Biol. Chem. 249, 594-605.

20 Fujikawa, K., Legaz, M.E., Davie, E.W. (1972) Bi ockemistry $11,4892-4899$.

21 Smith, R.L. (1973) J. Biol. Chem. 248, 2418-2423.

22 Esmon, C.T. (1979) J. Biol. Chem. 254, 964-973.

23 Lindhout, I., Govers-Riemslag, J.W. .., van de Waart, P., Hemkex, H.C., Rosing, J. (1982)

Biochemistry 21, 5495-5502.

24 Kappeler, $\mathbb{E}$. (1975) Z. K1in. Med, 153, 103-113. 
25 Nesheim, M. E., Myrmel, K.H. Hibbard, L., Mann, K.G. (1979) J. Biol. Chem. 254, 508-51?.

26 de Kruijef, B., Cullis, P.R. "Radda, G.K. (1975) Biochem. Biophys. Acta $406, B-20$.

27 Verkleij, A.J., Zweal, R.F.A. Roelofser, R., Comfurius, F., Kastelijn, D., van Deenen, L. L. M. (1973) Eiochim. Biophys. Acta 323, 178-193.

28 Bloom, I. W., Nesheim, M.E., Mann, K. G. (1979) Hiochemistry $18,4419-4425$.

29 Zwaal, R. F. A. Bevers, E.M., Comfurius, P. (1986) in "New Comprehersive Bioolemistry, vol. 13, Blood Coagulation" (Zwaal, R.F.A., Hemker, H.C., eds.) pp. 141-169. Elsevier. Ansterdam.

30 Volwerk, J.J., Pieterson, W. A., de Haas, G.H. (1974) Biochemistry $13,1446-1454$

31 Pieterson, W.A., Vidal, J.C., Volwerk, J.J., de liam, G.H. (1974) Biochemistry 13, $1455-1460$. 
CHANGES IN MEMBRANE PHOSPHOLIPID DISTRIBUTION DURING PLATELET ACTIVATION.

Summary.

Exposure of phospholipids at the outer surface of activated and control platelets was studied by incubation with a mixture of phospholipase A from Naja naja and bee venom, solely or in combination with sphingomyelinase from staphylococcus aureus, using conditions under which cell lysis remained below 10\%.

Incubation with phospholipase A alone revealed a markedly increased susceptibility of the phospholipids in platelets activated by a mixture of collagen plus thrombin, by the SH-oxidizing agent diamide, or by calcium ionophore A23187, as compared to control platelets or platelets activated separately by collagen or by thrombin.

collagen plus thrombin, diamide and ionophore treatied platelets revealed an increased exposure of phosphatidylserine at the outer surface accompanied by decreased exposure of sphingomyelin, as could be concluded from incubations with a combination of phospholipase $A$ and sphingomyelinase.

These alterations were much less apparent in platelets activated either by thrombin or by collagen alone.

The increased exposure of phosphatidylserine in activated platelets is accompanied by an increased ability of the platelets to enhance the conversion of prothrombin to thrombin by coagulation factor $\mathrm{Xa}$, in the presence of factor $V a$ and calcium.

It is concluded that the altered orientation of the phospholipids in the plasma membrane of platelets activated by collaeten plus thrombin, by diamide, or by calcium ionophore, is the result of a transbilayer movement. Moreover, the increased exposure of phosphatidylserine in platelets stimulated by the combined action of collagen and thrombin might be of considerable importance for the hemostatic process. 
Phospholipids in the plesma membrane of human platelets are not homogeneous ly distributed between both halves of the memane bilayer [1-3]. In resting, non-activated platelet, the outer surface of the membrane is characterizell by the presence of neutral phospholipids, particularly phosphatidylcholine and sphingomyelin. The negatively charged platelet phospholipids, phosphatidylserine and phosphatidylinositol, are almost exclusively present in the inner leaflet of the bilayer. We have previously shown that activation of platelets by simultaneous action of thrombin and collagen changes the distribution of the lipids in the plasma membrane in such a way that a aubstantial amount of the negatively charged phosphatidy serine becomes exposed at the membrane outer surface [4]. This property of activated platelets is of significant importance for their role in the hemostatic process, since negatively charged phospholipids markedly enhance several. reactions of the coagulation cascade. In this study we are dealing with the conversion of prothrombin into thrombin by complex of factor $X a$, factor $V a$ and calciumions. However, the above mentioned stimulatory effect of phospholipids also governs the conversion of factor $X$ into factor $\mathrm{Xa}$ by a complex of factor IXa, factor VIIIa and calcium-ions $[5-12]$.

Non-activated platelets have a low capacity to stimulate the formation of factor $\mathrm{xa}$ or thrombin, because of the nearly absolute absence of negatively charged phospholipids at the outer surface of the membrane. Simultaneous activation of platelets by collagen and thrombin results in a large enhancement of the rate of factor $X a$ or thrombin formation $[4,13]$. This increased activity has been ascribed to the increased exposure of negatively charged phosphatidylserine, which makes the platelet surface more suitable for the formation of prothrombin and factor Xa activating complexes.

In our previous experiments, exposure of phosphatidy1serine at the outer surface of activated platelets was demonstrated using phospholipase A from Naja naja or bee venom [4]. However, only the phospholipids of platelets activated by the combination of collagen and thrombin can be hydrollyzed by these lipolytic enzymes. The phospholipids of unactivated platelets or platelets activated by collagen or thrombin alone are hardly susceptible towards phospholipase Aa. Thus, from incubations with phospholipase As alone it cannot always be concluded whether activated latelets have an increased exposure of negatively charsed phospholipids. However, phospholipids of unactivated platelets do become available for hydrolysis by phospholipase A when sphingomyelinase (from Staphy10cocous aureus) is also present [1]. Therefore, the accessibility of phospholipids of activated platelets to a combination of phospholipase $A$ a and sphingomyelinase was investigated to establish whether a correlation exists 
between exposure of phosphatidylserine and platelet prothrombin converting activity after activation of the platelets by collagen, thrombin or a combination of these agents. Since platelets treated with the calcium ionophore A23187 also show a dramatic increase in prothrombin- and factor $X$-activating capacity [14], it was of interest to investigate whether these platelets also show alterations in the phospholipid distribution across the membrane.

Moreover, Haest et al. [15, 16] have found that treatment of erythrocytes with the sH-oxidizing agent diamide results in an increased accessibility of the aminophospho lipids. Therefore, it was investigated whether this agent is also able to alter the phospholipid arrangement in the platelet membrane and if this is accompanied by an increase of the prothrombin converting activity of these platelets.

\section{Materials and Methods.}

Materials.

Fatty acid free human serum albumin, nicotinamideadenine nucleotide, reduced form (NADH), indomethacin and diamide were obtained from Sigma. Dithiothreitol and o-phenantroline were from Baker. Collagen (type I) was from Hormon Chemie (Munich) and the calcium ionophore A23187 from Calbiochem. Venoms from the snake Naja naja and the bee Apis mellifica were purchased from Koch Light. Chromogenic substrate H-D-phenylalany 1-L-pipecoly 1arginine-p-nitroanilide (S-2238) was from Kabi Diagnostica (Stockholm, Sweden). Methylphosphatidic acid was prepared according to the method described in this thesis [17]. Coagulation factors $X a, V a$, prothrombin and thrombin were purified as described elsewhere [4]. Phospholipases As from N. naja and bee venom and sphingomyelinase from Staphylococous aureus were purified acoording to zwall

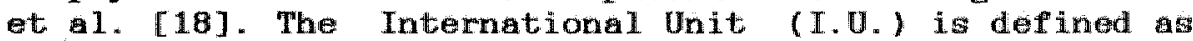
the amount of enzyme wich hydrolyses one micromole of substrate per minute under optimal conditions.

Isolation of plateletis.

Because relatively large amounts of platelets were required, a method was developed to isolate platelets from buffy coats obtained from the local hospital. The buffy coats were prepared from blood of healthy donors which was collected into the anticoagulant acid citrate dextrose (0.052M citeic acid, $0.08 \mathrm{M}$ trisodium citrate, $0.18 \mathrm{M}$ glucose, one part of the anticoagulant $A C D$ for every five parts of blood). For isolation of the platelets these buffy coats were diluted with rive volumes of a Hepes buffer pH 6.6, containing $137 \mathrm{mM} \mathrm{NaC1,} 2.68 \mathrm{mM} \mathrm{KCl,} 10 \mathrm{mM}$ Hepes, $1.7 \mathrm{mM} \mathrm{MgCl}, 25 \mathrm{mH}$ glucose and $0.05 \%(\mathrm{w} / \mathrm{v})$ fatty acid free human serum albumin (HSA). After centrifugation for 15 minutes at $200 \mathrm{~g}$, the plateletrich upper phase was recentrifuged at $1000 \mathrm{~g}$ to obtain a platelet pellet. This pellet was resuspended in Hepes buffer pH 6.6, and 
one volume of $A C D$ was added to fourteen volumes of the platelet suspension. The platelets were washed twice and finaly resuspended in the same Hepes buffer, adjusted to pH 7.5. this time ithout addition of ACD. Platelat concentration was determined with a Coulter counter. The washed platelet preparations contained less than one percent leukocytes or erythrocytes. Al1 platelet handing was carried out at room temperature.

Phospholipase treatment of latelets.

Stirred platelet suspensions $(10 \mathrm{ml})$, at a coneentration of $3,10^{\circ} / \mathrm{ml}$, were activated with various stimulators in the presence of $3 \mathrm{mM} \mathrm{CaCl}_{2}$ at $37^{\circ} \mathrm{C}$. After 15 minutes, an additional amount of $\mathrm{CaCl}_{2}$ (final concentration 10 mM) ms as o-phenantroline (final concentration $1 \mu \mathrm{g} / \mathrm{mi}$ ) were added, followed by a mixture of 36 I.U. phospholipase As from N. Naja and 26 I.U. phospholipase A from bee venom. In some expeximents sphingomyelinase (3.5 I.U.) was added 5 minutes after the addition of the phospholipases As. At various time intervals, phospholipase activity was inhibited by addition of $1 \mathrm{ml} 0.2 \mathrm{M}$ EDIA. Prior to addition of EDTA a sample of 1 mi was taken to measure the amount of platelet lysis. It should be noted that for every time point of the phospholipase treatment a seperate incubation was required, since platelet aggregation as a result of the activation procedure makes homogeneous subsampling unreliable.

Platelet lipids were extracted according to the procedure of Bligh and Dyer [19]. Methylphosphatidic acid $(250 \mu \mathrm{g})$ was added as an external standard, prior to the extraction procedure. Phospholipid analysis was carried out by twodimensional thin layer chromatography followed by phosphorous determination as described earlier [20]. To evaluate phospholipid desradation in intact cells only, corrections were made for phospholipid breakdown in the population of lysed cells, assuming that the phospholipids of the lysed cells are completely degraded. Only those experiments where 1ysis did not exceed $10 \%$ were taken into consideration.

Measurement of platelet lyais.

Lactate debydrosenase activity in the supernatant was usted as parameter for platelet lysis and was measured according to the method of Wroblewsi and La Due [21]. In the sumples containing diamide, the measurements were carried out in the presence of excess dithiothreitol (twice the concentration of diamide). The amount of platelet lysis was determined from a calibration curve made with different dilutions of a platelet preparation which was lysed completely by sonication for 3 minutes.

Measurement of platelet prothombin converting activity.

Prothrombin converting activity was measured as described before [4]. Final concentrations in the reaction mixture were: 5 . 10 platelets/ml, 15 nd factor $X a, 30$ nM factor Va, $4 \mu \mathrm{M}$ prothrombin and $6 \mathrm{mM}$ CaClz. Samples (25 41) for measuring the amount of thrombin formed were taken $30 \mathrm{~s}$ and $60 \mathrm{~s}$ after addition of prothrombin and assayed in 
a cuvette containing 1 ml buffer (50 mM $\operatorname{Tris,~} 120$ mo $\mathrm{NaCl}$ $2 \mathrm{mM}$ EDTA, $\mathrm{pH} 7.5)$ and $0.25 \mathrm{mM} 52238$. From the rate of change in absorbance at $405 \mathrm{~nm}$, the amount of thrombin was calculated using a calibration curve made with known amounts of activesite titrated thrombin.

\section{Results.}

Exposure of phospholipids at the platelet outer surface was studied using a mixture of two phospholipases A (the enzymes from N. naja and bee venom) solely or in combination with sphingomyelinase from $S$. aureus. An essential requirement for such a study is that all. phospholipids are sultable substrates for the enzymes used and that the amount of enzyme and time of incubation are sufficient to guarantee complete degradation in lysed cells. Therefore, lysed platelets obtained by sonication for 3 minutes were incubated with a mixture of phospholipase Ac (N. naja and bee venom) and sphingomyelinase, and phospholipid hydrolysis was measured. As shown in Fi. 1 , all phospholipid classes with the exception of phosphatidylinositol are almost completely degraded within 5 minutes under the conditions employed.
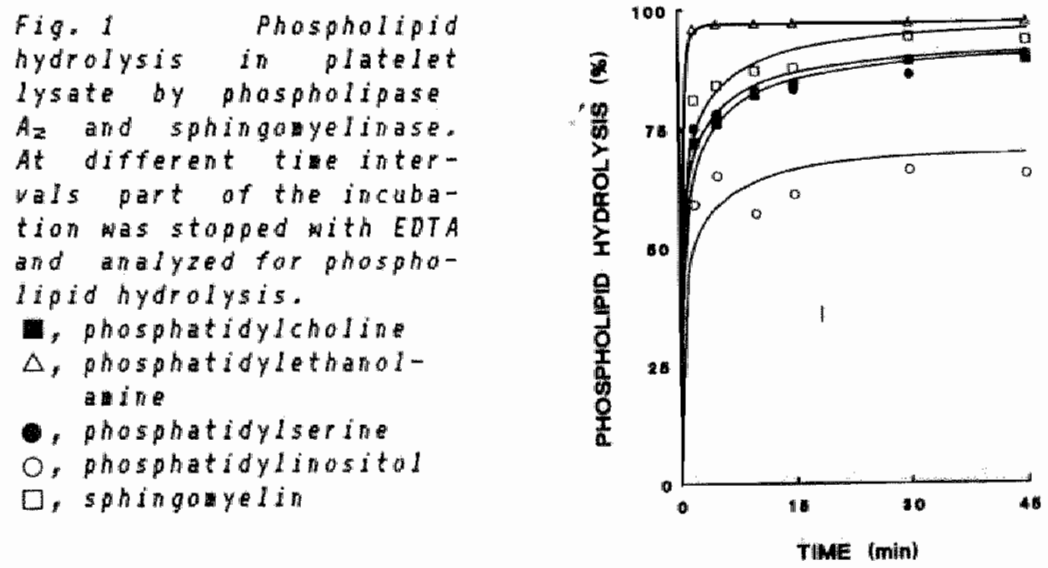

Since hydrolysis of phosphatidylinositol is incomplete, this phospholipid was not considered in further experi... ments. The results in Fig. 1 can be obtained by inoubation of lysed platelets with phospholipase Az and sphingomyelinase separately or in combination. In contrast, very little phospholipid hydrolysis occurs when intact, non-activated platelets are treated with phospholipase Az 
lysis, particularly if the platelets are activated prior to the addition of phospholipases. Therefore, careful examination of platelet lysis during treatment with the combination of phospholipase $A$ and sphingomyelinase is essential. With non-activated "platelets and platelets activated either by thrombin, collagen or diamide, breakdown of phospholipid levels off at a moment where platelet lysis is still less then 10\%, and neither phospholipid breakdown nor cell-lysis increase upon further 30 minutes incubation. A different picture was obtained using platelets triggered with collagen plus thrombin, or with the ionophore A23187. Fig. 2 shows the hydrolysis of total phospholipid as a funotion of time together with the lysis pattern during phospholipase treatment of platelets that have been activated with collagen plus thrombin.
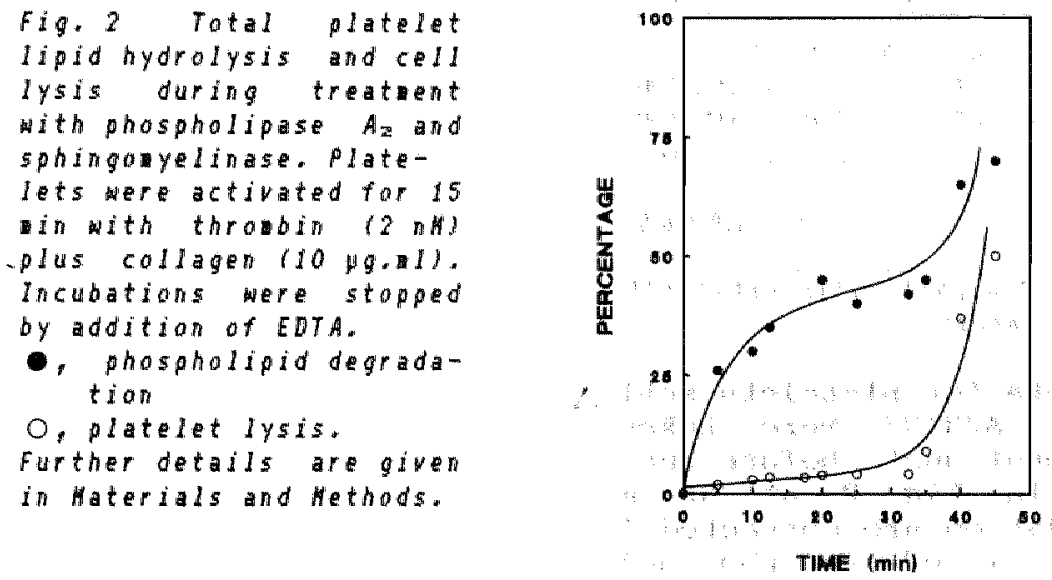

Phospholipid hydrolysis does not reach plateau in this incubation. During the first 30 minutes of phospholipase treatment, there is a small increase in cell lysis. At this time, phospholipid hydrolysis approximates $50 \%$. Prow longed incubation gives rise to a sudden increase in cell lysis as well as phospholipid degradation, suggesting that extensive destruction of cell structure oceurs. A similar time-course for hydrolysis and lysis was obtalned after phospholipase treatment of platelets activated by A23107.

Besides total phospholipid hydrolysis, we also determined the hydrolysis of each phospholipid class upon platelet incubation with a combination of sphingonyelinase and phospholipase Aa. The data are summarized in Table II. For control platelets and platelets activated by collagen. thrombin, or diamide, the hydrollysis: of each phospholipid class levelled off after 30 minutes; values at $t=45$ min 
are presented in this table.

\title{
TABLE II
}

Non-1ytic destadation of phospholipids by phospholipase Az (N. maja and bee venom) and sphingomyelinase (S.aureus) in activated human platelets.

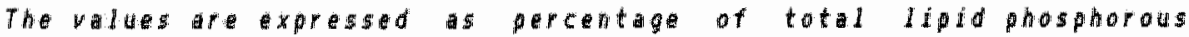

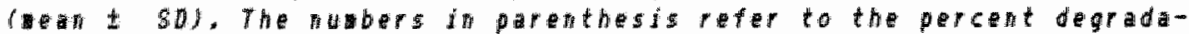
*ion of the corresporolno lipid class. nz nuber of experiaents. Ps,

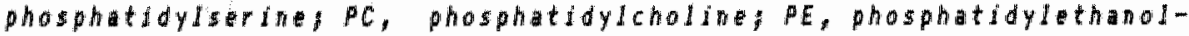

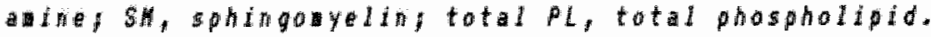

\begin{tabular}{|c|c|c|c|c|c|c|}
\hline Phosphollpid & Hydrutysis & & & & & \\
\hline$(n=12)$ & $\begin{array}{l}\text { Control } \\
(n=7)\end{array}$ & $\begin{array}{c}\text { Thrombin } \\
(n \div 9)\end{array}$ & $\begin{array}{c}\text { Collagen } \\
(n=9)\end{array}$ & $\begin{array}{c}\text { Throwon }+ \\
\text { callagen } \\
\text { (n) } 121\end{array}$ & $\begin{array}{l}\text { Dianide } \\
(m=7)\end{array}$ & $\begin{array}{l}423187 \\
n=71\end{array}$ \\
\hline
\end{tabular}

\begin{tabular}{|c|c|c|c|c|c|c|c|}
\hline PS & $10.9 \pm 0.7$ & $0.5 \pm 0.6(4)$ & $1.621 .0115 !$ & $2.1 \pm 2.04(9)$ & $5.0 \pm 0.31491$ & $5.340 .4(49)$ & $0.2 \pm 0.7175$ \\
\hline $\mathrm{PC}$ & $36.3 \pm 1.4$ & $6.5 \pm 1.5(17)$ & $12,944.6134)$ & $14.4 \pm 4.3(37)$ & $15.1 \pm 1.64411$ & $15.5 \pm 0.5(41)$ & $19.2 \pm 1.5150)$ \\
\hline PE & $26.0 \pm 0.8$ & 2.020 .9171 & $5,1 \pm 3,11191$ & $5.9 \pm 3.9(22)$ & $16.0 \pm 0.91601$ & $10,3 \pm 0,1,130)$ & $23,3 \pm 0.8187$ \\
\hline & $19.0 \pm 1.0$ & $12.0 \pm 1.5(63)$ & 13.243 .81691 & 12. $4 \pm 0.6(65)$ & $0.3 \pm 1.5(43)$ & $8.6 \pm 0.2(45)$ & $14.3 \pm 0.61751$ \\
\hline
\end{tabular}
PL 95,0
$21.0 \pm 2.4$
$32.8 \pm 6.8$
$34.8 \pm 6.2$
$44.5 \pm 2.3$
$39.7 \pm 0.7 \quad 65.0 \pm 1.9$

\begin{abstract}
- Phosphatidylinasitol (pL) is a itted fur reasans explained in Results.
\end{abstract}

The data for platelets activated by collagen plus thrombin or by A23187 were taken at a time of phospholipase treatment just before the sudden rise in platelet lysis (e.E. in Fig. 2 at $35 \mathrm{~min}$ ). The percentages of lipid degradation are corrected for cell lysis assuming complete hydrolysis of the phospholipids in the lysed cell population. Treatment of control cells with combination of phospholipase A and spingomyelinase leads to hydrolysis of $21 \%$ of total phospholipid which is in agreement with the findings of Perret et al. [3]. The hydrolyzed phospholipid fraction is mainly composed of the choline containing phospholipids, sphingomyelin and phosphatidy 1choline. Activation of platelets by collagen or by thrombin prior to addition of phospholipases results in an increased phospholipid hydrolysis. The amount of sphingomyelin hydrolyzed in these platelets is not different from that in control platelets, but an increased degradation of Glycerophospholipids is observed. However, the small quantities of phosphatidylserine and phosphatidylethano1amine that are hydrolyzed together with the large standard deviations make it difficult to discern whether there is indeed an increased susceptibility towards phospholipase Ace . Remarkably deviating patterns of phospholipid hydrolysis are found for platelets activated by collagen plus thrombin, diamide or A23187. Apart from a further increase 
in the extent of total phospholipid hydrolysis (even to a maximum of $65 \%$ for platelets activated by A23187) "the most striking feature is the significant increase in breakdown of phosphatidylserine and phosphatidylethano amine in these platelets.

A clear picture of the effects of the different platelet stimulators on the exposure of phospholipids at the membrane outer surface is obtained when the compositions of the hydrolyzed phospholipid fractions are compared. These compositions, which are calculated from the data in Table II, are presented in Table III. Compared to control platelets, there is an inorease in phosphatidylserine and phosphatidylethanolamine accompanied by decrease in sphingomyelin in the hydrolyzed phospholipid fraction, when platelets are activated by a mixture of collagen plus thrombin, by diamide, or by A23187.

TABLE III

Composition of phospholipid fractions hydrolyzed by phospholipase $A$ and sphingomyelinase treatment of activated human platelets.

Values are expressed as percentage of the hydrolyzed fiaction af total phospholipid (atean $\pm s 0$. Data are calculated fro Table ll bu setting the hydrolyzed total phospholipid fraction at $100 \%$. PI is rat taken into account for reasons explained in the Results section.

\begin{tabular}{rrrrrrr}
\hline & Control & Throabin & Collagen & \multicolumn{1}{c}{$\begin{array}{l}\text { Thrombint } \\
\text { collagen }\end{array}$} & Dianide & A23187 \\
\hline PS & $2.4 \pm 2.4$ & $4.9 \pm 3.2$ & $6.0 \pm 5.8$ & $11.2 \pm 0.9$ & $13.4 \pm 1.0$ & $12.6 \pm 1.1$ \\
PC $31.0 \pm 8.0$ & $39.3 \pm 16.2$ & $41.4 \pm 14.4$ & $33.9 \pm 3.4$ & $39.0 \pm 1.4$ & $29.5 \pm 2.5$ \\
PE & $9.5 \pm 4.4$ & $15.5 \pm 9.9$ & $17.0 \pm 11.6$ & $36.0 \pm 2.0$ & $25.8 \pm 0.5$ & $35.8 \pm 1.6$ \\
SH $57.1 \pm 9.7$ & $40.2 \pm 14.3$ & $35.6 \pm 6.6$ & $18.7 \pm 3.4$ & $21.7 \pm 0.6$ & $22.0 \pm 1.1$ \\
\hline
\end{tabular}

It is not clear why the standard deviations for the phospholipid hydrolysis of thrombin or collagen treated platelets are relatively high. Therefore it remins uncertain whether alterations in phospholipid orientation also occur in these platelets.

The effect of warious platelet activators on the ability of platelets to enhance the conversion of prothrombin into thrombin by factor Xa was investigated using a chromogenic substrate assay to measure the rate of thrombin formation. The results are presented in Table IV. It has previously been demonstrated that the rate of thrombin formation is strongly enbanced in the presernce of a negatively charged phospholipid surface, in particular one containing phosphatidylserine [5-9]. Therefore, the corresponding values for phosphatidylserine hydrolysis by exogenous phospholipases are also presented in this table, since the rate of thrombin formation may represent a measure of phosphatidylserine exposure at the outer surface. It is obvious from this comparison that an 
increased exposure of phosphatidylserine corresponds to an increased rate of thrombin formation.

TABLE IV

Comparison between prothrombin converting activity of activated human platelets and exposure of phosphatidy serine.

ate of thramin formation was asured after a Is in activation period in ayste containing 5.8 . 10 plateletslal, factor la

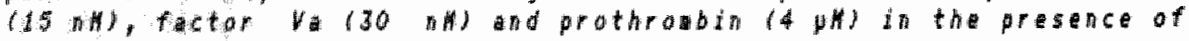
6 orletulehloride.

Rate of thrombin formetion ( $\mathrm{nM} / \mathrm{Min})$
Percentage of $\mathrm{PS}$

exposed*

\begin{tabular}{|c|c|c|c|}
\hline No stimulator & 34 & 4 & \\
\hline Thrombin $(2-20 \mathrm{nM})$ & 41 & 15 & $(p=0.05)$ \\
\hline Collagen $(10 \mu \mathrm{g} / \mathrm{ml})$ & 157 & 19 & $(\mathrm{p}=0.10)$ \\
\hline Thrombintcol lagen & 352 & 46 & $(p<0.00$ \\
\hline Diamide (5mM) & 356 & 49 & $(\mathrm{p}<0.00$ \\
\hline 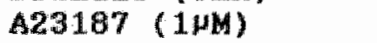 & 793 & 75 & $(p<0.001$ \\
\hline Lyted platelets & 1170 & 96 & $(p<0.001$ \\
\hline
\end{tabular}

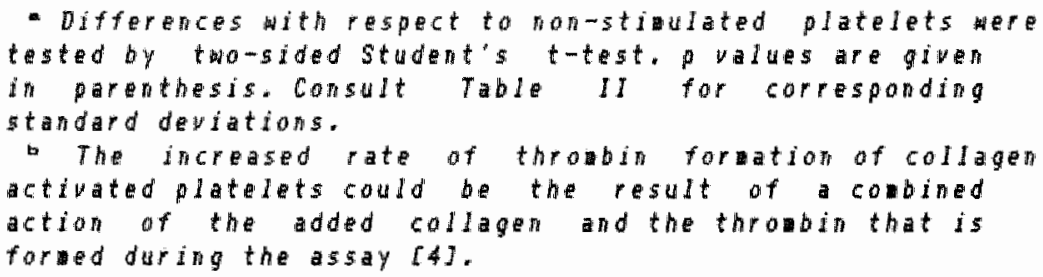

\section{Discusation.}

Platelet activation leads to morphological and metabolical changes. In particular, the enhanced turnover of phosphatidylinositol is one of the primary metabolic events that take place in the membrane during platelet activation [22-27]. However, 1ittle evidence is available indicating that the plaswa membrane is subject to structural alterations. Jaing fluorescent probes, Nathan et al. [20] have found indications for changes in microviscosity of phospholipids in the membrane of human platelets after activation by thrombin. Changes in the distribution of membrane phospholipids have been reported by Schick et a1. [29], who found increased labeling of phosphatidy $1-$ ethanolamine by trinitrobenaenesulfonic acid (TNBS) after trigering of platelets by thrombin. We bave previously shown [4] that activation of platelets simultaneously by collagen and thrombin results in an increased susceptibility of phospholipids towards exogenously added phospholipase Aa. This was not observed for platelets activated 
by either one of these activators separately. The increased susceptibility of phospholipids is also apparent following treatment of platelets with diamide or A23187. Differences in availability of phospholipids for phospholipase A in platelets activated by various means may reflect differences in structural organization of the membrane. In this respect, the difference between platelets activated by a combination of collagen and thrombin compared to platelets activated by either of these two is striking, since no differences are observed in the extert of platelet aggregation and release.

The activity of phospholipase As towards platelet membranes is significantly facilitated if sphingomyelin is degraded at the same time by the action of sphingomyelinase $[1,3]$. When platelet lysis is carefully controlled, this allows the study of the exposure of all indiwidual phospholipid classes at the outer surface of activated platelets in a similar manner as was described for unstimulated platelets by Perret et al. [3]. The amount of phospholipids that can be degraded under non-1ytic conditions can be directly influenced by the extent of platelet aggregation and especially release resulting from the activation procedure. Intact unstimulated platelets contain several types of intracellular membranes such as granule membranes, mitochondrial membranes and membranes of the dense tubular system. As was elegantly demonstrated by Perret et al. [3], 57\% of the total platelet phospholipids are present in the plasma membrane of unstimulated human platelets. Consequent $1 y$, complete degradation of the outer leaflet of the plasma membrane would be reflected ir 28x hydrolysis of the total phospholipid content of the cel1. During the platelet release reaction as a result of platelet activation, eranule membranes are thought to fuse with the plasma membrane. This would result in an increased amount of phospholipids that can be hydrolyzed. Assuming that as a result of the release reaction, 6o\% of the intracellular membranes have fused with the plasm membrane, approximately $80 \%$ of the platelet phospholipidis would be present in the plasma membrane. Thus, complete hydrolysis of the outer leaflet of the plasma membrane of the activated platelets would result in $40 \%$ hydrolysis of total phospholipids. On the other band, platelet argregation forms a complicatine factor sinoe it may prevent efficient action of phospholipases, restricting the total amount of phospholipid hydrolysis.

The following remarks can be made concerning the data for total phospholipid hydrolysis from Table II. Total phospholipid hydrolysis of intact unstimulated platelets amounts to 21\%, which is in close agreement to the $25 \%$ reported by Perret et al. [3]. In the absence of agreses tion or release this implies a very substantial hydrolysis of the phospholipids present in the outer leaflet. Activation of platelets by thrombin or collagen induces release as e11 as aggregation. The observed hydrolysis of $32.8 \%$ and $34.8 \%$, respectively, are higher than observed with 
control platelets as result of the release reaction, but Lower than the expected 40\%, presumably due to platelet aggregation. Activation of platelets with collagen plus thrombin results in release and aggregation to a similar extent as is indued by the activators separately, but the phospholipld hydrolysis is higher (44.5\%). In the case of diamide trettment of platelets, there is neither aggregato ion nor release which would predict a phospholipid hydrolysis of at most $28 \%$. The observation that almost $40 \%$ of the phospholipids are hydrolyzed in these cells, under non-lytic conditions, indicates that more than half of the plasma membrame phospholipids have been degraded. The greatest amount of hydrolysis is observed ith platelets activated by the calcium ionophore A23187; 65\% of the total phospholipids are hydrolyzed by phospholipase As and sphingomyelinase under non-lytic conditions. Activation by A23187 leads to substantial release and aggregatilon, although the size of the aggregates produced by A23187 is much smaller than those induced by collagen or thromblin. Since phospholipid degradation in ionophore treated platelets exceeds the expected 40\%, hydrolys is is apparently not restricted to half of the membrane phospho1ipids. Considering that the data have been corrected for phospholipid degradation in the population of lysed cells and that the plasma membrane is impermeable to phospholipases, the extent of phospholipid degradation observed with platelets that are activated by collagen plus thrombin, diamide or A23187, can be explained if one assumes a transbilayer movement of phospholipids (flip-flop). From the present data, it is difficult to ascertain whether the exposure of phospholipids is significantly changed upon platelet activation by either collagen or thrombin, due to the relatively lare standard deviations. Transbilayer movement of phospholipids does apparently not occur in control platelets, which indicates that the action of phosphollpases as such, does not necessarily induce 11. flop in these membranes. On the other hand it cannot be exoluded that phospholipase treatment induces flip-flop in platelets that have been activated by collagen plus thrombin, by diamide or by ionophore. However, if exposure of phosphatidyiserine at the platelet outer surface would be a result of the phospholipase treatment as such, one would expect a delay in the onset of hydrolysis of this phospholipid direotly after addition of phospholipase. Since neither phosphatidylserine nor the other phospholipids show any such lag period in hydrolysis, phospholipase induced flip-flop seems unlikely. On the other hand it is very well possible that transbilayer movement of the phospholipids continues during incubation with phospholipase. Therefore it cannot be distinguished whether the hydrolyzed phospholipids are continuously or transiently exposed at the outer surface during the time course of the phospholipase incubation.

As we have shown previously [4]. the increased phospholipid hydrolysis in platelets activated by collagen 
plus thrombin cannot be explained by the action of endogenous phospholipases. Also platelet treatment with A23187 or diawide does not produce sienificant phospholipid breakdown on percentage basis.

Transbilayer movement of phospholipids due to the activation of platelets could explain the increased exposure of phosphatidylserine and phosphatidylethanolamine. To balance this process, sphingomyei in seems to move from the outer to the inner leaflet of the plasma membrane. There is no large change in the orientation of phosphatidylcholine. Particularly after treatment with diamide, the phospholipid composition of the hydrolyued fraction is very similar to the total phospholipid composition, suggesting a total randomization of the phospholipids over both membrane halves. Transbilayer movement of phospholipids has been reported $[15,16]$ to occur in erythrocytes treated with diamide or tetrathionate. Approximately 50\% of the phosphatidylethanolamine and $30 \%$ of the phosphatidylserine became accessible to exogenous phospholipase Ae without hemolysis. The effect was correlated with a significant cross-linking of spectrin wich was proposed to play a role in maintaining the asymmetric phospholipid orientation in the erythrocyte membrane. Although treatment of platelets with diamide also results in a significant cross-linking of membrane proteins as was observed by polyacrylamide gel electrophoresis (data not shown), it is not clear whether in all cases exposure of phosphatidylserine at the platelet outer surface is dependent on a similar mechanism, since cross-1inking of membrane proteins was not observed following treatment with collagen plus thrombin, or A23187.

The increased exposure of phosphatidylserine at the outer surface of activated platelets may be of considerable importance for the hemostatic process. Unstimulated platelets have little phosphatidylserine exposed at their outer surface. This lack of negatively charged phosphow lipids is reflected in a relatively poor capacity of resting platelets to stimulate the formation of thrombin from prothrombin by factor $X a$, factor Va and calcium. The rate of thrombin formation is critically dependent on the presence of negatively charged phospholipid surface to which factors $X a$, Factor $V a$ and the substrate prothrombin can bind [4-13]. Those platelet activators that induce increased exposure of phosphatidylserine at the outer surface of the membrane as measured by exogenously added phospholipases, also induce the platelets to become more active in enhancing the rate of thrombin formation. Remarkable in this respect is the relationship between the amount of phosphatidylserine exposed and the rate of thrombin formation.

The wechanism by which transbilayer movement of phospholipids in the platelet wembrane can take place is not well understood. Although phospholipid filp-flop was demonstrated to be an extremely slow process in vesioles 
of pure phosphatidylcholine [30], rapid flip-flop in artificial and natural membranes has been reported (review, ref.31). One possible mechanism for transbilayer mowement of phospholipids is the existence or introduction of intrabilayer inverted micelles as described by Cullis and de Kruijfe [32,33]. These structures can be formed with those 1ipids having a conical shape, "such as diacylGlycerols and phosphatidic acid, that do not adopt bilayer atructures. The formation of these lipids has been suggested to play a triggering role for various cellulax responses to exogenous stimuli by altering membrane physical states $[32,34]$. In this respect, it is tempting to speculate that intermediates of the phosphatidylinositol-aycle, wich is activated during platelet stimulation [22-27], produce local bilayer disturbances that enable transbillayer movement of phospholipids. Experiments described in chapter 6 have demonstrated that the introduction of diglycerides in the pllatelet membrane by the action of phospholipase C from Clostridium welchii causes an increased exposure of phosphatidylserine at the outer surface of the plasma membrane. Whether or not differences in the activation of the phosphatidylinositolcycle exist as result of different platelet activation procedures remains to be investigated.

\section{References,}

1 Chap, H.J., Zwaal, R.F.A., $\operatorname{van}$ Deenen, L.L.M. (1977) Biochim. Biophys. Acta 467, 146-164.

2 Zwaal, R. F.A. (1978)

Biochim. Biophys. Acta 515, 163-205.

3 Perret, B., Chap, H.J., Douste-Blazy, L. (1979)

Biochim. Biophys. Aota 556, 434-446.

4 Bevers, E.M., Comfurius, P., van Rijn, J.L.M.L., Hemker, H.C., Zwaal, R.F.A. (1982)

Eur. it. Biochem. 122, $429-436$.

5 Papahadjopoulos, J., Ganahan, D.J. (1964)

Biochim. Biophys. Aeta $90,436-439$.

6. Bul1, R.K., Jevons, S., Barton, P.G. (1972) J. Biol. Chem. 247, 2747-2754.

7 Hemker, H.C., Kahn, M.J.P. (1967) Nature 215, 1201-1202.

B Gitel, S.N., Owen, W.G., Esmon, C.T., Jackson, C.M. (1973) Proc. Nat1. Aoad. Sei. USA 70, 1344-1348.

9 Marous, A.J. (1966) Advan. Lipid Res. 4, 1-37.

10 Van Dieijen, G., Tans, G., Rosing, J., Hemker, H.C. (1981) J Biol. Chem. 256, 3433-3442.

11 Rosing, J., Tans, G., Govers-Riemslag, J.W.P., Zwaal, R.F.A., Hiemker, H.C. (1981)

J. Biol. Chem. 255, 274-283.

12 Nesheim, M.E., Taswell, J.B., Marn, K.G. (1979)

J. Biol. Chem. 254, 10952-10962.

13 Zwal, R.F.A., Hemker, H.C. (1982)

Hemostasis $11,12-39$. 
14 Van Rijn, J.L.M.I., Rosing, J., Van Dieijen, G. (1983) Eur. J. Biochem. 183, 1-10.

15 Haest, C.W.M., Deuticke, B. (1976)

Biochim. Biophys. Acta 436, 353-365.

16 Heest, C. W.M., Plasa, G., Kamp, D., Deuticke, B. (1978) Biochim. Biophys. Acta 509, 21-32.

17 Comfurius, P., Zwal, R. F. A. (1977)

Biochim. Biophys. Acta 488, 36-42.

This thesis, chapter 1.

18 Zwaal, R.F.A., Roelofsen, B., Comfurius, P., van Deenen, L. L.M. (1975)

Biochim, Biophys. Acta $406,83-96$.

19 Bligh, E.G., Dyer, W.J. (1959)

Can. J. Biochem. Physiol. 37, 911-917.

20 Verkleij, A.J., Zwaal, R. F. A., Roelofsen, B., Confurius, P., Kastelijn, D., van Deenen, L.L.M. (1973) Biochim. Biophys Aota 233, 178-193.

21 Wroblewski, R., La Due, J.S. (1955)

Proc. Soc. Exp. Biol. Med. 90, 210-215.

22 Lloyd, J.V., Mustard, J.F. (1974)

Br. J. Haematol, 26, 243-253.

23 Mauco, G., Chap, H.J., Douste-Blazy, L. (1979)

FEBS letters 100, 367-370.

24 Lapetina, E.G., Cuatrecasas, P. (1979)

J. Clin. Invest. $63,580-587$.

25 Rittenhouse-Simmons, S. (1979)

J. Clin. Invest. $63,580-587$.

26 Be11, R.L., Kennerly, D.A. stanford, N., Majerus,

P.W. (1979) Proc. Nat1. Acad. Soi. USA 76, 3238-3241.

27 Broekman, M.J., Ward, J.W., Marcus, A.J. (1980) J. C1in. Invest. $66,275-283$. .

28 Nathan, I., Fleischer, G, Livne, A., Dviliansky, A. , Parola, A.H. (1979) J. Biol. Chem. 254, 9822-9828.

29 Schick, P.K., Kurica, K. B., Chacko, G.K. (1976) J. Clin. Invest. 57, 1221-1226.

30 Kornberg, R. D., MoConne11, H.M. (1971)

Proo. Nat1. Acad. Soi. USA 68, 2564-2568.

31 Op den Kamp, J.A.F. (1979)

Ann, Rev. Biochem. 48, 47-71.

32 Cul1is, P.R., de Kruijff, B. (1979)

Biochim. Biophys. Acta $559,399-420$.

33 Cullis, P.R., de Kruijff, B. (1978)

Biochem. Biophys. Acta 507, 207-218.

34 Ohki, K., Sekiya, T., Yamauchi, T., Nozawa, Y. (1982) Biochim. Biophys. Acta $693,341-350$. 
PLATELET PROTHROMBIN CONVERTING ACTIVITY IN HEREDITARY DISORDERS OF PLATELET FUNCTION

Summary.

Prothrombinase activities of platelets have been measured in diluted platelet-rich plasma using a chromogenio substrate assay and purified coagulation factors. No abnormalities in prothrombinase activities were found for platelets from patients with storage pool disease (dense-body deficiency), grey platelet syndrome, and Glanzmann's thrombasthenia. It is coneluded that neither release of dense bodies and a-granules nor aggregation of platelets are essential prerequisites for exposure of a procoagulant surface. Platelets from patients with Bernard-Soulier syndrome, however, have approximately 10 fold higher prothrombinase activities in the non-stimulated form than normal non-stimulated platelets. The increased prothrombinase activities cannot be completely ascribed to an increase in platelet size. It is suggested that the increased prothrombinase" activity reflects an inoreased exposure of phosphatidylserine at the outer surface of non-stimulated BernardSoulier platelets, earlier described by Perret et a1. (Thromb. Res.(1983) 31, 529-537). 
Platelet procoagulant activity is expressed in at least two sequential reactions of the coagulation cas cade: the activation of factor $X$ by a complex of factors IXa, VIIIa and calcium (intrinsic factor $X$ activation) and the conversion of prothrombin to thrombin by complex of factors $X a, V a$ and calcium, also referred to as the prothrombinase complex $[1-3]$. The essential role of platelets in both reactions is to provide a catalytic surface to which the coagulation fectors can bind. This results $1 \mathrm{n}$ an increased local concentration of these proteins, thus leading to an increased rate of factor $X a$ or thrombin formation $[4,5]$. The catalytic efficiency of the platelet surface is significantly greater when platelets are stimulated by the combined action of collagen and thrombin. We have demonstrated that an increased exposure of negatively charged phosphatidylserine at the outer surface of the platelet plasma membrane is responsible for the increased rate of factor $X a$ and thrombin formetion $[6,7]$. Negatively charged phospholipids are essential for a direct interaction of factors Va and VIIIa with the membrane, as well as for the $\mathrm{Ca}^{2+}$-mediated binding of the vitamin-K dependent coagulation ractors.

Platelet stimulation by collagen and thrombin induces release of dranule contents and platelet aggregation.

Since procoagulant activity is expressed particular1y as a result of simultaneous action of collagen and thrombin, the possibility cannot be excluded that either release of cranule contents or aggregation, or both, form an essential prerequisite for expression of this activity. On the other hand, however, it is known from previous work that the release reaction or aggregation as such is not sufficient, since platelets stimulated by thrombin or by ADP hardly evoke a procoegulant surface $[2,6,7]$. The present study was undertaken to investigate which platelet functions or structures in particular membrane slycoproteins or different types of Branules; are required for the generation of a procoagulant surface. To this end, platelets from patients with different platelet disorders were studied with respect to their ability to enhance the rate of thrombin formation in a system using purified congulation factors $\mathrm{X} a, \mathrm{Va}$ and prothrombin and a chromosenic substrate, specific for thrombin.

\section{Materials and Methods.}

Collagen type I was obtained from Hormon Chemie, Nunich. Coagulation factors $X A$, Va and prothrombin were purified as decribed by Rosing et al. [4]. Thrombin was derived from prothrombin after activation with factor $X_{a}$ according to Rosing et al. [4]. Thrombin specific chromoGenic substrate $\mathrm{H}-\mathrm{D}$-phenylalany 1-L-pipecoly 1-argininep-nitroanilide dihydrochloride (S2238) was obtained from 
AB Kabi Diagnostics, Stockholm. Fatty acid free human serum albumin was from Sigma Chemical Co., St Louis.

Platelet hand Ling.

Fresh blood was taken by venipuncture and was collected in 0.1 voll. of sodium citrate $(3.8 \% \mathrm{w} / \mathrm{v})$. Platelet rich plasma (PRP) was obtained by centrifugation at 120 for 15 minutes at room temperature. PRP from Barnard Soulier patients was obtained by allowing whole blood to sediment at $1 \mathrm{~g}$ for one hour at room temperature in tubes tilted at an angle of $45^{\circ}$. In order to avoid platellet damage or platelet activation as much as possible, platelets were not washed, but PRP was diluted 50-fold in a buffer containing $137 \mathrm{mM} \mathrm{NaCl}, 2.7 \mathrm{mM} \mathrm{KCl,} 2 \mathrm{mM} \mathrm{MgCl}$, $10 \mathrm{mM} H e p e s, 5 \mathrm{mM}$ lucase and $0.05 \%$ (w/v) fatty-aoid free human serum albumin, pH 7.5. Platelet count was determined by Iight-microscopy or with a Coulter counter. Al1 platelet handling was carried out at room temperature in siliconized glass or in plastic tubes.

Prothrombinase assay.

To study the influence of platelets on the conversion of prothrombin to thrombin by factors $X a$ and $V a$, platelets must be isollated and washed to remove plasma coagulation factors and other components which mient interfere with the coagulation assay. This procedure increases the risk of platelet activation and platelet damage which inevitably will affect the procoagulant activity $[1,6]$. In order to avoid this problem, which wight be particularly important for abnormal platelets, the prothrombinase assay was modified using a 50-fold diluted PRP instead of washed platelets. This does not significantly change the procoagulant activities relative to washed platelets at the same platelet count; thus the contribution of the 50-fold diluted plasma coagulation factors may be negleoted. Furthermore, this modification has the advantage of saving time-consuming washing procedures which enables a rapid screening of the procoagulant activity. It should be emphasized, however, that using this assy procedure, activation of 50-fold diluted PRP with collagen for 10 minutes in the presence of $3 \mathrm{mM}$ calcium leads to the formation of approximately 5 nM thrombin even before the prothrombinase assay is started. This amount of thrombin makes an estimation of the prothrombinase activity of platelets, stimulated by collagen alone, ambiguous since platelets in diluted PRP will in fact be activated by collagen plus the thrombin that is formed in the diluted plasma.

Measurement of platelet prothrombin converting activity was carried out as described before [1,6]. Brief$1 y, 290$ H 50 -fold diluted PRP was activated in the presence of $15 \mu 175 \mathrm{mM} \mathrm{CaCl}$ by $15 \mu 1$ collagen $(250$ $\mu_{\mathrm{g} / \mathrm{m}} \mathrm{l}$ and $5 \mu 1200 \mathrm{nM}$ thrombin at $37^{\circ} \mathrm{C}$ with continuous stirring. 10 minutes after activation, $50 \mathrm{w}$ of a freshly prepared mixture containing $30 \mathrm{nM} X a$ and $60 \mathrm{nM}$ Va was added. The enaymatic reaction was started 2 minutes later by the addition of $125 \mu 116 \mu$ prothrombin. The solution 
of prothrombin contained $14 \mathrm{mH} \mathrm{CaCl}_{2}$ to $\mathrm{Bive}$ a final caldum concentration in the assay of $6 \mathrm{mM}$. After 1 minute a sample was taken and immediately diluted in a buffer contining $120 \mathrm{mM} \mathrm{NaCl}, 50 \mathrm{mM}$ Tris and 2 mM EDTA (pH 7.5) to sop the reaction. The amount of thrombin formed was assessed by adding chromogenic substrate to this mixture and measuring the change in absorbance at $405 \mathrm{~nm}$ per minute, produced by the action of thrombin on $\$ 2238$. The concentration of thrombin was calculated from a calibration curve made with known amounts of active-site titrated thrombin. All measurements were done in triplicate (at least) in a standardized time scheme and were completed ithin one hour fter obtaining the plasma from the blood samples.

Because of differences in individual activities within each sroup of patients, ranges of activity are presented next to mean values and standard deviations. To allow comparison of the data of different patients all prothrombinase activities are calculated for a standard platelet count of $10^{\circ}$ cells per mi (final concentration in the assay system). Since prothrombinase activity is dependent on the amount of suitable phospholipid surface, maximal prothrombinase activity of a complete lysed platelet preparation (obtained by 3 minutes sonication of the 50-fold diluted PRP) was also measured.

Patients ccase histories.

Three unrelated patients with storage pool disease were studied. The diagnosis of storage pool disease relied on the basis of a normal platelet count, a prolonged bleeding time (Simplate II, General Diagnosties), aggregation abnormalities that were indicative for a secretion defect and abnorma1 levels of total ATP an ADP measured in ethanol extracts ith the luciferine-luciferase assay. The platelets of the patients contained a normal amount of B-thromboglobulin and a normal amounts of $\mathrm{B}-\mathrm{N}-\mathrm{g}$ lucuronidase (E.C.3.2.1.31) and B-N-acetylglucosaminidase (E.C. 3.2.1.30) indicating that the patients platelets were only deficient in dense granules. One patient has been diamosed previously as Hermanski-Pudlak syndrome $[8,9]$.

Three patients: with investigated. Biological for two pationts [10] pationt. Thus, platelet ageregation and rellease reduced after collagen

a crey platelet syndrome were data have already been reported and were similar for a thind count was decreased. Platelet of ${ }^{2} \mathrm{C}$-serotonin were markedly and thrombin stimulation. ADP, arachidonic acid and ionophore A23187 mediated aggregation were apparently normel.

of the thrombastenic patients we have studied one patient with type I and two patients with type II thrombastenia as defined by Caen [11]. The levels of glycoproteins IIb/III varied from undetectable to $20 \%$ of the normal value as reported by Nurden and Caen [12]. In these three patients platelet aggregation in response to $A D P$, adrenaline, collagen, arachidonic acid, ionophore and 
thrombin was absent and bleeding time was considerably prolonged.

Five unrelated patients ith Bernard-Soulier syndrome were studied. Two patients were described previously $[13,14]$. Diagnosis was made on the basis of thrombocytopenia with large platelets, prolonged bleeding time, absence of platelet agglutination with ristocetin despite normal von Willebrand factor related properties. Normal aggregation with collagen, epinephrine and ADP were seen except for two patients who showed subrormal collagen or ADP induced aggregation. Lack of glycoprotein Ib was already described for two patients [15] and was loo established for the other three patients by two-dimensional gel electrophoresis of membrane proteins labeled by in with Iodogen.

\section{Results.}

Table I summarizes the results obtained from patients with storage pool deficiences and Glangmann"s thrombasthenia. The results obtained with Bernard-Soulier platelets are presented in Table II.

Storage pool disease and grex platelet syndrome.

Three patients with $\alpha$-granule deficiency carey platelet syndrome) and three patients with dense body deficiency were studied. Basal prothrombinase activities of both types of abnormal platelets were similar to normal platelets.

TABLE I

Prothrombinase activities of pathological platelets. Mubers in parentheses refer to the range of activities found.

Prothrominase activity ons throabin / ain / $10^{\circ}$ alls per al)

\begin{tabular}{|c|c|c|c|c|}
\hline \multirow[b]{2}{*}{ Disarder } & & & & \\
\hline & Mon-stinulated & $\begin{array}{l}\text { Thiroubto } \\
\text { stivuluted }\end{array}$ & $\begin{array}{l}\text { Collogen } \\
\text { thrombin } \\
\text { stivulated }\end{array}$ & $\begin{array}{c}\text { Lytad } \\
\text { plateletis }\end{array}$ \\
\hline Control $(n=15)$ & $\begin{array}{l}5.5 \pm 2.0 \\
(2,1-7.0)\end{array}$ & $\begin{array}{c}12.7 \pm 4.0 \\
(8.5-18.7)\end{array}$ & $\begin{array}{l}70.5 \pm 17.1 \\
(52.7-89.3)\end{array}$ & $\begin{array}{c}5214146 \\
(343-715)\end{array}$ \\
\hline $\begin{array}{l}\text { Storage pool } \\
\text { disease }(n=\$)\end{array}$ & $\begin{array}{l}3.8 \pm 1.7 \\
(1.8-4.8)\end{array}$ & $\begin{array}{l}14.1 \pm 1.8 \\
(12.3-1.5 .8)\end{array}$ & $\begin{array}{c}54.1 \pm 15.5 \\
(36.8-66.7)\end{array}$ & $\begin{array}{c}47 \pm 123 \\
(393-613)\end{array}$ \\
\hline $\begin{array}{l}\text { Grey platelet } \\
\text { syndrowe }(n=3)\end{array}$ & $\begin{array}{l}3.1 \pm 4.7 \\
(0.1-8.5)\end{array}$ & $\begin{array}{c}21.7 \pm 1.8 \\
(14.4-31.4)\end{array}$ & $\begin{array}{l}99.4 \pm 40.9 \\
(64.9-145.3)\end{array}$ & $\begin{array}{c}16 \pm 242 \\
(416-699)\end{array}$ \\
\hline 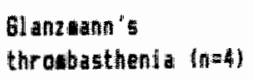 & $\begin{array}{c}5.8 \pm 2.7 \\
(2.6-6.6)\end{array}$ & $\begin{array}{l}12.1 \pm 3.4 \\
19.5-17.01\end{array}$ & $\begin{array}{c}59.5 \pm 16.8 \\
(42.7-78.2)\end{array}$ & $\begin{array}{c}361+407 \\
(264-470)\end{array}$ \\
\hline
\end{tabular}


Stimulation by thrombin resulted in slightly higher activities of the grey platelets compared to dense body deficient platelets, the latter being not significantly different from thrombin stimulated normal platelets.

Stimulation of both types of pletelets with collagen plus thrombin leads to prothrombinase activities that largely arexlap the range found for the corresponding normal platelets, although the range of activity of erey platelets is in the high and the activities of dense body deficient platelets are in the low region of the normal range. Nevertheless, the conelusion seems to be justified that neither release of a-granules, nor release of dense bodies is required for exposure of prothrombinase activity induced by collagen plus thrombin. It should be noted that although both abnormal platelets lack one type of franule and thus a certain amount of granule membrane phospholipids, the expected decrease in phospholipid content is not reflected in the prothrombinase values of lysed platelets.

GLangmann"s thrombasthenia.

Prothrombinase activities of platelets from patients with Glanzmann's thrombasthenis are indistinguishable from those of normal platelets, either in the stimulated or in the non-stimulated form (Table I). Maximal prothrombinase activity obtained after complete lysis was found to be in the same range as observed for control platelets, sugesting that there is no difference in phospholipid content or overall phospholipid composition of thrombastenic platelets. Washed suspensions of thrombastenic platelets were used to check aggregation induced by thrombin or the combined action of collagen plus thrombin. This was confirmed to be seriously impaired. It is concluded that ageresation is not a prerequisite for exposure of phosphatidylserine at the platelet outer surface, leading to an increased prothrombinase activity.

Bernard-Soulier platelets ("Biant" platelets)

The results obtained with platelets from patients with Bernard-Soulier syndrome are presented in Table II. The most remarkable feature of the platelets from this sroup of patients was the high level of the basal prothrombinase activity. In all five patients that were examined, the prothrombinase activity of the non-stimulated platelets was approximately 10-fold higher than that of non-stimulated normal platelets. Because of the large size of Bernard-Soulier platelets, PRP had to be obtained by sedimentation of whole blood for 1 hour at 1 g, which could be of influence on the procoagulant activity of the platelets. However, no difference in prothrombinase activity of normal platelets was found, whether PRP was obtained by sedimentation at 1 or by centrifugation at 120E. Furthermore, the possibility that Bernard-Soulier platelets, because of their abnormal size, are more readily activated or lysed, merely as a result of stirring during the prothrombinase assay, was checked by comparing prothrombinase activities after an incubation period of 10 
minutes. No significant difference in activity of stirred and non-stirred diluted PRP could be detected (data not shown).

\section{TABLE II}

Prothrombinase activities of Bernard-Soulier platelets. Activities are given as on throbin/ in t doo celis per 1 .

\begin{tabular}{|c|c|c|c|c|}
\hline Piatient & $\begin{array}{c}\text { Non- } \\
\text { stiaul ated }\end{array}$ & $\begin{array}{l}\text { Throabin } \\
\text { stiaulated }\end{array}$ & $\begin{array}{c}\text { Coll agen + thrombin } \\
\text { stiwulated }\end{array}$ & $\begin{array}{c}\text { Lysed } \\
\text { platelet }\end{array}$ \\
\hline 1 & $38.0 \pm 7.6$ & $56.0 \pm 16.3$ & 129.547 .8 & $670+69$ \\
\hline 2 & $21.9 \pm 12.9$ & $33.5 \pm 10.0$ & $90.1 \pm 10.8$ & $1239 \pm 180$ \\
\hline 3 & $30.0 \pm 14.4$ & $83_{4} 8 \pm 53_{4} 3$ & $193.5 \pm 33.5$ & $1238 \pm 76$ \\
\hline 4 & $69.6 \pm 18.0$ & $109.8 \pm 49.6$ & $161.8 \pm 81.3$ & $1473 \pm 127$ \\
\hline 5 & $44.8 \pm 21.1$ & $94.9 \pm 18.0$ & $121.8 \pm 53,5$ & $1029 \pm 50$ \\
\hline Meen & $42.8 \pm 17.4$ & $77.5 \pm 31.7$ & $140.9 \pm 37.2$ & $1130 \pm 302$ \\
\hline 6 & 17.443 .5 & $38.6 \pm 11.0$ & $80.6 \pm 6.4$ & $1027 \pm 112$ \\
\hline Control & $5.5+2.0$ & $12.7 \pm 4,0$ & $70.5 \pm 17.1$ & $521 \pm 146$ \\
\hline
\end{tabular}

Stimulation by thrombin Eives a two-fold inerease of the procoagulant activity of resting Bernard-Soulier platelets, an increase that is slightly less than seen with normal platelets. An even smaller increase compared with the increase seen with normal platelets is found when stimulation is carried out by the combined action of collagen plus thrombin. Prothrombinase activity of nocmal platelets increases from 5.5 to 70.5 nM IIa/min upon stimulation with collagen plus thrombin. In comparison, the activity of Bernard-Soulier platelets increases from 42.8 to $140.9 \mathrm{nM}$ IIa/min upon stimulation (Table II).

Finally, a large difference was found between the prothrombinase activities of the lysed platelets, which were on the average two-fold higher for the Bernard-Soulier platelets as compared to the control pletelets.

Since procoagulant activity is dependent on the amount af suitable phospholipid surface $[2,4,5]$, the increased prothrombinase activity of Bernard-Soulier platelets could be due to an increased size reported for these platelets $[16,17]$. On one occasion we had the opportunity to measure the mean platelet volume of preparations from three Bernard-Soulier patients. The values are given in Table III, including the corresponding values of the prothrombinase activities of the nonstimulated platelets. The non-spherical shepe and the existence of invaginations make it impossible to calculate a mean platelet surface area frow the data in Table III. However, an increase in volume is accompanied by a relatively smaller increase in surface area of the platelet. Thus, the increased prothrombinase activities of non-stimulated Bernard-Soulier 
This paper describes the procoagulant activity of patholofical platelets measured as the ability of plateletis to enhance the rate of thrombin formation by the action of factors $X a$ and $V a$ on prothrombin. The assay, which was originally developed for washed platelets, appeared to be equally valid when performed in PRP, diluted sufficiently to allow neglectance of the plasme coagulation factors in comparison with the concentrations of the purified factors $X a, V_{a}$ and prothrombin that are added to the system.

No large abnormalities were found in prothrombinase activities of storage pool deficient platelets. Thus, exposure of a procoagulant surface does not require release of dense body or $\alpha$-granule contents. This confirms the observation that stimulation of normal platelets by thrombin alone does not lead to a large increase in prothrombinase activity, which supports the idea that the expression of a procoagulant surface is not a result of the fusion of exanule membranes with the plasma membrane occurring during the release reaction $[1,6,7]$.

The major defect of platelets from patients ith Glanzmann's thrombasthenia is the lack of aggregation in response to several agonists. The primary cause of this defect is the absence of membrane Elycoproteins IIb and II $[12,15,19]$. The observation that the prothrombinase activity of these platelets does not differ from normal. platelets, either in the stimulated or in the non-stimulated form, allows the conclusion that glycoproteins IIb and IIIa are not directly involved in the exposure of this activity. Moreover, it can be conoluded that ageregation is not required for the expression of prothrombinase activity. This seems to be in contrast with findings of Hardisty and Hutton [20,21] and Walsh [22] who found severely impaired platelet factor 3 (PF3) activity in thrombasthenic platelets. Also based on observation with different pathologial platelets, it was concluded that PF3 activity was merely a reflection of platelet agtreGability [21]. However, the PH3 Assay used by these authors is not only dependent on the exposure of procoagulant phospholipids, but is also influenced by other factors as has been discussed prewious $1 y[1,6]$. Therefore, some caution should be exeroised when comparing platelet prothrombinase activities obtained by a Stypven assay (PF3) or by the more defined assay used here, which is only dependent on the exposure of a procoagulant surface. In conclusion, the bleeding severity in thrombas thenia is presumably not due to defect in prothrombinase activity. The most important determinant for this bleeding disorder is the decreased or absent fibrinogen binding to these platelets as described by Lee et al. [23].

Aberrant prothrombinase activities were found for Bernard-Soulier platelets. This was particularly manifested in the prothrombinase activities of non-stimulated 
platelets which appeared to be approximately 10-fold higher than found for normal platelets. Bernard-Soulier platelets are predominantiy characterized by their large size [16, 17] and the absence of membrane lycoproteins Ib; $V$ and $I X[14,24,25,26]$. Although $G P$ Ib is considered to be the high affinity binding site for thrombin and GP the surface substrate that is cleaved by thrombin [27], the prothrombinase activity of Bernard-Soulier platelets can till be increased upon treatment ith thrombin, though to a somewhat maller extent than in normal platelets. Maximal. prothrombinase activity after stimulation with collagen plus thrombin is only two-fold larger than for norme1 platelets. This probably reflects the increased size of Bernard-Soulier platelets, which can also be seen from comparison between the prothrombinase activities of lysed normal platelets and lysed Bernard-Soulier platelets This is in agreement with the observation of Perret et a1. [28] that Berrard-Soulier platelets have an incressed phospholipid content. However, the difference in size or phospholipid content is insufficient to explain the increased activity of non-stimulated Bernard-Soulier platelets (see Table II). The most likely explanation for the increased basal prothrombinase activity can be obtained from the work of Perret et al. [28] who found an abrormal phospholipid organization in Bernard-Soulier platelets. Specifically they found an increased exposure of phosphatidylserine (and phosphatidylethanolamine) at the platelet outer surface at the expense of sphingomyelin. We have previously shown that an increased prothrombinase activity is accompanied by an exposure of phosphatidylserine at the platelet outer surface [7].

The altered phospholipid distribution in Bernard-Soulier platelet membranes could have several possible causes. A lack of glycoprotein Ib could be responsible for a change in phospholipid organization. Several investigators $\left[29_{3}, 30,31\right]$ recent $1 y$ showed that glycoprotein Ib is associated with cytoskeletal structures and thus forms a site of interaction between cytoskeleton and plasma membrane. We have found that platelet cytoskeletal proteins might be involved in maintenance of the asyomotric phospholipid distribution [32] as was also demonstrated for the red cell membrane [33]. A defect in membrane-cytoskeletal interaction due to lack of glycoprotein Ib could lead to an altered membrane architecture and hence to a different phospholipid distribution in Bernard-Soulier platelets. Another possible explanation arises from the work of Chevalier et al. [34] who showed that Bernard-Soulier platelets have an abnormal distribution of intramembranous particles which are considered to be integral nembrane proteins that are visualized by freeze-fracture electron microscopy. The significantly decreased number of particles in the outer fracture face might indicate an increased protein-free phospholipid surface which could lead to an increase in possible binding sites for the prothrombinase complex. Finally, it 
is possible that the altered phospholipid asymetry reflects a partly activated state of the platelets induced during circulation, due to an increased susceptibility towards activators. This might be caused by the inereased platelet size. In this respect, it is of interest to mention that a positive relationship between platelet procoagulant activity and platelet size has been observed in a number of patients with diabetes mellitus [35]. Our observation wth the one Nay-Hegglin patient is not inconsistent with this notion.

\section{References.}

1 Bevers, E.M., Comfurius, P., Hemker, H.C., Zwaal, R.F.A. (1982) Haemostasis 12, 268-274.

2 Rosing, J., $\tan$ Rijn, J.L.M.L., Bevers, E.M., van Diei jen, G., Comfurius, P., Zwakl, R.F.A. (1985) Blood $65,319-322$.

3 Van Rijn, J.L.M.L., Rosine, J, van Dieijta, G., Bevers, E.M. , Zwal, R. F. A., Hemker, H.C. (1983) Arzneimitte1-Forschung $33,1365-1369$.

4 Rosing, J., Tans, G., Govers-Riemslag, J. W. P., Zwaal. R. F. A., Hemker, H.C. (1980) J Biol. Chem. 255, 274-283.

5 Van Dieijen, G., Tans, G., Rosing, J., Hemker, H.C. (1981) J. Biol. Chem. 256, 3433-3442.

6 Bevers, E.M., Comfurius, P., var Rijn, J.L.M.L., Hemker, H.C., Zwaal, R.F.A. (1982)

Eur. J. Biochem. $122,429-436$.

7 Bevers, E.M., Comfurius, P., Zwaal, R.F.A. (1983) Biochim. Biophys. Acta $736,57-66$.

(This thesis, chapter 4).

8 Gerritsen, S.M., Akkerman, H.W.N., Nijmeijer, A., Sixma, J.J., Witkop, C.J., White, J. (1977) Scand. I. Haematol. 13, 249-256.

- Akkerman, J.W.N., Nieuwenkuis, H.K., MommerstesgLeautaud, M.E., Gorter, G., Sixma, J.J. (1983) $\mathrm{Br}$. J. Haenatol. $55,135-143$.

10 Levy-Toledano, S. "Caen, J.P., Breton-Gorius, J. Rendu, F", Gyulna-Golenzer, C. Dupuy, E. "Legrand, Y., Maclouf, J. (1981) J. Lab. Clin. Med. 98, 831-898.

11 Caen, J. P. (1972) Clinics in Hematology 1 , $383-392$.

12 Nurden, A. T., Caen, J.P. (1976) Thrombosis and Haemostes is $35,139-150$.

13 Berndt, M.C., Gregory, C., Chong, B.H., Zola, H. , Castaldi, P.A. (1983) Blood 62, 800-807.

14 Caen, J.P., Nurden, A.T., Jeanmeau, C., Miche1, H., Tobelen, A., Levy-Toledano, S., SuJ.tan, $Y$. , Velensi, F., Berrard, J. (1976) J. Lab. Clir. Med. 87, 585-595.

15 Nurden, A. T. Caen, J.P. (1979) Seminars in Hematology $16,234-250$.

16 Evensen, S.A., Solum, N.O., Grattum, K.A., Hovie, T. (1974) Scand. J. Haematol. 13, 203-214. 
17 MoGi11, M., Jamieson, G.A., Drouin, J., Cho. M.S., Rock, G.A. (1984) Thrombosis and Haemostasis $52,37-41$.

18 Oski. F.A., Naiman, J.L;, Allen, D.M., Diamon, L.K. (1962) Blood 20;657-667.

19 Phil1 1 ps, D.R. "Poh Agin, P. (1977) J. Clin. Invest. $60,535-545$.

20 Fardisty, R. M. Hutton, R. A. (1966) Br. I. Haematol. 12, 764-776.

21 Hardsty, R.M., Hutton, R.A. (1976) Platelet Function Testing (ed. by H.J. Day, H. Holmsen and M.B. Zucker) P. 471. DEHW Publication No. (NIH) $1078-1087$.

22 Walsh, P.N. (1972) Br. J. Haematol. 23, 553-569.

23 Lee, H., Nurden, A.T., Thromaidis, A., Caen, J.P. (1981) Br. J. Haematol. 48, 47-57.

24 Defos, L., Tobelem, G, Lethielluex, P., Levy-Toledano, S. Caen, J.P., Colombani, J. (1977) Blood 50, 899-903.

25 Clemetson, K.J. MaGregor, J.L., James, E., Dechavanne, H. , Luscher, E. (1982) J. Clin. Invest. 70, 304-311.

26 Berndt, M.C., Gregory, C., Chong, B.H., Zola, H., Castaldi, P.A. (1983) Blood 62, 800-807.

27 Berndt, M. C., Phillips, D. R. (1981)

Platelets in Biology and Pathology (ed. by J.L. Gordon) pp. 43-75. Elgevier/North Holland, Amsterdam.

28 Perret, B., Levy-Toledano, S., Plantavid, M., Bredoux, R., Chap, H.J., Tobelem, G., Douste-Blazy, L., Caen, J.P. (1983) Thrombosis Research 31, 529-537.

29 Solum, N.O., Olsen, T.M. (1984)

Biochim. Biophys. Acta 799, 209-220.

30 Fox, J.E.B., Baughen, A.K., Phillips, D.R. (1983) B1ood 62,255 d.

31 Okita, J.R., Pidard, D., Newman, P.J., Montgomery, R.R., Kunioki, T.J. (1985)

I. Cel1. Biology 100, 317-321.

32 Comfurius, P., Bevers, E.M., Zwaal, R.F.A. (1985) Biochin. Biophys. Acte 815, 143-148.

(This thesis, chapter 7).

33 Haest; C.M. M. (1982)

Biochim. Biophys. Acta 694. 331-352.

34 Chevalier, J., Nurden, A.T., Thiery, J.M., Savariau, E., Caen, J.P. (1979) J. Lab. Clin. Med. 94, 232-245.

35 Rao, A.K., Goldbers, R.E., Walsh, P.N. (1984) J. Lab. C1ju. Med. 103, 82-92. 
STIMULATION OF PROTHEOMBINASE ACTIVITY OF PLATELETS AND ERYTHROCYTES BY SUB-LYTIC TREATMENT WITH PHOSPHOLIPASE C FROM CLOSTRIDIUM WELCEII.

Summary.

Treatment of platelets or red cells with small amounts of phospholipase $c$ from Clostridium welchii enables both cells, prior to the onset of lysis, to stimulate prothrombin conversion by factor $X a$ and $V a$ in the presence of calcium. Phospholipase C treatment of both cells also exposes significant mounts of phosphatidylserine at the outer surface. The level of phosphatidic acid formed from diglycerides produced by phospho1ipase $C$ action, is similar to that formed in activated platelets upon triggering the phosphatidylinositol cycle. A possible involvement of this cycle in the activation of platelets to become more procoagulant is discussed. 
We have previously shown that stimulation of huwan blood platelets by the combined action of collagen plua thrombin leads to increased exposure of phosphatidylserine in the outer leatlet of the plasma membrane, presumably resulting from an induced transbilayer movement of phospholipids $[1,2]$. This activaton procedure enables the platelets to enhance the conversion of prothrombin to thrombin by the coagulation factors $X_{a}$ and $V_{a}$ in the presence of calcium. This catalytic effect is caused by increased complex formation of coagulation factors and negatively charged polar headgroups in the membrane phospholipid surface [3-5]. Both in platelets and erythrocytes phosphatidylserine is the major negatively charged phospholipid present, but it is virtually absent from the exterior surface of the membrane [6-8]. Its exposure at the outer surface as can occur during platelet activation, may serve to stimulate the coagulation process $[9,10]$.

It has been shown by Mauco et al. [11] for human platelets and by Allan et al. [12] for human erythrocytes that introduction of diglycerides in the membrane by action of phospholipase $\mathrm{C}$ from Clostridium welchii results in the formation of phosphatidic acid, which suggests a transbilayer movement of diglycerides to the inner monolayer of the membrane where diglyceride kinase and ATP are available $[12,13]$. We have previously demonstrated [14] that incubation of platelets with phospholipase $C$ from $C$. welchii results in an increase of their ability to enhance the conversion of prothrombin to thrombin by the factor Xa-Va complex. At that time we suspected the known lytic effect of phospholipase $C$ from $C$. welchii $[6,11,12]$ to be responsible for this phenomenon since lysis results in exposure of the inner leaflet of the plasma membrane where phosphatidylserine is located, while this lipid is not degraded by phospholipase $C$ [6]. We now show, however, that before the onset of lysis, phospholipase c treatment of red cells and platelets enables both cells to stimulate prothrombin conversion and that this effect can be ascribed to an increased exposure of negatively charged phospholipid at the cell outer surface.

Materials and methods.

Phospholipase $C$ from Clostridium welchii and phospho1ipase Az from Naja naja were purified according to Zwaal et al. [6]. Blood coagulation factors $V a_{3}, X a$ and prothrombin were prepared as described in Rosing et a1. $[3]$.

Blood was drawn from healthy male volunteers and collected in acid-citrate-dextrose 10.052 citric acid, $0.08 \mathrm{M}$ trisodium citrate, $0.183 \mathrm{M}$ glucose, 1 vol of $\mathrm{ACD}$ to 5 vols of blood). Platelet-rich plasma and erythrocytes were separated by centrifugation at 200 \& for 15 minutes 
at room temperature. Erythrocytes were washed three times in $0.9 \%$ NaCl $(w / v)$ by centrifugation at 1000 for 10 minutes. Platelets were pelleted from platelet-rioh plasma by centrifugation at 600 for 15 minutes. The platelet pellet was carefully resuspended in a buffer containing $136 \mathrm{mM} \mathrm{NaCl}, 2.7 \mathrm{mM} \mathrm{KCl}, 2.0 \mathrm{mM} \mathrm{MgClz}, 25 \mathrm{mH}$ glucose, 10 m Hepes and $0.05 \%(w / v)$ fatty-acid free human serum albumin, pH 6.6 (Hepes buffer). The platelets were washed twice in this buffer by centrifugation at 600 for 15 minutes. Before each centrifugation 1 vol of ACD was added to 15 vols of platelet suspension. Finally the platelets were resuspended in Hepes buffer pII 7.5. Before adding phospholipase C, platelets and erythrocytes were diluted in Hepes buffer $\mathrm{pH} 7.5$ to a cell count of $5 * 10^{*} / \mathrm{m} 1$ using a Coulter counter. $\mathrm{Ca}^{-2}$ was added to a final. concentration of $3 \mathrm{~mm}$.

Hemolysis of erythrocytes was measured as the release of hemoglobin, determined by the optical density at 418 nm. Platelet lysis was measured as the leakage of lactate dehydrogenase [15].

Phospholipids were extracted from exythrocytes and platelets according to Bligh and Dyer [16], separated by two-dimensional thin layer chromatography and analyzed as phosphorous as described earlier [6]. Methyl-phosphatidic acid, prepared from ege phosphatidylcholine [17]. was used as external standard.

The rate of thrombin formation in the presence of red cells or platelets was measured essentially as described before [1]. Briefly: to $300 \mu 1$ of a cell suspension, $13 \mu 1$ $75 \mathrm{mM} \mathrm{CaCl}$ and $50 \mu 1$ of a mixture containing 30 nM factor $\mathrm{Xa}$ and $60 \mathrm{nM}$ factor $V_{a}$ were added. After a period of 2 minutes to allow equilibration of the clotting factors at the cell surface, the enzymatic reaction was started by addition of $125 \mu 116 \mu \mathrm{M}$ prothrombin. After 1 minute a sample was taken and immediately diluted in a buffer containing $120 \mathrm{~mW} \mathrm{NaCl,} 50 \mathrm{mM}$ Tris and 2 m $\mathrm{mDTA}$ (pH 7.5) to stop the reaction. The anount of thrombin formed was deterwined by measuring the change in absorbance at $405 \mathrm{~nm}$ per unit time, produced by the action of thrombin on the chromogenic substrate $\$ 2238$ (AB Kabi Diagnostica, Sweden). using a calibration curve made with known amounts of active-site titrated thrombin.

\section{Results and discussion.}

Figure 1 shows that upon incubation with phospholipase C from C. welchii (0.01 I.U./ml) both platelets and erytbrocytes show an increasing ability to enhance thrombin formation before significant lysis of the cells occurs. To confirm that this activity can be ascribed to the appearance of negatively charged phospholipids at the outer surface of the cells, phospholipase C-treated cells were subsequently subjected to treatment ith phospholipase from N. naja. 


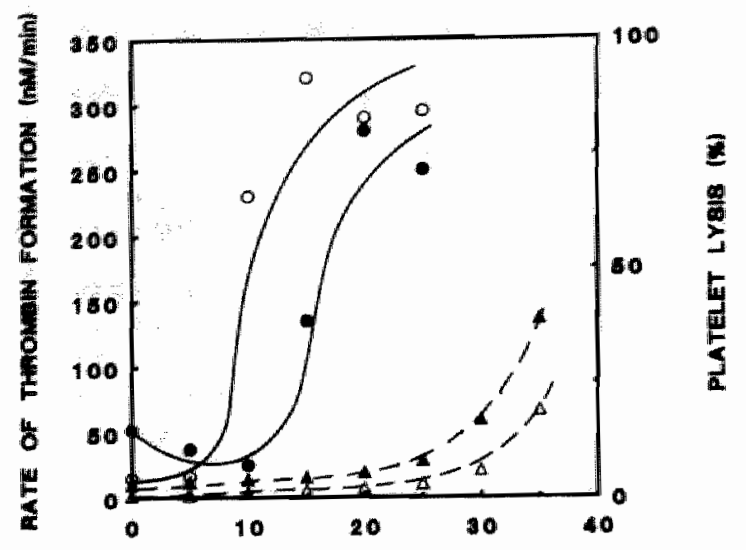

TIME (min)

Fig.t prothrobinase activity of huan red cells $(0)$ and

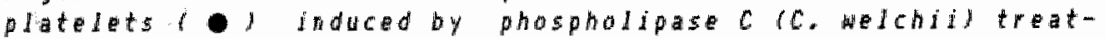
went. Dashed lings represent lysis of erythrocytes $(\Delta)$ and platelets $(\Delta)$.

0.01 IU/ul phospholipase $C$ is added at $t=0$ ll IUl is defined as the a wout of enzyme able to degrade 1 pale of substrate per nisute t 37 ac under optinal conditions $[6])$.

Since the incubation with phospholipase $c$ alone causes lysis after 30 minutes to both erythrocytes and platelets, cell suspensions (25 ml, $2 * 10^{\circ} \mathrm{cells} / \mathrm{ml}, 10 \mathrm{mM} \mathrm{Ca}{ }^{2+}$ ) were first inoubated during 10 minutes with phospholipase $C$ from c. welchii (0.01 I0/m1). After this preincubation period phospholipase Az from $\mathrm{H}$ maja $(3 \mathrm{IU} / \mathrm{m} 1)$ was added. Lys is remained below $10 \%$ for both cell preparations during 15 minutes following the addition of phospholipase As * Wile the lysis rapidy increased upon further incubation. Samples for lipid analysis were taken 15 minutes after addition of phospholipase Ae. Lipid degradation was stopped by adding RDTA (final concentration $15 \mathrm{mH}$ ) and o-phenantroline (final concentration $2 \mathrm{mM}$ ). Prior to lipid extration and analysis methy 1-phosphatidic acid was added axternal standard.

As shown in Table $I$, preincubation with phospholipase c allows extensive degradation of phosphatidylserine by subsequently added phospholipase As. Some 35 to $40 \%$ of the phosphatidylserine in both cells can be hydrolyzed while cell lysis remains below $10 \%$. It should be emphasized that phosphatidylserine is no substrate for phospholipase $C$ from C. welchii and also that this phospholipid is not destaded upon incubation of platelets [1] or red cells [6] with phospholipase As alone. Since in intact erythrocytes and platelets phosphatidylserine is almost exclusively located in the inner leaflet of the plasma membrane [6-8], 
the data suggest that substantial amounts of phosphatidy serine become exposed at the exterior surface of platelets and erythrocytes during phospholipase $C$ treatmenti.

\title{
TABLE I
}

Degradation of phospholipids in human platelets and erythrocytes by the combined action of phospholipase C (C.welchii) and phospholipase As (N. naja)

\section{Phospholipid}

Phosphatidylserine

Sphingomyel in

Phosphatidy lcholine

Phosphatidy lethanolamine
Erythrocytes

$33-39$
$29-40$
$15-27$
$18-21$

Platelets

$35-43$

$27-33$

$25-40$

$16-19$

\begin{abstract}
Range of degradation abtained fro 4 separate experdents is expressed as percentage of the and ant of each lipid class present in mon-treated cells. Data are corrected far cell Iysis assuring colplete phosphoijplodegradation in the population or the lysed cells. Lysis was allays below $10 \%$.

Phosphatidylserite is only degraded by phospholipase $A_{z}$ since it is no substrate for C. Welchit phospholipase C. Sphingoryelin is no substrate for phospholipase Az, its degradatian being solely caused by phospholipase c. phasphatidylchaline and phosphatidylethanola ine are attacked by both enzyos.
\end{abstract}

However, the amount of phosphatidylsexine degraded by phospholipase As cannot be directiy interpreted as the actual amount of this 1 ipid exposed at the outer surface. Cell lysis, which inevitably ocours, may precede a complete deetradation of the outer monollayer. Moreover, appearance of phosphatidylserine in the outer leaflet presumably results from a transbilayer movement and it is likely that this process proceeds during phospholipase Acs treatment. Also, it carnot be excluded that transbilayer movement is influenced by the phospholipase As tratment per se.

The increased exposure of negatively chared phospha tidylserine at the outer surface of both cells following phospholipase $C$ treatment can explain their ability to enhance prothrombin conversion. It may also be possible that the formation of phosphatidic acid, resulting from diglyceride kinase action on diglycerides formed by phospholipase $C$, contributes to this effect [18]. However, under our experimental conditions, treatment of both red cells and platelets with 0.01 IU of phospholipase $C$ for 10 minutes results in the formation of $2-4 \%$ of phosphatidic acid (expressed as percentage of total lipid phosphorous》. This amount is insufficient to fully explain the enhancement of prothrombinase activity, even assuming that a11 phosphatidic acid formed in the inner leaflet would be subject to transbilayer movement.

It has been shown that diglyceride formation in 
bacterial membranes induces phospholipid flip-flop $[19,20]$. Our results suggest that transbilayer movement of phospholipids (particularly phosphatidylserine) ocours after formation of diglycerides and phosphatidic acid in blood cell wembranes. A possible invalvement of ceramides formed from sphingomyelin by phospholipase $C$ action can be ruled out, since treatment of the cells with sphingomyoIinise does not lead to an increased exposure of phosphatidylserine towards exogenously added phospholipase Ae [6.8]. Also, sphingonyelinase treatment of red cells and platelets does not increase their ability to enhance prothrombin conversion to levels comparable to those obtained after phospholipase C treatwent [14].

Dillyoerides and phosphatidic acid can produce local disturbances in the bilayer structure by the formation of intra-bilayer inverted micelles, which can induce transbilayer movement of phospholipid [21]. Also, changes in physical properties of artificial membranes have been described [22] upon replacing phosphatidylinositol by diflycerides. In situ, diglyoerides and phosphatidic acid can be formed in many cells from phosphatidylinositol by the action of phosphatidylinositol-specific phospholipase $C$ and diglyceride kinase [23]. In activated platelets, this can lead to phosphatidic acid level close to $2 \%$ of total 1ipid phosphorous [24-26], which is very similar to the amount of phosphatidic acid formed during a 10 minutes incubation of the cells ith $0.01 \mathrm{IU} / \mathrm{ml}$ of phospholipase $C$. Therefore, diglycerides and phosphatidic acid formed in the PI-cycle of activated platelets may produce perturbations of the bilayer structure which could play a role in evoking transbilayer movement of phospholipids, leading to an increased exposure of phosphatidylserine in the outer leaflet. This process is of physiological importance since it would switch on the platelets to become more procoagulant.

\section{References.}

1 Bevers, E.M., Comfurius, P., van Rijn, J.L.M.L., Hemken, H.C., Zwal, R.F.A. (1982)

Eur. J. Biochem. 122, 429-436.

2 Zwad. R.F.A., Hemkex, H.C. (1982) Haemostasis $11,12-29$.

3 Ros ine, J., Tans, G., Govers-Riems lag, J. W. P., Zwaal, R. F.A., Henker, H.C. (1980)

J. Biol. Chem. 255, 274-283.

4 Nesteim, M. E., Eid, S., Manr, K.G. (1981)

J. Biol. Chem. 256, 9874-9882.

5 Pusey, M. L., Nelsestuen, G.I. (1983)

Biochem. Biophys. Res. Comm. 114, 526-532.

6 2wal, R. F. A., Roelofsen, B., Confurius, P., van Deeneri, L. L. M. (1975)

Biachim. Biophys. Acta 406, 83-96. 
7 Schick, P.K., Kurica, K. B., Chacko, G.K. (1976) J. Clin. Invest. 57, 1221-1226.

8 Chap, H.J., Zwaal, R.F.A. wan Deenen, L. L.M. (1977) Bioohim. Biophys. Aota 467, 146-164.

9 Z waal, R.F.A., Comfurius, P., van Deenen, L.L.M. (1977) Nature $268,358-360$. (This thesis, chapter 2).

10 Zwaal, R. F.A. (1978) Biochim. Biophys. Acta 515, 163-205.

11 Mauco, G., Chap, H.J., Simon, M.F., Douste-Blazy, L. (1978) Biochimie 60, 653-661.

12 Allan, D. Low, MG., Finean, J.B., Michell, R.H. (1975) Biochim. Biophys. Aota 413, 309-316.

13 Hokin, L. E., Hokin, M.R. (1963) Biochim. Biophys. Aota 67, 470-484.

14 Bevers. E.M., Comfurius, P., Zwal, R. F.A. (1982) Eur. J. Biochem. 122, 81-85. (This thesis, chapter 3).

15 Wroblewski, F., La Due, J.S. (1955) Proc. Soc. Exp. Biol. Med. 90, 210-215.

16 Bligh, E.G., Dyer, W.J. (1959) Can. I. Biocher. Physiol. 37, 911-917.

17 Comfurius, P., Zweal, R.F.A. (1977)

Biochim. Biophys. Acta 448, 36-42. (This thesis, chapter 1 ).

18 Nelsestuen, G.L., Broderius, W. (1977) Biochemistry $16,4172-4176$.

19 Bishop, D.G., Op den Kamp, J.A.F. van Deeren, L. L.M. (1977) Eur. J. Biochem. $80,381-391$.

20 Demant, E.J.F., Op den Kamp, J.A.F., var Deenen, L. L.M. (1979) Eur. J. Biochem. 95, 613-619.

21 Cullis, P.R., de Kruijff, B. (1979) Biochint. Biophys, Acta 559, 399-420.

22 Ohki, K., Sekiya, T., Yamauchi, T., Nozawa, Y. (1982) Biochim. Biophys. Acta $693,341-350$.

23 Miche11, R.H. (1975) Biochim. Biophys. Acta 415, 81-147.

24 Lapetina, E.G., Cuatrecasas, P. (1979) Biochim. Biophys. Acta 573, 394-402.

25 Mauco, G., Chap, H.J., Douste-Blazy, L. (1979) FEBS Letters 100, 367-370.

26 Bell, R.L. Majerus, P.W. (1980) J. Biol. Chem. 255, 1790-1792. 
THE INVOLVEMENT OF CYTOSKELETON IN THE REGULATION OF TRANSBILAYER MOVEMENT

OF PHOSPHOLIPIDS IN HUMAN BLOOD PLATELIES.

\section{Summary.}

Activation of human platelets by different activators resulted in a different extent of degradation of the cytoskeletal proteins actin-binding protein and myosin, as well as of the non-cytoskeletal protein P235. The highest extent of proteolysis was observed with Ca-ionophore A23187 and decreased on going from A23187> collagen plus thrombin? collagen $>$ thrombin $=$ ADP. The same order of potency has been found previously (BBA, 736 (1983) 57-66) for the ability of platelet activators to induce exposure of aminophospholipids in the outer leaflet of the platelet plasma membrane, and to stimulate platelets to become procoagulant. Degradation of cytoskeletal proteins as a result of platelet stimulation by collagen plus thrombin was prevented in the presence of dibutyry 1 cAMP or EDTA but not in the presence of aspirin. This also runs in parallel with platelet procoagulant activity. Moreover, platelets from a patient with a partial deficiency in platelet procoagulant activity revealed a diminished extent of desradation of cytoskeletal proteins upon platelet stimulation by collagen plus thrombin. It is conoluded that alterations in cytoskeletal organization upon platelet stimulation may lead to alterations in the orientation of (amino)phospholipids in the plasma membrane, and may therefore play a regulatory role in the expression of platelet procoagulant activity. 
The asymmetric distribution of phospholipids between the imer and the auter layer of the platelet plasma membrane $i s$ disturbed wen platelets are treated with calcilum ionophore A23187, SH-oxidizing agent diamide, or when platelets are stimulated by the combined action of collagen and thrombin $[1,2]$. These treatments result in an increased exposure of aminophospholipids in the outer leaflet of the plasma membrame, resulting from an induced transbilayer movement of phospholipids. Consequently, these platelets become able to enhance the conversion of coegulation factor $X$ to $X a$ by complex of coagulation $f$ actors IXa and VIIIa, and of prothrombin to thrombin by a complex of coagulation factors $X a$ and $V_{a}$ [1-3]. Both catalytic effects are caused by complex formation of coagulation factors and negatively charged phospholipid headeroups provided by the increased exposure of phosphatidy serine $[4,5]$.

The non-random orientation of phospholipids in resting platelets resembles that in red cells [6-9]. The origin of this asymmetry and the mechanisms responsible for its regulation are still open to conjecture, but recent studies with red cells have indicated that interactions between the major oytoskeletal pratein spectrin and anionic phosphatidylserine may contribute to the maintenance of the orientation of this phospholipid in the inner leaflet of the membrane bilayer [10-13]. Oxidation of spectrin SH-groups by diamide [10], or decoupling of spectrin from the bilayer in spicules from irreversibly sickled erythrocytes [13], results in increased exposure of aminophospholipids (including phosphatidylserine) at the outer surface of the erythrocyte. Also in platelets, treatment with diamide has been shown to produce extensive cross-1inking of cytoskeletal proteins (including actinbinding protein, heavy chain myosin and actin) $[14,15]$, and this may result in a dramatio reorientation of aminophospholipids by a mechanism similar to that operating in diamide treated red cells [2,12]. Another distinct possibility to enhance transbilayer movement of phospholipids in platelets is by alteration of the cytoskeleton structure upon activation. In this respect, it is of interest that cytoskeletal organization differs between platelets activated by thrombin or by calcium ionophore $[16,17]$. Platelets contain a caleium-dependent protease $[18,19]$ that produces almost complete breakdown of actin-binding protein (as well as of the non-cytoskeletal protein P235) when platelets are activated by A23187, whereas activation by thrombin does not result in degradation of cytoskeletal proteins as judged from one-dimensional polyacrylamide gel electrophoresis [16]. In a recent study using two-dimensional polyacrylamide gel electrophoresis, Fox et al. [20] were able to show limited calcium-dependent proteolysis of actin-binding protein upon stimulation of platelets with thrombin. 
In view of the finding that the amount of phosphatidylserine exposed at the platelet outer surface depends on the activation procedure [2], we mere interested to study whether this would correlate with calcium-dependent proteolysis of cytoskeletal proteins. For this purpose, we used one-dimensional polyacrylamide gel electrophoresis for convenient comparison between the gels. Moreover, two of the known products of oaloium-dependent proteolysis ( $\mathrm{M}, 48 \mathrm{kD}$ and $135 \mathrm{kD}$ ) are not found on two-dimensiomal gels, presumably because they have isoelectric pointa beyond the range of the Ampholines usually employed [20]. On one-dimensional gels, however, the degradation fragment of $\mathrm{M} 100 \mathrm{kD}$ is usually not observed, perhaps because it comigrates ith $\alpha$-actinin ( $M$ 105 kD) [19].

Materials and Methods.

Human platelets were isolated from freshly drawn blood and washed by centrifugation as described previously [2]. All steps in the washing procedure were carried out in plastic tubes at room temperature. Prior to the activation procedure, washed platelets were resuspended at a concentration of $2 * 10$ - platelets/ml in Hepes buffer (pH

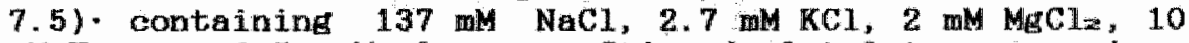
mM Hepes and $5 \mathrm{mM}$ lucose. Stirred platelets suspensions were made $3 \mathrm{mb}$ in calcium (unless otherwise stated) and activated with different stimulators at $37^{\circ} \mathrm{c}$. After a 5 minutes activation period, platelets were spun down at 1000 for 2 minutes. Platelet pellets were dissolved in $2 \% \operatorname{SDS}(w / v), 5 \% \quad B$-mercaptoethanol ( $v / v)$ and $1 \mathrm{mM}$ EDTA. Electrophoresis was carried out as described by Laemmi [31] using $7.5 \%$ polyaorylamide gels with $4 \%$ stacking gel. Gels were stained with Coomassie Briliant Blue.

Cytoskeletal preparations were made essentially as described by Rosenberg tet. [32]. Briefly, to a platelet preparation (control or activated) was added $1 / 10^{\text {th }}$ vol of a solution containing $10 \%$ Triton $X-100,100 \mathrm{mM}$ EDTA, pH 7.5. After stirring for 10 minutes in ice, the samples were centrifuged at 1000 for 10 minutes. The pellets were treated as described above for total platelet preparations.

\section{Results and Discussion.}

Fi.g. 1 shows the protein patteros of control platelets, and platelets activated for 5 minutes with thrombin, collagen, collagen plus thrombin, calcium ionophore A23187, and ADP. On the basis of their apparent molecular weights and by comparison with previous studies $[16-20]$, actin-binding protein, P235, heavy chain myosin, a-actinin and G-actin were identified. In concordance ith previous investigators using a similar one-dimensional polyacrylamide gel electrophoresis $[16,17]$, A23187 produced virtual 
complete breakdow of actin-binding protein and the protein P235 and the formation of four major degradation products of $190 \mathrm{kD}, 135 \mathrm{kD}, 93 \mathrm{kD}$ and $48 \mathrm{kD}$ (FiE. 1 , lane $\mathbf{E})$.

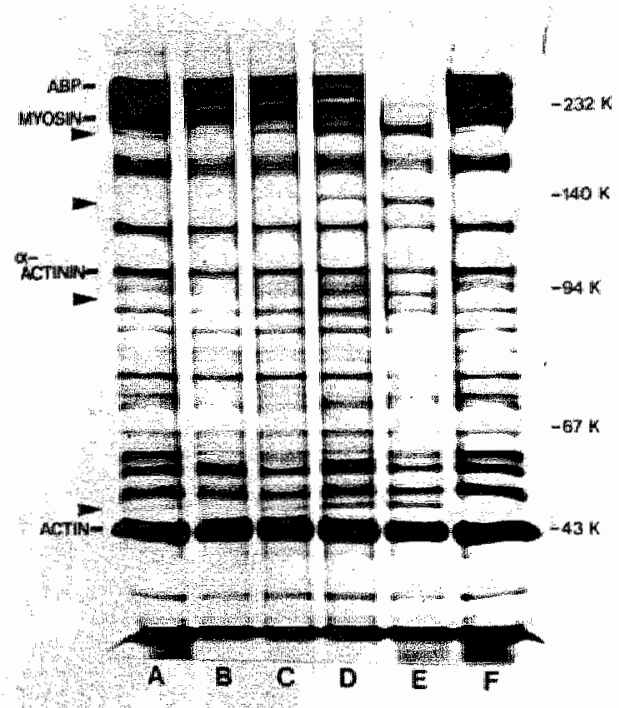

Filds protein patterns from activated platelets. Lane A, non-stinulated platelets lane B, stivulated with 2 nothoubi

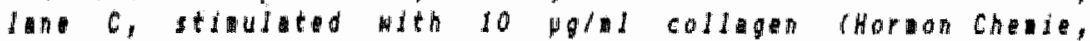

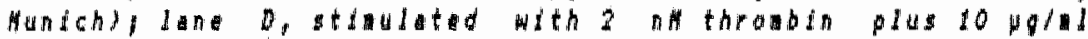
collogen Jane E, stinulated with H calciulonophore A23187, lane F, stinulated with $10 \mu$ it $A D P$.

Platelet activation, saple preparation and electrophoresis me carried out as described in the tert.

The cytoplastic protein P235 is located between ABP and ayosita. The arrotheads distignate the four najor degradation paducts.

Indicated on the right side are the positions of the alecular weight standards catalase $(232 \mathrm{~kb}$, lactate dehydrogenase 1140

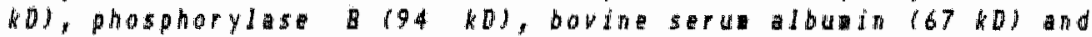
ovalbutit ( $43 \mathrm{kD})$.

Gvidence has been obtained that calcium-dependent proteolysis of actin binding protein results in the formation of fragments $\mathrm{M} 200 \mathrm{kD}$ and $93 \mathrm{kD}$, while $\mathrm{P235}$ is degraded to fragments of $\mathrm{M}$ - $200 \mathrm{kD}$ and $48 \mathrm{kD}$ [21]. Treatment of platelets with A23187 also revealed an essentially complete breakdown of heavy chain myosin, an effect which has not been recognized before. In this respect it is of interest to mention that platelet myosin was shown to be cleaved by endogenous proteases during myosin isolation, to give separable rod (M $130 \mathrm{kD}$ ) and head (M- $100 \mathrm{kD})$ polypeptides [22]. Therefore, it is possible that the degradation fragment $\mathrm{M} 135 \mathrm{kD}$ observed in ionophore treated platelets represents the rod fragment of 
myosin.

In contrast to the effect of A23187, platelet wotivation by thrombin (even at a concentration of $20 \mathrm{nM}$ ) produced no visible ealcium-dependent proteolysis (Fif. 1 , lane B), although limited breakdown has been shown to appear on two-dimensional gels [20]. Stimulation of platelets by collagen seemed to be somewhat more effective than thrombin in that winor forwation of the four degradation fragments (M $190 \mathrm{kD}, 135 \mathrm{kD}, 93 \mathrm{kD}$ and $48 \mathrm{kD}$ ) occurred (Fig 1, lane C). No change in the extent of degradation was observed when the collagen concentration ranged from 4 to $40 \mu / m l$ or when the activation period varied from 2 to 15 minutes. Simultaneous activation of platelets by collagen plus thrombin produced much more polypeptide degradation (Fig. 1, lane D), than treatment of platelets with either of these stimulants separately. It is evident that activation by collagen plus thrombin resulted in substantial formation of the same four degradation products as observed upon platelet activation by ionophore. Also, a decrease in actin-binding protein, P235 and presumably also in heavy chain myosin is apparent in gels of collagen plus thrombin activated platelets. In general, the degradation patterns were highly roproducible, provided that platelet activation was performed at concentrations below $10^{*}$ platelets/ml under stirring to produce ageregation. At higher platelet concentrations, the appearance of the degradation products was usually less reproducible, particularly in the preparations activated by collagen or by collagen plus thrombin. It is well known that the higher the platelet concentration, the larger are the ageregates formed. It is therefore conceivable that this will reduce the fraction of platelets in direct contact with collagen, as more platelets will be aggregated by released ADP. Activation of platelets by ADP in the presence of extracellular calcium did not produce any of the proteolysis fragments (Fig. 1, lane F).

Fig. 2 shows that formation of the four degradation fragments induced by activation of the platelets with collagen plus thrombin was essentially the same irrespeotive of whether platelets were activated for 1 or for 15 minutes (Fif. 2, lanes $B$ and C). However, when platelets were treated first with dibutyryl cAMP (Fig. 2, lane D) or when extraceliular calcium is replaced by EDTA (F1. 2 , lane E) none of the desradation fragments were formed. Pretreatment of the platelets ith aspirin did not prevent the formation of the four degradation fragments when platelets are subsequently activated by collagen plus thrombin (Fig. 2 , lane F). We have previously show that the appearance of phosphatidylserine at the platelet outer surface as induced after platelet stimulation by the combined action of collagen plus thrombin is abolished in the presence of dibutyryl cAMP or EDTA, but is not prevented in the presence of aspirin [23]. 


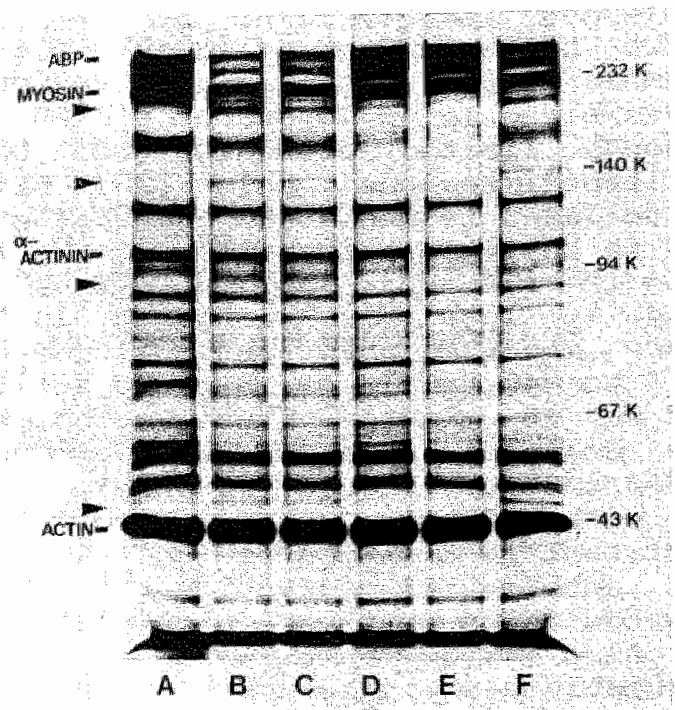

Fiq.2" Effect of different platelet function inhibitors on protein patterns fro collagen plus throbin activated platelets. Lane $A$, non-stiolated plateletsi lane B, stinulated with collagen plus throbin for 1 ning lane $C$, for 15 nin; lanes D,E,F preincubated for 5 lin mith inhibitors, followed by a stialation with collagen plus throbin for 5 win latie $D$ dibutyryl calle ( 3 all); lane $E, 1$ un EDTA in the absence of calciul lane $F$, aspirin (Inglal). Further experinental detajis are described in the legend to Fig.t.

Fig. 3 shows the protein composition of the cytoskeletons, obtained as the Triton-insoluble residues. The main proteins in these preparations are actin-binding protein ( $\mathrm{H} 250 \mathrm{kD}$ ), heavy chain myosin ( $200 \mathrm{kD}$ ), a-actinin (M $105 \mathrm{kD})$ and actin $(\mathrm{H}-43 \mathrm{kD})$, which is in agreement with other investisators [22]. In addition it was confirmed that a prominent polypeptide of $456 \mathrm{kD}$ is recovered in the cytoskeleton of throwbin-activated platelets [24].

Yields of cytoskeletons were negligible with ionophore treated platelets which may reflect extensive calciumdependent proteolysis of cytoskeletal proteins. Relative to heavy chain myosin, the largest reduction of actinbinding protein was observed with platelets activated by collagen plus thrombin (Fig. 3, lane $\mathrm{B}$ ), apart from ionophore treated platelets of which not eaough material could be collected. Of the four degradation products observed in protein patterns of the platelet preparations after activation by collagen plus thrombin (Fig. 3, lane F). only the polypeptide of $135 \mathrm{kD}$ was (presumably partly) recovered in the corresponding Triton-insoluble residue (Fie. 3, lane E). We did not observe that the highest molecular weight fragment (M 190 kD) remained associated with the cytoskeleton, as did Truglia and 
Stracher [19] after treatment of platelet preparations with highly purified ealcium-dependent protease from platelets. The reasons for this discrepancy are not known. but could easily be due to differences in experimential conditions.

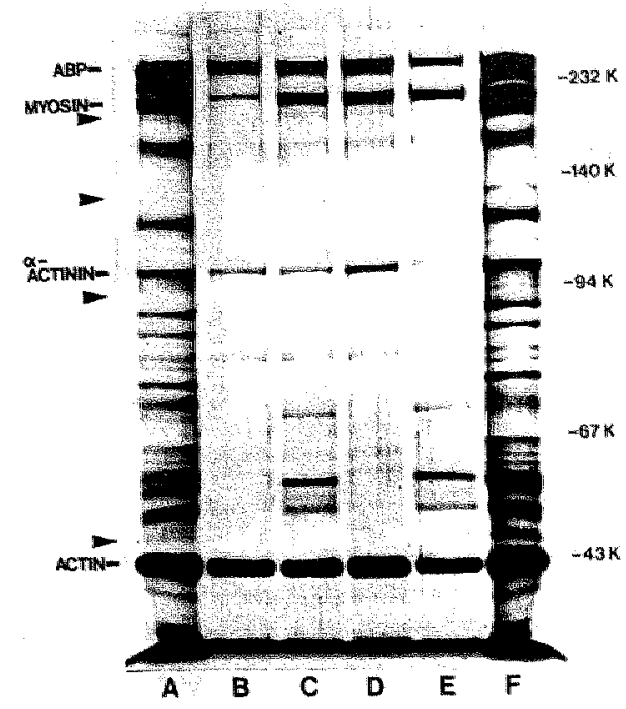

Fig.3 protein patterns of cytoskeletons from (activated) platelets. Lane $A$, total protein pattern frac non-stinulated plateletsy lane a, cytaskeletans af non-stinulated plateletsi lane $C$, cytoskeleton after throbin 12 nit stioulation lane $D$, cytosk leton after sti ulation with collagen (10 Hg/aI), Iane E, cytoskedeton after stivalation with collagen plus throubin lane F. total proteinsattern after stinulation with callagen plus throbin. Cytoskeletons aere prepared as described in the tert. For further experinentald detis se fig.

The results clearly indicate that the extent of calciumdependent proteolysis upon platelet avtivation depends on the activator: A23187> collagen plus thrombin > collagen $>$ thrombin $=$ ADP. It is remarkable that both the amount of phosphatidylserine exposed the outer surface and the concordant ability of platelets to stimulate prothrombinase activity is similarly dependent on the platelet activator (Fig. 4). In addition, we recently studied platelets from patient earlier described by Weiss et al. [25] to have a deficiency of platelet procoagulant activity. These platelets appeared to have a reduced capability to promote both prothrombin- and factor $X$-activation after stimulation by collagen plus thrombin, and this was accompanied by reduced exposure of phosphatidylserine at the platelet outer surface [26]. 
Fin. Al Relation between prothrobih converting activity and exposure of phosphatiolyser ine in actiluted hunand blood platelets. Each point represents a different platelet treatuent as indicated. Contr." non-stivulated platelets. This plot is a graphic representation of data fro Ref.2.

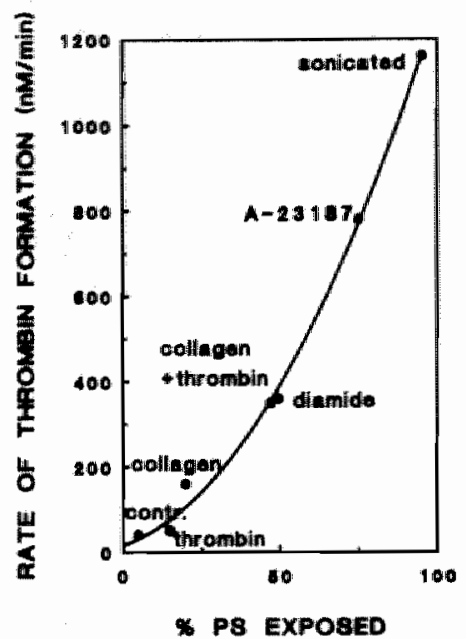

It is of interest that these platelets also revealed a diminished calcium-dependent proteolysis upon stimulation with collagen plus thrombin (Fig. 5, compare lane D with B).

Fio.5i Pletelet protein paterns frow a patient ath a bleding disorder. lanes $A$ and $B$ are frome control donor, lanes $c$ and D frow the patient. Lanes $A$ and $C$, non-stivulated Datelets, lanes $B$ and $D_{\text {. }}$ platelets stisulated with collagen alus throwit. Futher experiontal detalis are given in Fi. i.

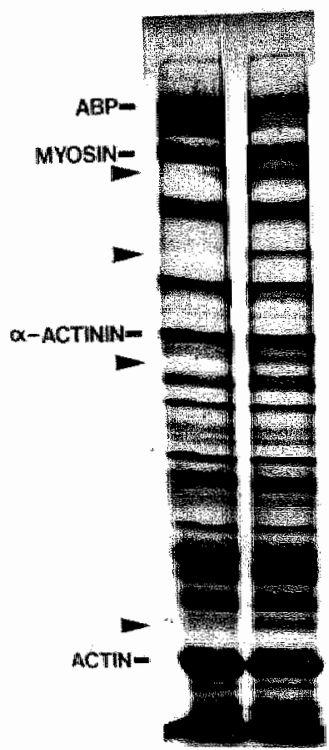

A B

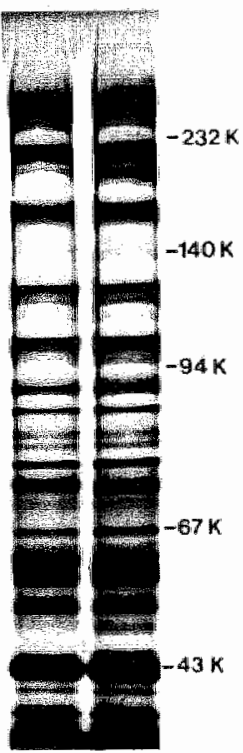

C D

In particular, the formation of degradation fragments $\mathrm{M}-135 \mathrm{kD}$ and $93 \mathrm{kD}$ was found to be strongly reduced compared to identically activated normal platelets. Treatment of the patients platelets with Ca-ionophore A23187 produced the same extent of proteolysis as found with ionophore-treated normal cells. This strongly 
sugiests that the patients platelets are not (partly) deficient in calciumdependent protease, but that they have a decreased ability to raise the cytoplasmic calcium concentration upon activation. Also, it is ilkely that activation of normal platelets by collagen plus thrombin produces a higher increase in cytoplasmic calcium concentration than activation by either of these agonists separately. Dibutyry 1 cAMP prevents calcium-dependent proteolysis by suppressing cytoplasmic calcium concentrations. The inbibitory effect of EDTA strongly indicates that extracellular calcium has to be taken up in order to attain cytoplasmic calcium levels, sufficiently high to stimulate $\mathrm{Ca}^{2+}$-dependent protease activity.

It is conceivable that degradation of cytoskeletal proteins is accompanied by alterations in cytoskeletal organization which result in a detachment of the cytoskeleton from the interior half of the lipid bilayer membrane. In so far as direct interactions between cytoskeletal proteins and phosphatidylserine exist in platelets (which will be demonstrated in chapter 8 of this thesis), a decoupling might facilitate transbilayer movement of phosphatidylserine similar to that postulated for red cell membranes $[12,13]$. It should be emphasized, however, that loss of phospholipid asymmetry does not automatically have to occur upon decoupling of oytoskeleton from the membrane. It has been demonstrated that spectrin-free microvesicles obtained from ionophoretreated red cells retain their asymmetric phospholipid distribution, unless incubated for 16 hours at $37 \circ \mathrm{C}$ [27]. It is therefore more likely that decoupline of the cytoskeleton from the 1 ipid bilayer is a prerequisite for the rapid transbilayer movemeht to occur, the rate of which would be dependent on structural alterations in the membrane bilayer itself to form sites that allow for transbilayer reorientation [28-30].

\section{Reforences.}

1 Bevers, E.M., Comfurius, P., $\operatorname{ran}$ Fi.jn, J.L.M.L., Hemker, H.C., Zwad, R.F.A. (1882)

Eur. I. Biochem. $122,429-436$.

2 Bevers, E.M., Comfurius, P., Zwas. R. A. A. (1983)

Biochim. Biophys. Acta 736, 57-66.

(This thesis, chapter 4 ).

3 Rosing, J." van Rijn, J.L.M.L., Beverg, E.M. van Dieijen, G., Comfurius, P., Zwaal, R. F.A. (1985) B1ood 65, 1557-1561.

4 Rosing, J., Tans, G., Govers-RiemsIag, J.W.P., Zwaal, R.F.A., Hemker, H.C. (1980)

J. Biol. Chem. 255, 274-283.

5 Van Dieijen, $G$. Tans, G., Rosing, J., Herker, H.C. (1981) J. Biol. Chem. 256, 3433-3442. 
6 Zwal, R.F.A., Roelofsen, B., Confurius, P., van Deenen, L. L.M. (1975)

Bichin: Biophys. Acta 406, B3-95.

7 Chap, H.J., Zwael, R.F.A., van Deenen, L.I.M. (1977) Biochim. Biophys; Acta 467, 146-164.

8 Zwal. R. F.A. (1978)

Biochim. Biophys. Acta 515, 163-205.

9 Schick, P.K. (1979) Semin. Hemato1. 16, 221-233.

10 Haest, C.W.M., Plasa, G., Kamp, D., Deutioke, B. (1978) Biochin. Biophys. Acta 509, 21-32.

11 Mombers, C., de Gier, J., Deme1, R. A., van Deenen, L. L.M. (1980) Biochin. Biophys. Acta 603, 52-62.

12 Hast, C.W.M. (1982)

Biochim. Biophys. Acta $694,331-352$.

13 Franck, P.F.H., Bevers, E.M., Lubin, B.H., Comfurius, P., Chiu, D. T. - Y., Op den Kamp, J.A. F., Zwa I, R.F.A., var Deenen, L.L.M., Roelofsen, B. (1985)

J. C1in. Invest. $75,183-189$.

14 Davies, G.E., Palek, J. (1982) Blood 59, 502-513.

15 Bosia, A., Spangenberg, P., Lösche, W. Arese, P. Ti11, 0. (1983) Thromb. Res. 30, 137-142.

16 White, G.C. (1980) Biochim. Biophys. Acta 631, 130-138.

17 Megowan, E.B., Yeo, K.-T., Detwiler, T.C. (1.983) Arch. Biochem. Biophys. 227, 287-301.

18 Phillips, D.R., Jakabova, (1977) J. Biol. Chem. 252, 5602-5605.

19 Truglia, J.A., Stracher, A. (1981) Biochem. Biophys. Res. Comm. 100, 814-822.

20 Fox, J.E.B., Reynolds, C.C., Phillips, D.R. (1983) J. Biol: Chem. 258, 9973-9981.

21 Fox, J.E.B., Goll, D.E., Reynolds, C.C., Phillips, D.R. (1985) J. Biol. Chem. 260, 1060-1066.

22 Adelstein, R. S., Pollard, T.D., Kueh1, W.M. (1971) Proc. Nat1. Acad. Soi. USA 68, 2703-2707.

23 Zwaal, R.F.A., Comfurius, P., Bevers, E.M., Hemker, H.C. (1984) Heemostasis 14, 320-324.

24 Fox, J.E.B., Phillips, D.R. (1983) Semin. Hematol, 20, 243-260.

25 Weiss, H.J., Vicio, W.J., Lages, B.A., Rogerg, J. (1979) Am. J. Med. 67, 206-213.

26 Rosing, J., Bevers, E.M., Comfurius, P., Hemker, H.C., van Dieijer, G., Weiss, H.J., Zwaal, R. F.A. (1985) Blood $65,1557-1561$.

27 Raval, P.J., Allan, D. (1984) Biochim. Biophys. Acta 772, $192-196$.

28 Van Deanen, L. L.M. (1981) FEBS Letters 123, 3-15.

29 Comfurius, $\mathrm{P}$. Bevers, $\mathbb{E} . \mathrm{M} .$, Zwael, R.F.A. (1983) Biochem. Biophys. Res. Comm. 117, 803-808.

(This thesis, chapter 6).

30 Dressler, V. Haest, C.W.M., Plasa, G., Deuticke, B., Erusalimski, J.D. (1984)

Bioohim. Biophys. Acte 775, 189-196.

31. Laemmli. U.K. (1970) Nature $227,680-685$.

32 Rosenberg, S., Stracher, A., Lucas, R. C. (1981) J. Cell. Biol. 91, 201-211. 
INTERACTION BETWEEN PHOSPHAT IDYLSER INE" AND

ISOLATED CYTOSKELETON OF HUMAN BLOOD PLATELETS.

\section{Sumary.}

Binding experiments were performed to demonstrate a direct interaction between cytoskeletons from human blood platelets and phosphatidylserine. A centrifugation technique employing radiolabeled phosphatidylserine-vesicles and Triton $X-100$ insoluble residues from unstimulated human platelets was used to assess the binding. Interaction between cytoskeleton and phospholipid is demonstrated to be specific for phosphatidylserine. No binding was observed for phosphatidylcholine. The binding of phosphatidylserine was saturable and dependent on the concentration of cytoskeleton used. "The interaction between phosphatidylserine and the cytoskele ton appeared to be completely reversible.

The existence of a reversible and specific interaction between phosphatidylserine and the cytoskeleton of unstimulated platelets would suggest a role for the cytoskeleton in the maintenance of the asymmetric distribution of this lipid in the plasma membrane. We have previously shown (Comfurius et a1. Biochim. Biophys. Acta 815, 143-148) that in activated platelets a stfong correlation exists between degradation of platelet cytoskeletal proteins by the endogenous aliciumdependent protease (calpain) and exposure of phosphatidylserine at their outer surface. Nevertheless, hydrolysis of the isolated cytoskeletion by calpain did not result in change in the parameters of the binding between phosphatidylserine and cytoskeleton. Also, sulfhydry 1 oxidation of the cytoskeleton by diamide did not affect its binding properties for phosphatidylser ine, in spite of the fact that diamide treatment of platelets results in exposure of phosphatidylserine at the outer surface.

Exposition of phosphatidylserine upon activation of platelets cannot be directly ascribed to a change in affinity or number of binding sites of the modified cytoskeleton as measured in model systems. However, it cannot be excluded that topological rearrangements of the cytoskeleton as occur within the cell during platelet activation lead to a decreased contact between cytoskeleton and 11pid, irrespective of the binding parameters. 
Introduction.

The existence of transbilayer asymmetry of phospholipids in the plasma membrane of different cells is well established [tor a review see Ref. 1]. This asymmet$r$ ic distribution leads to an outer monolayer of the plasma membrane enciched in phosphatidylcholine (PC) and sphingomyelin and an inner monolayer containing the majority of phosphatidylethanolamine and virtually all phosphatidylserine (PS). The ability of platelets to expose PS at their outer surface upon activation, is related to their function in blood coagulation [2]. In particular, the rates of two sequential enzymatic reactions of the coagulation cascade (the conversion of factor $X$ into $X a$ and the formation of thrombin from its precursor prathrombin) are greatly enhanced by the avilability of negatively charged phospholipid surface containing PS [3].

With respect to the mechanisms responsible for maintaining the agymetric lipid distribution, attention has been focussed on the possibility of a direct interaction between phospholipids and proteins present in the cell interior. In the cytoplasm of cells a protein network is present, referred to as the cytoskeleton, part of which is located near the plasma membrane [for recent reviews see Refis. 4-71. Since 1977 several studies on human exythrocytes have indicated the existence of an interaction between phospholipids and components of the cytoskeleton [8-15]. Furthermore, Haest et al. [16] and Franck et al. [17] showed that treatment of erythrocytes with the sH-oxidizing agent diamide, which causes extensive crosslinking of cytoskeletal proteins, leads to an enhanced transbilayer movement of phospholipids. In erythrocytes from patients with sickle cell anaemia, polymerization of haemoglobin during deoxygenation is thought to induce a mechanical decoupling between nembrane and cytoskeleton [18], resulting in an enhanced rate of

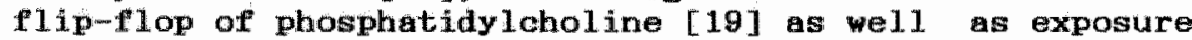
of PS at their outer surface. The latter is most manifest in isolated membrane vesicles that are pinched off from protrusions of the cell body during reversible sickling [18]. Also after treatment of platelets with dilauroy lecithin, formation of right-side out membrane vesicles is observed, exposing PS at their outer surface [20]. These vegicles appeared to be essentially devoid of high molecular weight cytoskeletal proteins, spectrin for erythrocyte- and myosin for platelet derived vesicles respectively. For intact platelets we found a striking correlation between modification of the cytoskeleton and exposure of PS at the outer surface of the plasma membrane. Pransbilayer phospholipid asymmetry as measured using phospholipases, is rapidly lost upon stimulation by certain platelet agonists [21]. This reorganization of phospholipids is strictly correllated with the breakdown of cytoskeletal proteins by the endogenous $\mathrm{Ca}^{2 *-d e p e n d e n t}$ protease (ca]pain) [22-24]. 
The aim of the present study was to investigate whether direct interactions between phosphatidy Iserine and the cytoskeleton of unstimulated platelets can be demonstrated and to what extent modifications of the oytoskeleton as induced by calpain or diamide can be held responsible for a reorganization of the lipids in the plasma membrane upon platelet activation.

Materials and Methods.

1,2-dioleoylphosphatidyl-[14 C]-serine (1.11 $\mathrm{GBq} / \mathrm{mmol})$ and 1,2-dipalmitoylphosphatidy $1-[14 \mathrm{C}]$-choline $\quad(3.7$ GBq/mmol) were obtained from Amersham International $U . K$. . Phosphatidylserine was purified from brain extract type III (Sigma) using CN-cellulose column chromatography as described before [25]. Ege yolk phosphatidyloholine (Sigma) was used without further purification. Platelet calpain (calcium-dependent protease, $\mathbb{E C} 3.4 .22 .17$ ) was partially purified according to Fox (26). Ficoll was from Pharmacia Fine Chemicals. Diamide (azodicarboxylic acid bis[dimethylamide]) and HEPES (4-(2-hydroxyethyl)-1-piperazine ethanesulfonic acid) were obtained from siema Chemical Co.. A11 other reagents were of the highest grade commercially available.

Isolation of platelets.

Blood was collected from hoalthy volunteers. ACD was used as anticoagulant $(0.052 \mathrm{M}$ citric acid, $0.08 \mathrm{M}$ triso diumcitrate, $0.183 \mathrm{M}$ sucose, 1 part ACD for 5 parts of blood). Platelet rich plasma (PRP) was obtained by centrifugation at $150 \mathrm{~g}$ for 15 win. After addition of $2 \%$ $(v / v)$ of ACD to the PRP, "platelets were sedimented by centrifugation at $750 \mathrm{~g}$ for 15 min. "The platelet pellet was washed twice in Hepes buffer $\mathrm{pH} 6.6(136 \mathrm{mM} \mathrm{NaCl}, 2.7 \mathrm{mM}$ $\mathrm{KCl}$, $2 \mathrm{mM} \mathrm{MgCl}, 10 \mathrm{mM}$ HEPES, $5 \mathrm{mM}$ eluoose and $0.5 \mathrm{mg} / \mathrm{ml}$ fatty acid free human serum albumin). Before each centrifugation $5 \%(v / v) A C D$ was added to prevent ags regation during sedimentation. Finally the platelets were resuspended in Hepes buffer pH 7.4 and the count was adjusted to $2.5 * 10^{\circ} / \mathrm{ml}$ using a coulter counter.

Preparation of cytoskeletons.

Platelet cytoskeletons were essentially prepared as described by Fox [26]. Briefly, washed platelets were cooled on ice and made $10 \mathrm{mM}$ in EDTA. After addition of Triton $X-100$ to a final concentration of $1 \%(w / v)$ the suspension was stirred on ice for 30 minutes. Cytoskeletons were collected by ultracentrifugation ( $4^{\mathrm{m}} \mathrm{C}$, $30 \mathrm{~min}$., $100,000 g)$. Pellets were washed once with $1 \%$ (w/v) Triton in buffer $A(136 \mathrm{mM} \mathrm{NaCl}, 2.7 \mathrm{mM} \mathrm{KCl}, 10 \mathrm{mM}$ HEPES, $1 \mathrm{mM}$ EDTA, pH 7.4). Another two washes with buffer A followed to remove the Triton. Finally the preparation was resuspended in buffer A in half the volume of the original platelet suspension. The preparation was sonicated until homogeneous by visual inspection. This suspension is arbitrarily set to contain $5 * 10^{\circ}$ cytoskeletons per m1 based on the 
assumption that one cytoskeleton is isolated from each pilatelet.

Preperation of phospholipid vesicles.

Phospholipid vesioles were prepared by direct probe sonication at room temperature in buffer $A$ at a concentration of $500 \mathrm{\mu M}$. Labeled species were added before sonication in concentration of $37 \mathrm{kBq}$ per jmole of total 1ipid. After sonication the suspension was centrifuged for 30 min. at $100,000 \mathrm{~g}$ (room temperature). Lipid concentration in the supernatant was determined as phosphorous [27].

\section{Bindina assay.}

It appeared that after preparing phospholipid vesicles by sonication, it was not possible to obtain a non-sedimentable fraction by taking the supernatent of a pre-centrifuged sample. Also from that supernatant a substantial fraction (20-40\%) was sedimented under the experimental conditions. Centrifugation of sonicated vesicles for 30 win. at $100,000 \mathrm{~g}$ in buffer $\mathrm{A}$ induces a phaspholipid cradient in the tube, resulting in about $80 \%$ of the 1 ipid being present in the bottom $20 \%$ of the tube. Increasing the density of the medium to $1.035 \mathrm{~g} / \mathrm{ml}(10 \% \mathrm{w} / \mathrm{v}$ Ficoll) results in a completely even distribution of the vesicles over the length of the tube. Centrifugation of cytoskeletion in 10\% Ficoll resulted in essentially complete sedimentation (more than 95\%) of the cytoskeletal proteins.

Binding experiments were carried out using a Beckmann TL-100 ultracentrifuge equipped with a rotor for $200 \mathrm{Hl}$ tubes. In capped incubation vessels the desired dilutions of phospholipid and cytoskeletons were mixed by vortexing with $25 \%$ solution $(w / v)$ of Ficoll in buffer $A$, suffieient to reach a final concentration of Ficoll of $10 \%$ $(w / v)$. After incubation for 30 min. at room temperature $200 \mu 1$ of the mixture was transferred to a centrifuge tube and spun for 30 min. at $100,000 \mathrm{~g}$. To assess the unbound fraction of phospholipid $100 \mathrm{H}$ of the supernatant is transferred to a vial for liquid sointillation courting. 
Results and discussion.

Cytoskeleton of unstimulated platelets is able to bind PS in a concentration dependent manner. The fraction of bound lipid as a function of the concentration of cytoskeleton is shown in Fig. 1 .
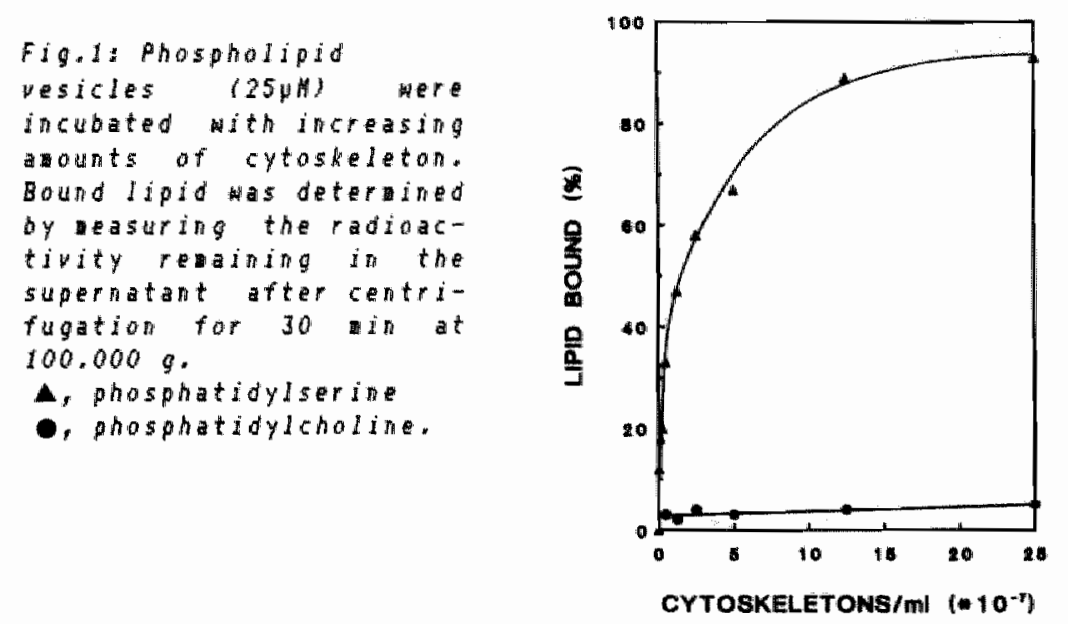

Binding is specific for PS compared to PC-vesicles which do not bind over the whole range of cytoskeleton concentrations tested.

Fig.2: Cytoskeleton in to concentrations as incubated with different concentrations of phosphatidylserine westeles. The concentration of bound lipid was neasured as described in Fig.l.

- $5 * 10^{\circ} \mathrm{cytask} .1 \mathrm{i}$

A, s*107 oytosk./mi.

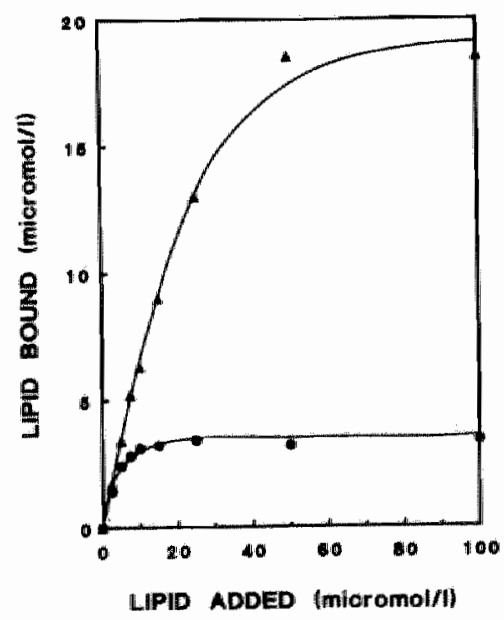


The binding curves obtained using two concentrations of cytoskeleton and variable amounts of lipid are shown in Fig. 2, demonstrating that binding is saturable, which strongly suggests that aspecific sedimentation of lipid ia negligible. When ${ }^{4} \mathrm{C}-\mathrm{PS}$ in PS-vesicles is replaced by 4.-PC the same binding curve is obtained. Replacing 14C-PC in PC-vesicles by ${ }^{14} \mathrm{C}-\mathrm{PS}$ also does not affect the binding, i.e. no binding is observed. This indicates that binding involves intact vesicles, rather than monomexic 1ipid. Since the cytoskeletal preparation consists of a mixture of proteins and since it is unclear how many 1 ipid molecules of a vesicle actually participate in binding, no attempt was made to transilate the data into an apparent $\mathrm{Kd}$ or number of binding sites".

The reversibility of the binding of $P S$ is shown in Fis. 3. When 10 MN labeled phospholipid is preincubated with cytoskeleton $\left(5 * 10^{*} / \mathrm{ml}\right)$ for $30^{*}$, about $65 \%$ of the labeled lipid can be sedimented. Addition of increasing amounts of non-1abeled PS to this mixture results in progressive displacement of label from the cytoskeleton.

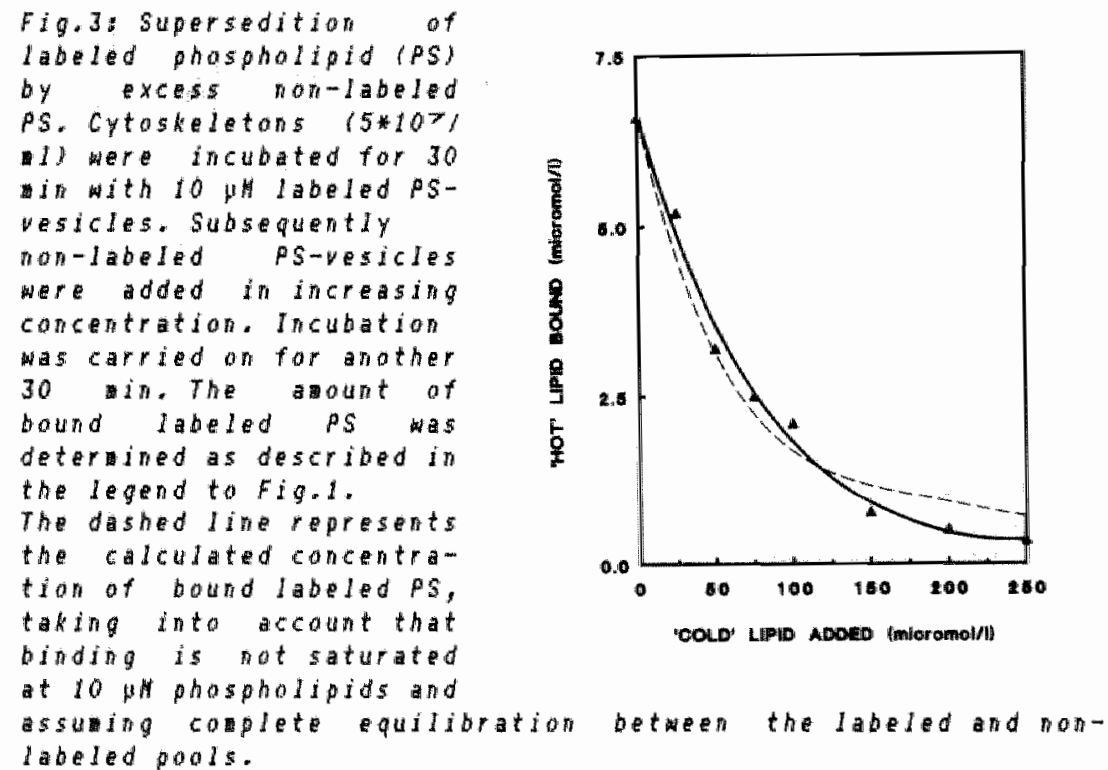

However, if non-labeled PC is used, no change in the amount of bound PS is observed (not shown). Since addition of $10 \mathrm{\mu M}$ of lipid is not saturating for this amount of cytoskeleton (see $\mathbb{F i g} .2$ ), addition of extra non-1abeled PS will, apart from displacing labeled $P S_{\text {, also occupy }}$ residual free binding sites. Taking this into account, one can calcullate the amount of label which should be replaced by non-labeled species, assuming complete equilibration of labeled and non-labeled pools. Comparing the two lines in Fig. 3 (the dashed line representing the calculated 
displacement of labely shows that virtually all labeled PS equilibrates with added non-labeled PS, demonstrating the complete reversibility of the bindine.

Previously we have shown that PS-exposure at the outer surface of activated platelets is strictly correlated with modification of the cytoskeleton $[20,22-24]$. Conditions leading to exposure of PS appeared to involve degradation of cytoskeletal proteins by endogenous calpain, which becomes activated by a considerable rise in intracellular $\mathrm{Ca}^{2+}$-concentration as for instance effected by Ca-ionophore or stimulation by the combined action of collagen plus thrombin. Moreover, when platelets are made permeable for leupeptin, a specific inhibitor of calpain, activity of this protease was diminished during platelet activation in parallel with a lower amount of PS becoming exposed at the platelet outer surface [24]. Furthermore, intracellular modification of cytoskeleton by means of the sulfhydryl oxidizing compound diamide also results in exposure of PS at the platelet outer surface [21].

Isolated cytoskeleton from unstimulated human platelets was treated with calpain or diamide to study the effect of these treatments on the PS binding properties of the cytoskeletion.

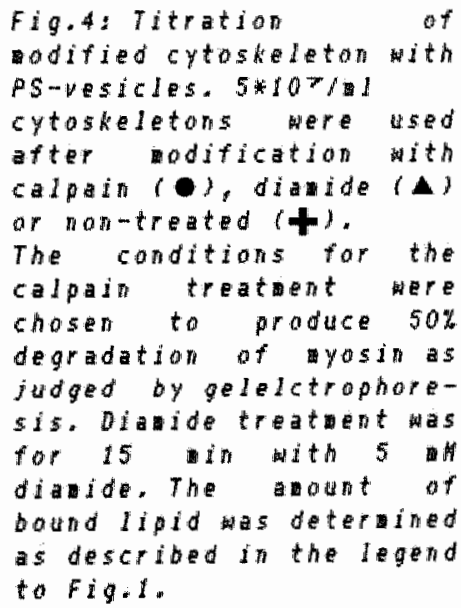

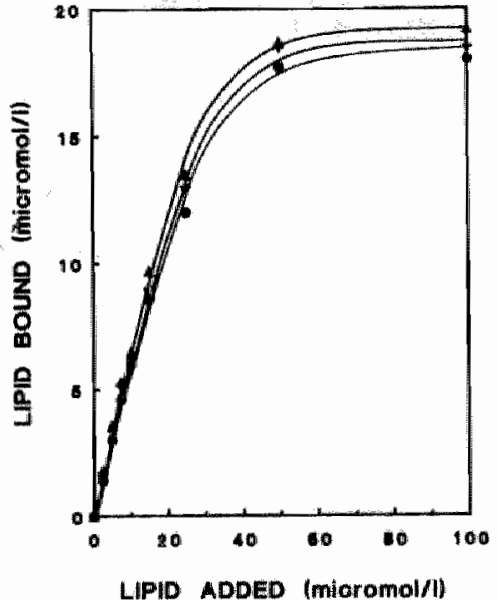

LIPID ADDED (mioromol/l)

To enable detection of either a change in affinity or a decrease in the number of binding sites, a lipid titration was carried out at a fixed concentration of cytoskeletion. However, though the protein degradation by calpain as we1. as the crosslinking by diamide could be confirmed by gelelectrophoresis (not shown), no change in binding characteristics of PS could be observed (FIE. 4).

This indicates that rlip-flop of PS during stimulation of the platelet cannot be the consequence of loss of 
PS-binding capacity of the cytoskeleton after modification, as measured in model systems. However, the present results do not exclude possible role of the cytoskeleton in the regulation of PS asymmetry within the cell. At least two possibilities rewain:

i. Loss of affinity for PS only occurs during modification of the oytoskelieton. Although this cannot be approached by the present technique, experiments described recently by Verhallea [28] seem to support this notion. Based on observations using the fluorescent membrane probe trimethy lamoon ium dipheny lhexatriene (TMA-DPH) it was shown that the occurence of fast flip-flop is restricted to the timeperiod during which calpain is active and cytoskeletal proteins are in the process of being descaded.

ii. Modification of the cytoskeleton in intact platelets induces a change in its three-dimensional structure resulting in a mechanical decoupling of membrane and cytoskeleton, irrespective of a pottential affinity for PS. Such a phenomenon was demonstrated by Spangenberg et al. [29] who showed that upon treating platelets with diamide, crosslinking of proteins leads to a contraction of the cytoskeleton, thereby beoming concentrated in the center of the cell.

Another possible mechanism involved in maintaining the asymmetric disribution of $P S$ is the presence of a transporting system (transiocase), specific for aminophospho1ipids, as was demonstrated in erythrocytes by Seigneuret and Devaux [30]. The existence of a phospholipid translocase in erythrocytes was 1 ater confirmed [31-35] and was also shown to be present in other cells, including platelets [36-38]. This mechanism, thought to consist of a protein, is capable of transporting exogenously added aminophospholipids from the outer to the inner monolayer of a plasma membrane. The process was shown to be ATP-dependent and sensitive to sulfhydryl oxidizing agents. Recently we obtained evidence [39] that the translocase present in human platelet plasma membranes is also capable of transporting endogenous PS -exposed at the platelet outer surface as a mesult of an activation procedure-back to the inner leaflet of the membrane.

Both the experiments showing the existence of an aminophospholipid translocating entity and the present observation that an interaction between $P S$ and cytoskeletal proteins oould be present in intact platelets, are consistent with the model proposed by williamson et al. [40]. On theoretical grounds they reach the conclusion that maintenance of the asymmetric distribution of phospholipids can best be explained by the action of a translocase, in conjunction with a direct interaction between PS and cytoskeleton, reducing the amount of free lipid being avilable for spontaneous transbilayer movement.

However, the rapid transbilayer movement of phosphatidylserine as acours during pllatelet activation is not directly related to a change in the binding parameters of 
the PS-cytoskeleton interaction after modifloation of the cytoskeleton. This transbilayer movement is not restricted to PS alone, but involves the other phospholipids as well [21]. Therefore, it cannot be excluded that this prooess is caused by gross structural rearrangements of both membrane and cytoskeleton, in which potential interactions between PS and cytoskeletal proteins are only of secondary importance.

\section{References.}

1 Op den Kamp, J.A.F. (1979)

Ann. Rev. Biochem. 48, 47-71.

2 Zwarl, R.F.A. (1978)

Biochim. biophys. Acta 515, 163-205.

3 Rosing, J., van Rijn, J.L.M.L., Bevers, E.M., van Dieijen, G., Comfurius, P., Zwaal, R. F. A. (1985) Blood 65, 319-332.

4 Geiger, B. (1983) Biochim. Biophys. Aota 737, 305-341.

5 Bennett, V. (1985) Ann. Rev, Biochem. 54, 273-304.

6 Weber, K., Osborme, M. (1985)

Seient. Amer. 253, 92-102.

7 Nigeli, V., Burger, M.M. (1987) J. Membr. Bio1. 100, 97-121.

8 Mombers, C., Verkleij, A.J., de Gier, J., van Deener; L. L.M. (1979) Biochim. Biophys. Aota 551, 271-281.

9 Mombers, C., de Gier, J., Demel, R.A., var Deenen, L. L. M. (1980) Biochim. Biophys. Acta 603, 52-62.

10 Sato, S. B., Ohnishi, S. (1983)

Eur. J. Biochem. 130, 19-25.

11 Maksymiw, R., Sui, S. F., Gaub, H., Sackmann, E. (1986) Biochemistry 26, 2983-2990.

12 Rybicki, A. C., Heath, B., Lubin, B., Schwartz, R. S. (1988) J. Clin. Invest. 81, 255-260.

13 Cohen, A.M., Liu, S.-C. "Derick, L.H. "Palek, J. (1986) Blood 68, 920-926.

14 Cohen, A.M., Liu, S.-C. "Lawler, J., Deriok, L.H., Palek, J. (1988) Biochemistry 27, 614-619.

15 Williamsor, P., Bateman, J, Kozerzky, K. Mattooks, K. Hermanowicz, N., Choe, H. - R., Bohlegel, R. A. (1982) Cel1. $30,725-733$.

16 Haest, C.W.M., Kanp, D., Plasa, G., Deuticke, B. (1977) Biochim. Biophys. Acta 469, 226-230.

17 Franck, P.F.H., Op den Kamp, J.A.F., Roelofgen, B., var Deenen, L. L.M. (1986)

Biochim. Biophys. Acta $857,127-130$.

18 Franck, P.F.H., Bevers, E.M., Lubin, B., Comfurius, P., Chiu, D.T.-Y., Op den Kamp, J.A.F., Zwa.l, R.F.A., van Deenen, L.L.M., Roelofsen, B. (1985) J. Clin. Invest. 75, 183-190.

19 Franck, P.F.H., Chiu, D.T. - Y. Op den Kamp, J.A.F., Lubin. B., wan Deenen, L.L.M., Roelofsen, B. (1983) J. Biol. Chem. 258, 8435-8442. 
20 Berera, E.M., Verhallen, P.F.J., Linskens, M. M. A., Comfurius, P., Zwaal, R.F.A. (1987)

Biochin. Biophys. Acta 903, 197-205.

21 Bever, E.M., Comfurius, P., Zwaal, R.F.A. (1983) Biodtuin. Biophys. Acta 736, 57-86.

(This thess, chapter 4 ).

22 Comfurius, P., Bevers, E.M., Zwaal, R.F.A. (1985) Biochin. Biophys. Aota 815, 143-148.

(this thesis, chapter 7 ).

23 Verbalien, P.F.J., Bevers, E.M., Comfurius, P., Zweal, R. F.A. (1987) Biochim. Biophys. Acta 903, 206-217.

24 Verballen, P.F.J., Bevers, E.M., Comfurius, P., Zwaal, R.F.A. (1988) Biochim. Biophys. Acta 942, 150-158.

25 Comfurius, P., Zwaal, R.F.A. (1977) Nature $268,358-360$. (This thesis, chapter 1 ).

26 Fox, J.E. B. (1985) J. Clin. Invest. $76,1673-1683$.

27 Bottoher, C.J.F., van Gent, C.M., Pries, C. (1961) Ana1. Chin. Acta 24, 203-205.

28 Verbellen, P.F.J. (1968)

PhD thesis, University of Limburg, The Netherlands.

29 Spangenberg, P., Til1, 0., Gschmeissner, S., Crawford, N. $(1987)$ Br. J. Haematol. $67,443-450$.

30 seigneuret, M., Devaux, P.F. (1984)

Proc. Nat1. Acad. Soi. USA $81,3751-3755$.

31 Daleke, D.L., Huestis, W.H. (1985)

Biochemistry $24,5406-5416$.

32 Tilley, L., Cribier, S., Roelofsen, B., Op den Kamp, J.A. D., van Deenen, L.L.M. (1986)

FEBS Letters 194, 21-27.

33 Schroit, A.J., Madsen, J. (1987)

Biochemistry 26, $1812-1819$.

34 Zachowski, A., Fel lmann, P., Herve, P., Devaux, P.F. (1987) FEBS Letters 223, 315-320.

35 Connor, J., Schroit, A.J. (1988)

Biochemistry $27,848-851$.

36 Zachowski, A., Herrmann, A., Paraf, A., Devaux, P.F. (1987) Biochim. Biophys. Acta 897, 197-200.

37 Sune, A., Bette-Bobil1o, P., Bienvenue, A., Fellmann, P., Devaux, P.F. (1987)

Bioohemistry 26, 2972-2978.

38 Martin, O.C., Pagano, R. E. (1987)

J. Biol. Chern. 262, 5890-5898.

39 Bevers, E.M., Tilly, R., Senden, J., Comfurius, $P_{\text {, * }}$ Zwat, R.F.A. (1989) Biochemistry, 28, 2382-2387.

40 Williamson, P., Antia, R., Sohlegel, R. A. (1987) FEBS Letterg $219,316-320$. 


\section{GEnEr $=1$ di}

It 111 be clear from the contents of this thesis that the present ideas about regulation of phospholipid asymmetry have been developed during the last ten years. In 1977 , little was known about spontaneous or indueed flip-flop in natural and artificial phospholipid mem branes. At thet time, transbilayer movement of phospholipids was considered to be a very unlikely event, occurring with half-times in the order of several days in lipid vesicles $[1,2]$, to severa $]$ hours in intact erythrocytes [3-5]. In fact, the very concept that phospholipids have an asymmetric distribution in biological membranes was not postulated until the early seventies, namely by Bretscher $[6,7]$. Since then, this membrane phospholipid asymetry has been demonstrated in a wide variety of cells using different techniques whereby one or both membrane sides were reacted with group-specific reagents, lipid transfer proteins or phospholipases (for reviews, see Refis. 8 and 9). Both for erythrocytes $[10,11]$ and platelets $[12-14]$ it was shown that the membrane asymmetry is most pronounced in case of sphingomyelin and $P S$, which are mainly confined to the outer and inner leaflets of the membrane respectively. The other two major lipids, PC and

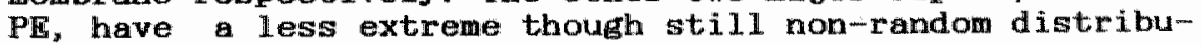
tion over both halves of the membrane.

A physiological role for the asymmetric distribution of membrane phospholipids was postulated by Zwaal $[15,16]$. based on the catalytic properties of negatively charged phospholipids in blood coagulation. It was proposed that platelets, by exposing a surface containing negatively charged phospholipids during cell activation in reponse to vascular injury, can play a role in the regulation of coagulation. Localization of negatively charged (procoagulant) PS in the inner membrane leaflet of unstimulated platelets thus is essential in preventing untimely acoeleration of clotting reactions. Obviously, this applies to all blood cells and cells lining the vessel wal1. Indeed, comparing intact cells with completely lysed preparations on their ability to stimulate the rate of thrombin formation; it was shown that not only erythrocytes and platelets, but also intact leukocytes and endothelial cells, are virtually devoid of catalytic potency [17], which implies a similar asymmetric distribution of PS in all these cells.

Apart from the role lipid asymmetry plays in refulating haemostasis, it has also been suggested that it is instrumental in the removal of cells from the circulation. It was shown that enhanced binding of erythrocytes to endothelial cells [18] and recogaition by macrophages $[19,20]$, correlates with surface exposure of PS in erythrocytes. These cells are, therefore, rapidly cleared from the circulation [21]. Those erythrocytes which bind to endothelial cells also demonstrate binding of the anionic fluorescent dye Merocyanine 540 . This dye was 
found to be a reporter of decreased packing density in phospholipid bilayers [22]. It also binds strongly to fluid-phase lipid vesicles, but much less avidly to gel-phase vesicles. Based on the premise that packing densty is decreased when wembrane asymmetry is last [23], binding of this probe has been used to test several aspects of phospholipid asymmetry. For instance, it was show that in lymphocytes the asymetric distribution of liplds develops during maturation of the cells. Mouse thymocytes were able to bind Merocyanine 540 (MC540), indicating loosely packed outer monolayer, while mature cells which enter the eirculation were unable to bind MC540 [24]. This sugests a reorganization in the lipid distribution over the plasma membrane, leading to more tightly packed auter monolayer in mature cells (in a state consisting primarily of PC and Sph). Also, erythroid precursor cells and cells transformed to a leukemic pheaotype by viral infection, arresting them at the proerythroblast stage, were able to bind MC540 [25]. The suggestion that membrane lipid asymmetry is not yet completely established in immature cells was confirmed by the work of Rawylar et al. using phospholipases $[26,27]$. They found a partial asymmetry to occur in erythroid precursor cells, with $P E$ and $P C$ still being randomly distributed over the membrane, although $\mathrm{PS}$ and Sph are already mainly present in the leaflet to which they are confined in the mature erythrocyte. In addition to these studies showing generation of lipid asymmetry during cellular maturation, also changes in membrane lipid distribution resulting in loss of lipid asymmetry were assessed using MC540 (vide infra).

At present, transbilayer movement of lipids (flipflop), which for a long time has been considered to be a rare phenomenon, is thought to occur at considerably increased rates whenever the regular bilayer structure is distorted [28]. Among the processes implicated in the acouleration of flip-flop in artificial lipid vesicles are insertion of transmembrane proteins [29], gel to liquidcrystaline phase transition [30], difference in surface pressure between the two monolayers [31] and formation af non-bilayer structures [32]. These non-bilayer structures car be formed when lipids are present that have a corlot molecular shape, i.e. a small polar head group relative to the oross-section of the acyl chains, such as didiyceride, phosphatidic acid, cardiolipin and unsaturated PF. Instead of bilayer structures these lipids tend to form hexagonal phases, the smallest unit of such structure being the intrabilayer inverted micel]e [32]. In these inverted micelles, the lipids experience fast isotropic motion, which can readily be detected by ${ }^{1} \mathrm{P}$ NMR. Also by means of freeze-fracture electron microscopy these structures can be visualized as lipidic particles [33]. Inverted micelles are thought to be involved in both enhanced transbilayer movement of lipids and fusion processes as occur in endo- and exocytosis 
[28]. For platelets [34] and also for erythrocytes [35], it has been shown that geveration of diglycerides in the outer monolayer of the membrame by treatment ith exogenously added phospholipase C from C. welchil leads to subsequent formation of phosphatidic acid. Conversion of diglyceride to phosphatidic acid is carried out by the enzyme diglyceride kinase in the presence of ATP. Since both this enzyme and ATP are only present in the cell interior, the formation of phosphatidic acid suggests that flip-flop of diglycorides must have taken place. It hav been demonstrated [36] that enhanced flip-flop is not restricted to dielycerides, since both in platelets and in erythrocytes treatment with phospholipase C from C. welchii induces exposure of PS at the outer surface of the plasma membrane as well.

Enhanced flip-flop of phospholipids not directly connected with formation of non-bilayer structures has been observed under several conditions. For erythrocytes it has been suggested that treatment with the sH-oxidiaine agent diamide leads to altered membrane asymmetry asi detected by availability of the lipids for exofenous phospholipases [37]. However, it has been found [38] that diamide treatment causes destabilization of the bilayer rather than a stationary change in phospholipid distribution. This is indicated by an enhanced flip-flop rate of PC $[39,40]$, as wel1 as by increased binding of MC540 [41]. suggesting a wore disordered membrane. "The observation that nembrane destabilization by SH-oxidizing agents is accompanied by sulfhydryl oxidation of the cytoskeletal protein spectrin led to the proposal [42] that the cytoskeleton might be involved in the regulation of membrane phospholipid asymmetry. This concept was supported by the findings of Mombers et al. [43,44] who demonstrated interaction between PS and spectrin by studying the effect of spectrin on the phase transition of lipid vesicles and the penetration of spectrin into lipid monolayers. In ultrastructural studies [45] and a study employing differential scanning calorimetry, monolayers and microfluorescence [46], the interaction between spectrin and PS was confirmed. However, not only spectirin, but also other proteins of cytoskeletal oritin were found to interact with phospholipid. The erythrocyte protein band 4.1 was proved to bind to PS vesioles through a centrifugation technique $[47,48]$, an interaction which appeared to be reduced upon phosphorylation of the protein [49]. Also a-actinin [50], profilactin [51] and vinculin [52] appeared to interact directly with phospholipids.

With platelets, further evidene for the possible involvement of the cytoskeleton in regulation of 1 ipid asymmetry can be obtained from experiments showing flip-flop of lipids upon modification of the oytoskeleton [53-55]. For example, activation of platelets by the combined action of collagen plus thrombin ox by the calcium-ionophore A23187 gives rise to surface exposure of PS. Concomitant with the flip-flop of PS, degradation of 
cytoskeletal proteins by calpain as observed [53]. The same phenomenon accurred hen platelets were treated ith local anaesthetics (dibucain or tetracain) [54] or with fluoride-ions [55]. In addition, studies with erythrocyten reveal increasing evidence that disturbances of the cytoskeleton can ive ise to enhanced flip-flop rates of phospholipids, if not to loss of phospholipid asymmetry $[41,56-59]$. These observations support the notion that cytoskeleton-lipid interactions play a role in the regulation of membrane 1 ipid asymetry.

Recently, another mechanism was discovered which supposedly plays an important role in the generation and regulation of membrane 1ipid asymmetry. In 1984, Seigneuret and Devaux [60] introduced spin-labeled phospholipids in erythrocytes and followed the fate of these molecules by measuring the amount of spin-label which could be reduced by external ascorbate. The non-reducible fraction likely represents the 1 ipids which have been translocated to the inner leaflet of the membrane. The transport of lipid from outer to inner monolayer was also assessed from shape changes occurring in the cells upon incorporation of exogenous 1 ipid. They showed that after incorporation of lipids the erythrocytes crenated immediately. When spin-labeled $P S$ or $P E$ was added, the initially formed echinocytes reversed their shape to discoid and even to stomatocytes, which can be taken to imply transport of material from the outer to the inner leaflet of the bilayer. This process was accompanied by a lower amount of spin-label that could be reduced from the outside. The inward transport of phospholipids inferred from these observationss was shown to be rather specific for aminophospholipids (with a preference for PS over PE) and to be dependent on the presence of hydrolyzable ATP.

The spin-labeled phospholipid analogues used in these studies contain a six-carbon acyl chain at the two-position to which a nitroxide group is attached and have the advantage of being readily incorporated in the membrane. A disadvantage may be the structural divergence from the native lipid molecules, induoing the risk of not truely reporting the transport properties of endofenous 1 ipid.

However, similar experiments were performed by other Hroups, using differently labeled phosphollipids. Tilley et a1. [61] incorporated radio-labeled long-chain phosphoLipids into erythrocytes by means of a transfer protein and used phospholipases to determine the fraction which remins aveilable for degradation at the exterior surface. The fate of incorporated 1ysophospholipids was measured by Bergmann et a1. [62]. Daleke and Huestis [63] used a range of phospholipids with different acyl chain length and recorded changes in erythrocyte morphology to assess the transport of the incorporated lipids. A11 these studies essentially confirmed the first observations with spinlabeled phosphalipids, i.e. an APP-dependent transport system for phospholipids is present, which selectively translocates PS and to a lesser extent PE from the outer 
to the inner leaflet of the red cell membrane. Further more, a transport system with the same characteristios was found in plasma membranes of other cells: lymphooytes [64], cultured fibroblasts [65] and platelets [66]. Apart from its ATP-dependence, this transport was also shown to be inhibited by modification of free sH-groups $[63,64,67$, 68] or by increase in cytosolic calcium concentration $[67,69]$. Also, competition between PS and PE for the same translocation site was demonstrated [67], as well as competition between stereoisomers [65]. These observations lead to the conclusion that this outward-inward translocase activity is produced by one or more membrane proteins and functions as lipid pump in the ceneration and maintenance of membrame phospholipid asymmetry.

A mechanistic mode1, adapted from Williamon et a1. [70] is depicted in Fig. 1, which in all cells could be responsible for the maintenance of the asymmetric distribution of phospholipids.

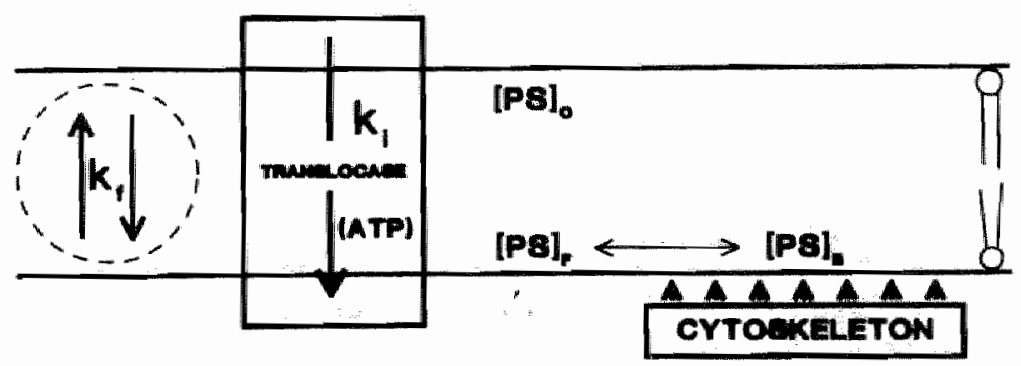

Fig.d Scheatic representation of involvenent of translacase and cytoskeleton in the alitenace of Ps asyuetry.

frow left to right the follawing processes are depleted. The dashed circle represents spontaneous filp-flop, occuritio with a $r$ ate constant $k$. Any Ps alectle which igrates to the outer vonolayer by spontaneas flip-flop is transported back the the inner monolayer through the action of the ATPudependent translocase. This transport is characterized by a rate constant $k_{*}$. The anount of PS avilable for spontaneous flip-flop is redaced by binding to the cytoskateton.

The ajor difference with the wodel as proposed by williason et a. [70] is that they propose a bidirectional flippase, both indard and outard transport accurping with the same rate constant.

This model takes into account direct interactions between amino-phospholipids and the cytoskeleton, well as the existence of an amino-phospholipid translocaste. The 
asymotic distribution of phospholipids in the plasma membrane of eelis is mantained by the action of the txakilocase. Any PS or, to a lesser extent, PE molecule which migrates by spontaneous flip-flop to the outer leaflet of the membrane is transported back to the inside at the expense of ATP hydrolysis. The amount of lipid experiencing this spontaneous flip-flop is restricted by interaction with cytoskeletal proteins; thereby reducing the amount of ATP needed to waintain asymmetry. The major differenes ith the theoreticel madel proposed by Williamwon is that we reject the need for autward transport to be ATp dependent, since any disturbance of the bilayer dlowing flip-flop implies (net) transport of asymmetrially distributed lipid species driven by the concentration gradient. It can be envisaged that inward transport of PS and PE is coupled to outward transport of Sph and PC, in ordex to maintain the balance of material between the two leaflets of the membrane.

Algo in resting platelets, the asymmetric distribution of the phospholipids is thought to be maintained by this mechanism. This view is supported by experiments demonstratine the existence of a translocase capable of transporting exogenously incorporated PS and PE to the inner leaflet $[66,71]$. Also endogenous PS, first exposed at the platelet outer surface as the result of activation, can be transported back to the inner leaflet of the merobrane [72]. Moreover, interaction of PS with the platelet cytoskeleton could be proved, in contrast to $P C$, which does not bind [73].

However, to explain the involvement of platelets in the hemostatic process, these mechanisms are of 1 imited use because they focuss on the maintainance of 1 ipid asymmetry and not on the reverse process that can occur during platelet activation. Platelets contribute to the formation of clot by becoming procoagulant, which involues exposure of $P S$ at their outer surface [15]. This is inextricably correlated with desradation of coytoskeletal) proteins by calpain [53-55]. In spite of this correlation, it was not possible to show any influence of either sulfhydryl oxidation or proteolytic digestion of the cytoskeletal proteins on their affinity for PS-vesicles in vitro [73]. This may exclude a possible role for a change in binding parameters in the process of PS-exposwre. However, involvement of topolofical rearrangements of the cytoskeleton ocourring within the platelets after activation cannot be excluded to play a role in PS exposure. The concept of involvement of the cytaskeletion other than by a change in the binding to PS is supported by experiments described by Verhallen [74]. Using the fluorescent membrane probe trimethylamonium-dipheny 1hexatriene (TMA-DPH), Verhallen showed that only during the period of time platelet oalpain is active accelerated tip-fiop of the probe is observed. In unstimulated platelets, the probe is transported to the inner leaflet of the membrane ith an apparent halftime of about 60-90 
minutes. However, if the translocation rate of the probe is measured during activation by a calcium-ionophore, the halftime is in the order of seconds rather than minutes, the whole process of fast flip-flop being conpleted win 30 seconds. This transient burst of flip-flop of the probe is inextricably correlated with the rapid breakdown of cytoskeletal proteins and exposure of PS. In this context, it may be worth mentioning that platelets from patiant buffering from a moderately severe bleeding disorder as described by Heiss et al. [75] showed a dininished breakdown of cytoskeletal protein upon stimulation by the combined action of collagen and thrombin [53], together with a decreased exposure of PS and a reduction of their potency to entance the formation of factor $\mathrm{Xa}$ and of thrombin $[76]$.

Based on the above correlations between modification of the cytaskeleton and the rate at which loss of lipid asymmetry can occur, and taking into account the model previously proposed by Verhallen [74], the followine mechanism is postulated for the platelets" ability to present a procoagulant surface at which clotting factors can interact (Fig. 2 ).

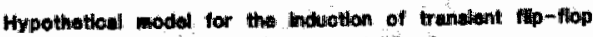

during ortodkeleton modtionaton.

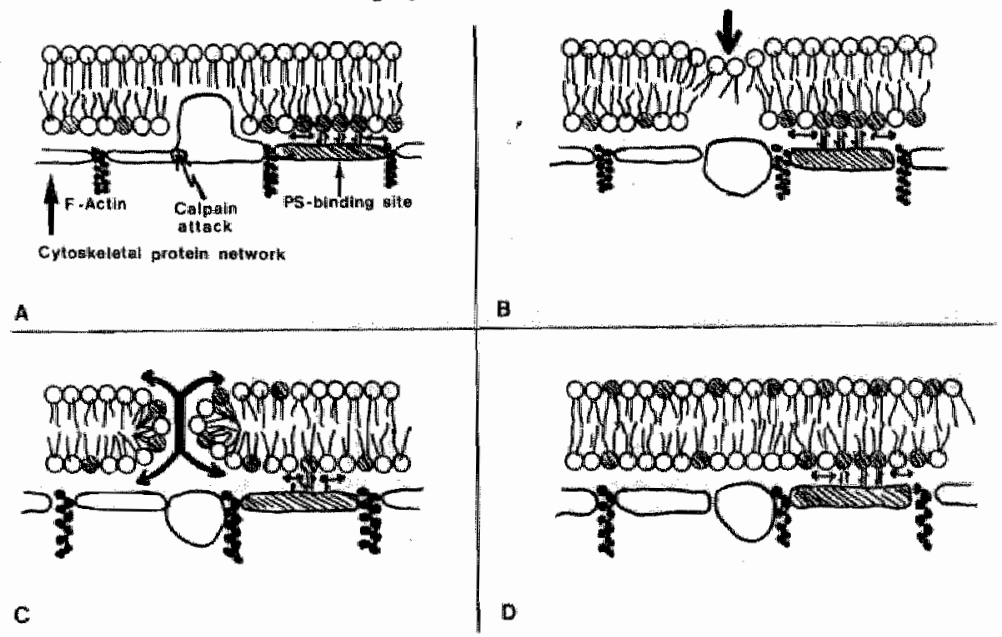

Fig.2: A hypothetical wodel is depicted of one of several possible mechanisus leading to foration of hydrophillc pore like structures. Via these pores the asyotric distribution of PS is last by diffusion, driven by the concentration oradient. ps alecules are reppesented by shaded circles. Further detalls are described in the text.

Intercalated between the lipids of the inner leaflet of 
the plasma nembrane is a bydrophobic part of a protein of the cytoskeleton (Fig. 2A). Removal of this peptide chain from its position by enzymatic degradation, by oxidative txeatment with diamide (shown to concentrate the cytoske1eton in the center of the cell [77]), or by asmotic swelling of the cell wembrane, will result in a difference in material present in both monollayers and hence, in a difference in lateral pressure between the two leaflets of the membrane (Fig. 2B). This condition is visualized to favour transilayer movement, possibly via non-bilayer structures [20,31]. As suggested earlier by Verhallen [74], the pressure difference is annihilated by formation of pore-11ke structure (Eig. 2C). Through these pores the available surface for lipid diffusion increases, which favours dissociation of lipids bound to protein. As a result, the lipids will dilute over the total area of surface available, producing a randomization of lipids over the two monolayers before closing of the pores when the pressure difference is terminated by net transport (Fic: 2D).

Although this is a highly speculative model, several aspects are prone to experimental verification. For instance, a protein which is intercalated in the interior leaflet of the membrane should be subject to labeling with hydrophobic photoafinity reagents, but only before stimulation of the platelet, not afterwards. Also, as already stated by Verhalien [74], the formation of pores in the bilayer during fast flip-flop could be detected as an increased permeability of the cells to uncharged polar solutes or small ions.

\section{References.}

1 de Kruijef, B., Wirtz, K. W. A. (1977)

Biochim. Biophys. Aota 468, 318-326.

2 Kormberg, R.J. MoConnel1, H. M. (1971)

Biochemistry 10, 1111-1120.

3 Renoo:j, W., var Golde, L.M.G. Zweal, R. F.A., Roelofsen, B. van Deenen, L.L.M. (1974)

Biochim. Blophys. Acta 363, 287-282.

4 Renooij, W., van Golde, L.M.G., Zwasi, R.F.A., van Deener, L.L.M. (1976) Eur. I. Bioohem. 61, 53-58.

5 Rousgelet, A., Guthmann, C., Matricon, I., Bienvenue, A., Devaux, P. F. (1976)

Biochim. Biophys. Acta 426, 357-371.

6 Bretscher, M.S. (1972) Nat. New Biol. 236, 11-12.

7 Bretscher, M.S. (1972) J. Mol. Biol. 71, 523-528.

8 Op dem Kamp, J.A.F. (1979)

Ann. Rev, Biochem, 48, 47-71.

9 Etemadi, A.H. (1980)

Biochim. Biophys. Acta 604, 423-475.

10 Gordesky, S. E. Marinetti, G.V., (1973)

Biochem. Biophys. Res. Comm. 50, 1027-1031. 
11 Verkleij, A.J., Zwal, R.F.A. "Roelofsen, B., Comfurius, P., Kastelijn, D., van Deenen, L.L.M. (1973) Biochim. Bioplyys. Acta 323, 178-193.

12 Schick, P.K. (1979) Sem. Hermatol, 16, 221-233.

13 Chap, H.J., Zwarl, R.F.A., van Deenen, L.L.M. (1977) Biochim. Biophys. Acta 467, 146-164.

14 Ferret, B., Chap, H.J., Douste-Blagy, L. (1979) Biochim. Biophys. Acta 556, 434-446.

15 Zwaal, R.F.A., Comfurius, P., war Deenen, L. L.M. (1977) Mature $268,358-360$. (This thesis, chapter 2 ).

16 Zwaal, R. F.A. (1978) Biochim. Biophys. Acta 515, 163-205.

17 Zwaal, R.F.A., Bevers, E.M. Comfurius, P. (1986) in "New Comprehensive Biochemistry, vol. 13, Blood Coagulation" (Zwaal, R.F.A., Hemker, H.C., eds.) pp. 141-169. Elsevier, Amsterdam.

18 Schlegel, R. A., Prendergast, T.W., Willimson, P. (1985) J. Cell. Physiol. 123, 215-218.

19 Tanaka, X. Sohroit, A.J. (1983)

J. Biol, Chem. 258, 11335-11343.

20 McEvoy, L., Williamson, P., Sohlegel, R. A. (1986) Proo. Natl. Acad. Soi. USA 83, 3311-3315.

21 Schroit, A.U., Madsen, J.W., Tanaka, Y. (1985) J. Biol. Chem. 260, 5131-5138.

22 Williamson, P., Mattocks, K., Soblege1, R.A. (1983) Biochin. Biophys. Aota 732, 387-393.

23 Lupu, F., Calb, M., Fixman, A. (1988)

Thromb. Res. 50, 605-616.

24 Del Buono, B.J., Nilliamson, P., Schlegel, R.A. (1986) J. Cell. Physiol. 126, 379-388.

25 Schlegel, R.A., Phelps, B.M. (1980) Cel1 20, 321-32R.

26 Rawyler, A., van der Schaft, P.H., Roelofsen, B., Op den Kamp, J.A.F. (1985) Biobhemistry 24, 1777-1793.

27 Van der Sohaft, P.H., Roelofsen, B., Op der Kamp, J.A.F., van Deenen. L.I.M. (1987)

Biochim. Biophys. Aota $900,103-115$.

28 van Deenen, L. L.M. (1981) FEBS Letters 123, 3-1.5.

29 de Kruijff, B., van Zoelen, E.J.J., Van Deenen; L.L.M. (1978) Biochim. Biophys. Acta 509, 537-542,

30 de Kruijff, B., van Zoelen, E.J.J. (1978)

Biochim. Biophys. Acta 511, 105-115.

31 de Kruijef, B., Wirtz, K.W.A. (1977)

Biochim. Biophys. Acta 468, 318-326.

32 Cullis, P.R., de Kruijff, B. (1979)

Biochim. Biophys, Aota 559, 399-420.

33 de Kruijff, B., Verkleij, A.J., van Echteld, C.J.A., Gerritsen, W.J. Momberg, C., Noordam, P.C., de Gier, J. (1979) Biochim. Biophys. Acta 555, 200-209.

34 Mauco, G., Chap, H., Douste-BIazy, L. (1978) Biochimie $60,653-661$.

35 Allan, B., Low, M.G., Fineen, J.B., Michel1, R. H. (1975) Biochim. Biophys. Acta 413,309-316.

36 Comfurius, $P_{*}$, Bevers, E.M., Zwaal, R. F. A. (1983) Biochem. Biophys. Res. Comm. 117, 803-808. (This thesis, chapter 6). 
37 Haest, C.W.M. Plasa, G., Kamp, B., Deuticke, B. (1878) Biochin. Biophys. Acta 509, 21-32.

98 Eranck, P.F.H., Op den Kamp, J.A.F., Roelofisen, B., van Deenen, L. L.M. (1986)

Biochin. Biophys. Acta $857,127-130$.

39 Frangk, P.F.H. Roelofisen, B., Op den Kamp, J.A.F. (1982) Biochim. Biophys. Acta 687, 105-108.

40 Toumois, H., Leunissen-Bijveit, J. Haest, C.W.M., de Ger, J., de Kruijff, B. (1987)

Biocheristry 26, 6613-6621.

41 Wiliamon, P., Bateman, J., Kozarsky, K. , Mattocks, K. Hermanowioz, N., Choe, H. -R., Sobleed, R. A. (1982) Ce11 $30,725-733$.

42 Haest, C.W. M. (1982)

Biochin, Biophys, Acts 694, 331-352.

43 Mombers, C., Verkleij, A.J., de Gier, J., van Deenen, L. L.M. (1979) Biochim. Biophys. Acta 551, 271-281.

44 Mombers, C., de Gier, J, Demel, R. A., van Deenen, L. L.M. (1980) Bipchim. Biophys. Acta 603, 52-62.

45 Cohen, A.M., Liu, S. - C., Derick, L.H., Palek, J. (1986) Blood 68, 920-926.

46 Maksymiw, R., Sui, S. - F., Gaub, H., Sackmann E. (1987) Biochemistry 26, 2983-2990.

47 Sato, S.B., Ohnishi, S. (1983)

Eur. J. Biochem. $130,19-25$.

48 Rybicki, A.C., Heath, R., Lubin, B., Sobwartz, R. S. (1988) J. C1in. Invest. 81, 255-260.

49 Eder, P.S., Soong, C. -J., Tao, M. (1986)

Biochenistry $25,1764-1770$.

50 Burn, P., Rotman, A., Meyer, R. K., Burger, M.M. (1985) Nature $314,468-472$.

51 L.

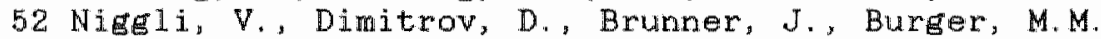
(1986) J. Biol. Chem. 261, 6912-6918.

53 Comfurius, P., Bevers, E.M., Zwaal, R.F.A. (1985) Biochim. Biophys. Acte 815, 143-148.

(This thesis, chapter 7).

54 Verhallen, P.F.J., Bevers, E.M., Comfurius, P., Zwal, R.F.A. (1987) Biookim. Biophys. Acta 903, 206-217.

55 Verballen, P.F.J., Bevers, E.M. Confurius, P., Zwat, R. F. A. (1988) Biochim. Biophys. Acts 942, 150-158.

56 Franck, P.F.H., Chiu, D.T. - Y., Op den Kanp, J.A.F., Lubin, B., van Deenen, L. L.M. (1983)

J. Biol, Chem, 258, 8435-8442.

57 Choe, H. - E., Willimson, P., Rubin, E., Sohlegel, R.A. (1985) Cell Biol. Int. Reports 8, 597-606.

58 Arduini, A., Chen, Z., Stern, A. (1986)

Biochim. Biophys. Aota $862,65-71$.

59 Choe, H. - R., Schlege1, R.A., Rubin, E, Williamson, P., Westeman, M. P. (1986) Br. J. Haematol. 63, 761-773.

60 Seigneuret, M. Devaux, P.F. (1984)

Froc. Nat1. Acad. Soi. USA 81, 3751-3755.

61 Tilley, L. , Cribier, S. "Roelofsen, B., Op der Kamp, J. A.F., van Deenen, L. L. M. (1986)

FEBS Letters 194, 21-27. 
62 Bergmanr, W. L. "Dress 1er, W., Haest, C. W. M., Deuticke. B. (1984) Biochim, Biophys. Acta 772, 328-336.

63 Daleke, D.L., Huestis, W.H. (1985)

Biochemistry 24,5406-5416.

64 Zachowski, A., Herrmann, A., Paraf, A., Devaux, P.F. (1987) Biochim. Biophys. Acta 897, 197-200.

65 Martin, O.C., Pagano, R.E. (1987)

J. Biol. Chem. 262, 5890-5898.

66 Sune, A., Bette-Bobi110, P., Bienvenue, A., Fell mann, F., Devaux, P.F. (1987) Biochemistry 26, 2972-2979.

67 Zachowski, A., Favre, E., Cribier, S., Hervé, P., Devaux, P.F. (1986) Biochemistry 25, 2585-2590.

68 Connor, J., Schroit, A.J. (1988)

Biochemistry 27, 848-851.

69 Bitbol, B. Fellmann, P., Zachowski, A., Devaux, P. . (1987) Biochim. Biophys. Acta 904, 268-282.

70 Williamson, P., Artia, R., Sohlegel, R. A. (1987) FEBS Letters 219, 316-320.

71 Sune, A. Bienvenue, A. (1988)

Biochemistry 27,6794-6800.

72 Bevers, E.M., Tilly, R.H., Senden, J.M.G., Comfurius, P., Zwaal, R.F.A. (1989) Biochenistry 28, 2382-2387.

73 Comfurius, P., Bevers, E.M., Zwaal, R.F.A. (1989) Biochim. Biophys. Acta, in press.

(This thesis, chapter 8).

74 Verballen, P.F.J. (1988)

Ph. D, thesis, University of Limburg, the Netherlands.

75 Weiss, H.J., Vicic, W.J., Lages, B.A. "Rogers, J. (1979) Am. J. Med. 67, 206-213.

76 Rosing, J., Bevers, E.M., Comfurius, P., Hemker, H.C., van Dieijen, G., Weiss, H.J., Zwaal, R. F.A. (1985) Blood 65, 1557-1561.

77 Spangenberg, P., Til1, U., Gschmeissner, S., Crawtord, N. (1987) Br. J. Haematol. $67,443-450$. 
Since long it is known that bllood cells as well as other cell types possess a plasma membrane which is composed of a bilayer of phospholipids. These phospholipids are non-randomly distributed over the two halves of the bilayer, the monolayers. Choline-containing species are predominantly located in the outer motnolayer, while amino-phospholipids mainly reside in the inner monolayer. This asymetrio distribution is correlated with tho process of blood coagulation since several reactione of the coagulation cascade are speeded up in the presence of a suitable phospholipid surface and the lipid which is most active in stimulating clotting reactions, phospham tidylserine, is in all cells almost exclusively preaent in the inner monolayer. Thus, these cells are virtually ineffective in stimulating coggulation (chapter 2). One cell type, namely the blood platelet, is capable of undergoing a massive transport of the procostalant lipid phosphatidylserine from inner to outer monolayer upon stimulation. Such a stimulation occurs when the endom thelial cells, which are lining vessel walls, wre damaged, thereby exposing subendothelial structures to the bloodstream. To collagen fibrils, which are present in the subendothelium, blood platelets adhere and become activated. If these platelets are at the same time triggered by the first traces of thrombin, formed as the result of initiation of the coagulation cascade, they become procoagulant. In this form they very afficiently catalyze several reactions of the coagulation cascade, resulting in a strone positive feedback. It is shown that generation of a procoagulant surface is the result of transbilayer: movement (flip-flop) of phosphatidylserine (chapter 4). No protein receptors could be demonstrated to play a role in binding of elotting factors to the platelet surface, supporting the notion that the procoagulant nature of the platelet surfece is determined solely by phostiolipids (chapter 3). Also platelet aggregation and release reaction were shown not to be involved in the generation of procoagulant activity (chapter 5).

To our present knowledge platelets can be activated to become procoagulant in two general ways: on the one hand by an increase in intracellular calcium concentration, on the other by modification of internal free SH-Groups.

Both phenomena appear to produce a common result: modifi cation of the intracellular protein matrix, the cytom skeleton. When intracellular calcium incrases, as for instance effected by Ca-ionophore, proteolytic digestion by the endogenous Ca-dependent enzyme onlpain leads to disruption of the cytoskeletal structure. Incubation of the cells with diamide, which crosslinks free SH-groups, results in changes in the topology of the cytoskeleton. It is shown that a correlation exists between modification of the cytoskeletion and the occurrence of PS flip-flop 
(chapter 7) which has been confirmed using various experimental setups.

However, although a direct interaction is demonstrated between isolated cytoskeleton and PS-vesicles in binding experiments, it appeared impossible to show a change in the binding parameters of this interaction after modifying the cytoskeleton with either calpain or diamide (chapter 8). The latter observation excludes the possibility that flip flop of PS takes place as a mere ressult of changes in the cytoskelleton leading to a loss in its capacity ta interact with this lipid.

This thesis ends with the presentation of a putative model which endeavours to explain the role of the cytoskeleton in both the maintenance of phosphatidylserine asymmetry in cells and the rapid loss of this asymmetric distribution by flip-flop, which is suggested to be a property unique to blood platelets. 
Het is reeds lang bekend dat cellen, waronder ook de cellen die in het bloed voorkomen, ongeven worden door een plasmamembraan die is opgebouw uit ex dubbellage van phospholipiden. Deze phospholipiden zijn niet fillekeurig verdeeld over de twee helften van de bilage, de monolaten. Choline-houdende lipiden zijn voomamelijk gelokalimeerd. in de buitenste monolage, terwijl de mino houdende phospholipiden de meerderheid van de binnenste monolares uitmaken. Deze asymmetrische verdeline staat reothtotravk in verband met het bloedstollingsproces andezien verschillende reakties van de stollingskaskade versneld worden door de anwerigheid van een geschikt phospholipidoppervlak en het lipid wat het meest aktief is in bet atimleren van de stollingsreakties; phosphatidylserine, in alle cellan gelokalisered is in de binnenste monolase. Als gevole biervan zijn cellen niet aktief in de stolling (hoofstuk 2). Eén celtype, namelijk de bloedplatilat, iE in atad, na aktivatie, en massal transport te bewerkstelligen van het procoagulante lipid phosphatidy 1 Berine van de binnenste nar de buitenste monolade van de celmembraan. Een dergelijke stimulatie van het bloed... plat je treedt op waneer de erdotheelicellen, die de vaatwand bekleden, beschadigd worden. Bloedplaatjea hechten an collagernvezels in het ondex 1 igende subendotheel en worden daardoor deaktiveerd. Als dere plat.jes tezelfdertijd worden gestimuleerd door de eerste spoort jes thrombine, die ontstar als gevolg van het itimuleren van de stolling, worden ze procoagulant. In deze toestand aj in $z i j$ in staat zeer efficient vérschillende reacties van de stollings cascade te stimuleren, wat resulteert in een sterke positieve terugkoppeling. Er wordt aangetoond dat het ontstaan van een procoagulant oppervlak het gevole is van transbilaag beweging (flip-flop) van phosphatidy 1 serine (hoofdstuk 4). Er kon eteen arnwijulne worden gevonden voor een eventuele betrokkenheid van eiwit receptors in de binding wan solfaktorer an het oppervak van bloedplaatjes, wat het idee ondersteund dat het procoagulanto karakter van een celoppervlak vitsluitond wordt bepaald door de darin anwezige phospholipiden (hoofdstuk 3). Ook van de ageregatie var bloedplatujes en de releasereaktie werd angetoond dat deze niet noodzakelijk zijn voor de vorming van een proeoagulant oppervlak (hoofdstuk 5).

Voor zover nu bekend is, kunnen plat,jes op twee algemene manieren geaktiveerd worden zodanig dat en procoagulant. oppervlak wordt gevormd: enerzijds door verhoging wan de interne calciumconcentratie, anderzijds door modificatie van intracel lulaire vrije SH-groepen.

Beide fenomenen blijken te leiden tot een gemenschappelijk resultaat: de intracellulaire eiwitmati $x$, het cytoskelet, wordt gemodificeerd. Als de intracellulaire calciumconcentratie toeneemt, zoals b. v. wordt veroorzakt 
door een Ca-ionophoor, zal door aktivatie van het endogene Ca-aifhankelijke eman calpaine proteolytische afbraak van cytoskelet eiwitten leiden tot ontbinding van de structure van het cytoskelet. Inkubatie van de cellen met diamide, ern regens wat crosslinking van SH-groepen teweeglbrengt. resulterert in veranderingen in de ruimtelijke structur van het cytoskelet. Er wordt aangetoond dat er een korrelatie bestaat tussen modificatie van het cytoskelet en het optreden van PS flip-Ilop (hoofdstuk 7), wat onder diverser experimentele omstandigheden later bevestigd kon worden:

Toch, hoewel in bindingsexperimenten een direkte interaktie gedemonstreerd wordt tussen geisoleerd cytoskelet en PS-vesicles (hoofdstuk 8), bleek het onmogelijk een verandering in de eigenschappen van deze interaktie aan te tonen na modificatie van het cytoskelet met hetzij calpaine of diamide. Deze lastste observatie sluit uit dat flip-flop vam PS tijdens aktivatie van bloedplaatjes een rechtstreeks gevole is van een verandering van de capaciteit van het cytoskelet om PS te binden.

Dit proefschrift besluit met het poneren wan een model dat poogt de rol te verduidelijken van het oytoskelet in zowel het handhaven van de asymmetrische verdeling van phosphatidylserine als ook het verlies van asymmetrie, wat een fenomen is dat mogelijk slechts in bloedplatjes voorkomt. 


\section{DANAEUIOARD}

Om te beginnen il ik mijn gezin roemen, die de laatste twee jaar wel heel erg weinig aan mij hebben gehad. Troh is deze periode dankzij hun steun tot twee jaar berarkt gebleven. Saskia, Marloes, Menno, jullie hebben er goed aan gedaan mij telkens weer an hot werk te zetten, ook wanneer ik niet echt veel zin had. Het heeft well gewerkt, maar hopelijk komen we als familie nu in wat rustifer varwater.

Rob, het zal niet snel nog eens gebeuren dat je een promovendus gedurende bijna twintig jaar kan opleiden voor het wetenschappelijk bedrijf. hat me in jouw kijk op de wetenschap altijd het meest heeft angesproken is het streven nar eenvoud, zowel bij bet opzetten van experimenten als bij het zoeken naar passende interpretaties. Ik beb de illusie dat ik daarvan in de loop der jaren iets heb opgestoken. Vender wil ik zeker niet onvermeld laten dat zonder jouw initiatief dit proefschrift niet tot stand zou aijn gekomen, wasrvoor ik je zeer erkentelijk ben.

Edouard, we hebben de afgelopen jaren prettig en ik geloof ook vruchtbaar samengewerkt. Ik ben blij dat je ls mijn co-promotox een grote bijdrage hebt willen leveren an de uiteindelijke vorm van dit proefschrift.

Als het iemand opvalt dat het gebruikte Engels beter is dan men van mij gewend is, dan heb ik dat te danken aan dhr. P.M.G. Pieters, die mij heeft behoed voor talloze stijl en frammatica fouten.

Mariet, hoewel de uiteindelijke versie van dit proefschrift niet via jouw tekstverwerker is gemakt, wil ik wel vermelden dat het een geruststellend idee is om altijd bij je te kunmen aankloppen voor de meest ü̈teenlopende klusjes.

Tenslotte wil ik nog iedereen bedanken met wie ik in de loop der jaren heb samengewerkt, promovendi, analisten en gasten, voor de bijdragen die zij aan dit werk geleverd hebben. 
De schrijver van dit proefschrift werd op 21 februari 1947 te Utrecht geboren. Na het behalen van het HBS-B diploma an de Gemeentelijke HBS werd, alvorens de dienstplicht te vervulien, het diploma leerling analist behaald. Na zijn diensttijd werd bij in 1969 als analist angesteld bij de vakgroep Biochemie van de Subfakulteit scheikunde der Rijksuniversiteit Utrecht. In 1971 legde hij met goed gevolg het staatsexamen Biochemisch Laboratoriumassistent van de S.A.L. af. Hij trouwde in 1974 en werd de trotse vader van een dochter (in mei 1977) en een zoon (november 1978).

Toen wijn huidige promotor in 1977 als hoogleraar werd benoemd an de Rijksuniversiteit Limbure, is hij op diens verzoek meeverhuisd naar Mastricht, als analist bij de vakgroep Biochemie van de Medische Fakulteit. In die tijd werd de erondslag gelegd voor het werk wat tot dit proefschrift heeft geleid. Inmiddels werd hij bevorderd tot laboratoriumhoofdassistent. In de eerste helft van 1983 volgde hij aan de Katholieke Universiteit de kursus deskundigheid stralingshyeiene nivo III.

Teneinde toelating te verkrijgen tot promotie werd in het kursusjaar $87 / 88$ door hem het daartoe benodigde HLO-dîploma behald an de Hogeschool Heerlen. 


\section{LIST OF FLELICATIONS}

1. R.F.A. Zwaa1, B. Roelofsen, P. Comfurius and L. L.M. van Deenem, Complete purification and some properties of phospholipase C from Bacillus cereus.

Biochem. Biophys. Acta, 233 (1971) 474-479

2. B. Roelofsen, R. F.A. Zwaal, P. Comfuriug, C. B. Woodwerd and L.L.M. van Deenen,

Action of pure phospholipase $A$ and phospholipase $C$ on human erythrocyties and ghosts.

Biochem. Biophys. Acta, 241 (1971) 925-929

3. A.J. Verkleij, R.F.A. Zwaal, B. Roelofsen,

P.Comfurius, D. Kastelijn and L.L.M. van Deenen,

The asymmetric distribution of phospholipids in

the human red cell membrane. A combined study

using phospholipases and freeze-etch electron

microscopy.

Biochem. Biophys. Acta, 323 (1973) 178-193

4. R. F. A. Zwaal, B. Roelofsen, P. Comfurius and

L.L.M. Van Deenen,

Organization of phospholipids in human red cell

membranes as detected by the action of various

purified phospholipases.

Biochem. Biophys. Acta, 406 (1975) 83-96

5. P. Comfurius and R.F.A. Zwaal,

The enzymatic synthesis of phosphatidylserine and

purification by CM-cellulose column chrowatography.

Biochem. Biophys. Acta, 448 (1977) 36-42

6. R.F.A. Zwaal, P. Confurius and L.L.M. van Deenen,

Membrane asymmetry and blóod coagulation.

Nature, $268(1977) \quad 358-360$

7. H.J. Chap, P. Comfurius, L.L.M. van Deenen, E.J.J. van Zoelen and R.F.A. Zwaal,

On membrane 1 ipids and their interactions with

proteins.

Fed. Bur. Biochem. Soo. Meet. (Proc) 36 (1978) 1-14

8. G. Tans, H. van Zutphen, P. Comfurius, H.C. Hemiker and R.F.A. Zwaal,

Lipid phase transitions and proooagulant activity.

Eur. J. Biochem., 95 (1979) 449-457

9. E.M. Bevers, P. Comfurius and R.F.A. Zwaal, Activation of platelet factor 3 .

Thrombos. Haemost., 42 (1979) 211

10. R.F.A. Zwaal, P. Comfurius and E.M. Bevers, Hembrane changes during platelet activation.

Proc. 2Za Dutch Fed. Meeting, 1981, no. 517

11. E.M. Bevers, P. Comfurius and R.F.A. Zwaal, The nature of the binding site for prothrombinase at. the platelet surface as revealed by 1 ipolytic enzymes. Eur. J. Biochem., 122 (1982) 81-85 
12. E.M. Bevers, P.Comfurius, J.L.M.L. van Rija, H.C. Hewker and R.F.A. Zwaal,

Generation of platelet prothrombin converting activity and the exposure of phosphatidylserine at the platelet outer surface.

Eur. J. Bilochem. 122 (1982) $429-436$

13. R.M. Bevers, P. Comfurius, H.C. Hemker and

A. F.A. Zwanl.

On the clot-promoting activity of human platelets in a one-gtage prothrombinase assay.

Haemostasis, 12 (1982) 268-274

14. C.M. Bevers, P. Comfurius, J. Benveniste and

R.F.A. Zwaal,

The effect of PAF-acetber on the procoagulant activity of rabbit platelets.

Thrombos. Haemost., 50 (1983) 14

15. J.L.M.L. van Rijn, P. Comfurius, G. van Dieijen,

J. Rosing, E.M. Bevers and R.F.A. Zwaal,

Exposure of a procoagulant platelet surface for

prothrombin and factor $X$ activation.

Thrombos. Haemost., 50 (1983) 251

16. E.M. Bevers, J. Rosing, J.L.M.L. van Rijn, G. van

Dieijen, P. Comfurius and R.F.A. Zwaal,

The formation of two areas with different phosphati-

dylserine conoentration at the outer surface of

activated blood platelets.

Abstr. nr. p7, 24th ICBL Toulouse (1983)

17. P. Comfurius, E.M. Bevers and R.F.A. Zwaal,

Transbilayer movement of phospholipids in biological membranes induced by diglycerides.

Abstr. nr. p8, 24th ICBL Toulouse (1983)

18. E.M. Bevers, P. Comfurius and R.F.A. Zwaal,

Changes in membrane phospholipid distribution during platelet activation.

Biochem. Biophys. Acta, 736 (1983) 57-66

19. P. Comfurius, E.M. Bevers and R.F.A. Zwaal,

Stimulation of procoagulant activity of platelets and erythrocytes by sub-lytic treatment with phospholipase C from Clostridium welchii.

Biochem. Biophys. Ress. Comm., 117 (1983) 803-808

20. E. M. Bevers, $\mathbb{P}$. Comfurius, H.C. Hemker and

R.F.A. Zwaa1,

On the procoagulant activity of platelets stimulated

by collagen and thrombin.

Thrombos. Res., 33 (1984) 553-554

21. R.F.A. Zwaal, P. Comfurius, H.C. Hemker and

E. M. Bevers,

The inhibition of platelet prothrombinase activity by prostacyclin.

Haemostasis, $14(1984) 320-324$

22. J. Rosing, J.L.M.L. van Rijn, E.M. Bevers, G. van Dieijen, P. Comfurius and R.F.A. Zwaal, The role of activated human platelets in prothrombin and factor $X$ activation.

Blood, 65 (1985) 319-332 
23. P.F. H. Franck, E.M. Bevers, B.H. Lubin, P. Comfurius, D. T. Chiu, J.A.F. Opdenkamp, R.F.A. Zwaa1, L. L.N. van Deenen and $B$. Roelofsen, Uncoupling of the membrane skeleton from the lipid billayer: The cause of accelerated phospholipid flip-flop leading to an enhanoed procoagulant activity of sickled cells.

J. Clin. Invest., 75 (1985) 183-190

24. P. Comfurius, E.M. Bevers and R.F.A. Zwal, The involvement of cytoskeleton in trans-bilayer movement of phospholipids in human blood plateleta. Biochim. Biophys. Acta, 815 (1985) 143-148

25. J. Rosing, E.M. Bevers, P. Comfurius, H.C. Hemker, G. van Dieijen, H.J. Weiss and R. F.A. Zwarl, Impaired factor $X$ - and prothrombin activation associated with decreased phospholipid exposure in platelets from a patient with a bleeding disorder. Blood, 65 (1985) 1557-1561

26. E.M. Bevers, P. Comfurius, H.K. Nieuwenhuis, S. LevyToledano, J. Esnouf, S. Belluci, J.P. Caen and R. F. A. Zwaal, Platelet prothrombin converting activity in heriditary disorders of platelet function.

Brit. J. Haemato1., 63 (1986) $335-345$

27. R.F.A. Zwaal, E.M. Bevers and P. Comfurius, Platelets and coagulation. In: New Comprehensive Biochemistry, vol. 13, "Blood coagulation" (Zwarl, R.F.A. and Hemker, H.C. eds.) Elsevier, 1986, Chapter 6, PP. 14l-169

28. P.F.J. Verhallen, P.Comfurius, E.M. Bevers and R. F.A. Zwaal

On the regulatory role of the cytoskeleton in the expression of platelet procoagulant activity.

Agents and Actions, 20 (1986) 181-187

29 P.F.J. Verhallen, E.M. Bevers, P. Comfurius, H.M.A. Linskens and R.F.A. Zwarl, Calpain-mediated cytoskeletal degradation correlates with timulation of platelet procoagulant activity. Thromb. Haewostas. 58 (1987) 6 (abstr. 22)

30 E.M. Bevers, P.F.J. Verhallen, P. Comfurius, W.M.A. Linskens and R.F.A. Zwaal

Loss of phospholipid asymmetry in small vesicular structures pinched off from platelet membranes upon incubation with dilauroyllecithin. Thromb. Haemostas. 58 (1987) 457 (abstr. 1686)

31 E.M. Bevers, P.F.J. Verhallen, W.M.A. Linskens, P. Comfurius and R.F.A. Zwaal

Loss of phospholipid asymmetry in dilauroylphosphatidyloholine induced plasma membrane vesicles from human platelets Biochim. Biophys. Acta 903 (1987) 197-205 
R.F.A. Zwaal

Correlation between calpain-mediated cytoskeletal

degradation and expression of platelet procoagulant activity. A role for the platelet membrane-skeleton in the regulation of membrane lipid asymmetry? Biochim. Biophys. Acta 903 (1987) 206-217

33 E. Middelkuop', B.II. Lubin, E.M. Buver's, J.A.F. Op dua Kamp, P. Comfurius, Y. Chiu, R.F.A. Zwaal, L.L.M. van Deenen and $B$. Roelofsen

Studies on sickled erythrocytes provide evidence that the asymetric distribution of phosphatidylserine in the red cell membrane is maintained by both an ATP-dependent translocation and an interaction with membrane skeletal proteins.

Biochim. Biophys. Acta 937 (1988) 281-288

34 H. Chap, P. Comfurius, E.M. Bevers, J. Fauvel,

P. Vicendo, L. Douste-Blazy and R.F.A. Zwal

Potential anticoagulant activity of lipocortins and other caleium/phospholipid binding proteins.

Biochem. Biophys. Res. Commun. 150 (1988) 972-978

35 P.F.J. Verhallen, E.M. Bevers, P. Comfurius and R.F.A. Zwaal.

Fluoride-dependent calcium induced platelet procoagulant aotivity shows that calpain is involved in increased phospholipid transbilayer movement. Biochim. Biophys. Acta 942 (1988) 150-158

36 R.F.A. Zwaal, P. Comfurius and E.M. Bevers Phospholipases and other tools to study phospholipid orientation in blood cell membranes.

Bul1. Sco. Chim. Biol. 53 (1988) 20-21

37 P.F.J. Verhallen, P. Comfurius, E.M. Bevers, A.J.W.G. Visser and R.F.A. Zwaal

Cytoskeletal degradation by calpain results in

"flip-flop" of phosphatidylserine in the plasma membrane of activated platelets.

In: Structure and Function of the Cytoskeleton (ed. B.A.F. Roneset) Colloque INSERM, J. Libbey Eurotext Ltd. vol. 171, pp. 307-312

38 E.M. Bevers, R.H.J. Tiliy, J.M.G. Senden, P. Comfurius and R.F.A. Zwaal

Exposure of endogenous phosphatidylserine at the outer surface of stimulated platelets is reversed by restoration of amino-phospholipid translocase activity.

Biochemistry $28(1989) 2382-2387$

39 E. Middelkoop, E.E. v.d. Hoek, E.M. Bevers, P. Comfurius, A.J. Slotboom, J.A.F. Op den Kamp, B.H. Lubin, R.F.A. Zwaal and B. Roelofsen Involvement of ATP-dependent aminophospholipid translocation in maintaining phospholipid asymetry in diamide-treated human erythrocytes.

Biochim. Biophys. Acta 981 (1989) 151-160. 
40 P. Comfurius, E.M. Bevers and R.F.A. Zwaal Interaction between phosphatidy Iserine and isolated cytoskeleton of human blood platelets. Biochim. Biophys. Acta (1989) in press.

$41 \mathrm{P}$. Comfurius, E.M. Bevers and R.F.A. Zwaal Enaymatic synthesis of phosphatidylserine on swall scale by use of a one-phase system.

Submitted. 